I.

Aus der chirurgischen Universitätsklinik zu Kiel (Prof. Helf erich)

\title{
Zur Kenntniss der lateral-retroperitonealen Tumoren.
}

\author{
Von \\ Dr. Rudolf Göbell, \\ Assistenzarzt.
}

Im Jahre 1829 lenkte J. F. Lobstein (67)*) die Aufmerksamkeit auf die Gewächse, welche immer hinter dem die Rückwand des Unterleibs auskleidenden Theil des Bauchfells beginnen und sich unabhängig von den hier gelegenen Organen entwickeln. Er nannte sie Tumeurs rétropéritonéales. Er nahm an, dass diese Geschwülste auf der Wirbelsäule ihren Anfang nehmen, und sprach die Vermuthung aus, dass der primäre Sitz in dem Lymph- und dem ihm angehörenden Drüsensystem zu suchen sei.

Diese Abdominalmassen sind nach Lobstein (67) aus einer Vereinigung von ungleichen Geschwülsten gebildet, wovon einige ein dichtes und drüsenartiges Gewebe, andere eine speckige Substanz, wieder andere endlich eine weiche breiartige hirnähnliche Materie darstellen. Sie haben keine Kapsel und enthalten oft mit Blutgerinseln gefüllte Möhlen.

Augenscheinlich hatte Lobstein, worauf auch schon Witzel (138) hinwies, verschiedenartige Tumoren vor sich gehabt. Sicherlich hat er keine Nebennierengeschwülste gesehen, da er besonders betont, dass sich die Nebennierenkapsel sehr widerstandsfähig gegen die Geschwülste erwies.

Erst die histologische Untersuchung lehrte die Natur dieser Geschwülste kennen. Je nach Art des Tumors, welcher dem Pathologen vorlag, fiel die mikroskopische Diagnose aus, und so kamen Virch ow (124) und Förste r (144) zu verschiedenen Anschaungen. Letzterer sah die Geschwülste als primären Markschwamm der lumbalen Lymphdrüsen, ersterer als reine medulläre Spindelzellen-

*) Die eingeklammerten Ziffern im Text beziehen sich auf das am Schluss befindliche Litteraturverzeichniss.

Deutsche Zeitschrift f. Chirurgie. LXI. Bd. 
sarkome und fibröse Häute, namentlich Fascien als wahrscheinlichen Ausgangspunkt an. König(146) liess die langsamer wachsenden Fibrosarkome von dem fascialen Theile des Bauchfelles ausgehen, die schnell sich entwickelnden Geschwülste dagegen in der Regel von den retroperitonealen Lymphdrüsen.

Jedenfalls bestand noch bis zum Jahre 1886, wie sich aus der Arbeit von Witzel (138) ergiebt, die Meinung, dass die retroperitonealen Tumoren, abgesehen von einigen seltenen Ausnahmen, Sarkome darstellen.

Seitdem haben aber immer zahlreichere Beobachtungen verbunden mit genauen histologischen Untersuchungen dargethan, dass gerade der retroperitoneale Raum besonders reich ist an mannigfaltigen Tumoren und pathologischen Gebilden, welche nicht von den grossen drüsigen Organen ihren Ursprung nehmen. Es verlohnt sich daher schon der Mühe, eine genaue pathologisch-anatomische Klassificirung vorzunehmen, wie sie auch schon in den Arbeiten von van der Veer (123), Latte (65) und Eduard Frank (37) durchgeführt worden ist.

T opographisch unterschied schon Lobstein (67) in Rücksicht auf ihren primitiven Sitz Becken- und Lendengeschwülste. Die klinisch wichtige Trennung der Lendengeschwülste in mediale und laterale retroperitoneale Tumoren nahm Witzel vor und charakterisirte die lateralen retroperitonealen Tumoren in vortrefflichster Weise.

Witzel (138) wich aber von der ursprünglich von Lobstein gegebenen Definition der retroperitonealen Geschwülste ab und rechnete die Nierentumoren mit Recht zu den lateralen retroperitonealen Tumoren. Seitdem hat sich insbesondere durch die Fortschritte der Nieren- und Nebennierenpathologie und -Chirurgie eine Wandlung vollzogen. Heutzutage versteht man unter den lateralen retroperitonealen $\mathrm{T}$ umoren mehr aus praktischen als aus logischen Gründen diejenigen Geschwülste, welche sich unabhängig von den Nieren und Nebennieren im lateralen retroperitonealen Raum entwickeln.

Drei in der hiesigen Klinik zur Operation gelangte Fälle von diesen soeben definirten lateralen retroperitonealen Tumoren gaben mir Veranlassung, mich mit diesem Gebiet der chirurgischen Pathologie zu beschäftigen. Das Resultat gestatte ich mir mitzutheilen.

Meinem hochverehrten Chef Herrn Geheimrath Helferich erlaube ich mir für die Anregung zu dieser Arbeit und für die Ueberlassung des Materials auch an dieser Stelle meinen besten Dank auszusprechen. 
Anatomie der Regio retroperitonealis lateralis.

Lateral retroperitoneal nennt man die Gegend des Abdomens, welche nach oben vom Zwerchfellansatz, median von der Wirbelsäule und nach unten von der Linea terminalis (innominata) begrenzt wird (Witzel) (138). Nach aussen findet ein allmählicher Uebergang in die Regio lateralis abdominis statt. Witzel hat zur Abgrenzung das Colon herangezogen. Indessen wird gerade die Lage des letzteren durch die Tumoren dieser Region stark beeinflusst. Hinten bildet in der Iliacalregion das Darmbein, in der Lumbalgegend die aus der Aponeurose des M. transversus hervorgehende Fascia lumbodorsalis die trennende Schicht, und zwar im Gebiet des M. quadratus lumborum das hintere Blatt dieser den Muskel umschliessenden Fascie.

Der laterale retroperitoneale Raum erhält seine eigenthümliche Configuration durch die Muskeln. Während der M. quadratus lumborum eine fast gleichmässige, zwischen der 12. Rippe und dem Darmbeinkamm gelegene Platte bildet, nimmt der M. psoas von oben nach unten stärker an Umfang zu. Dadurch entwickelt sich aus der in der Höhe des 2. Lendenwirbels von den beiden Muskeln geformten, der unteren Hälfte der Niere zum Lager dienenden flachen Mulde weiter nach abwärts eine tiefe Rinne. In der letzteren, welche sich nach unten zwischen M. iliacus und M. psoas fortsetzt, steht der Ausbreitung des lockeren fettreichen Gewebes kein Hinderniss entgegen. Eine zweite zur Entwicklung von Fettgewebe disponirte Stelle ist der vom M. quadratus lumborum und dem Darmbeinkamm gebildete Winkel, in welchem die von Küster (145) Massa adiposa pararenalis genannte aussen vom M. quadratus gelegene Fettmasse meist an Stärke zunimmt.

Macht man einen ausreichend grossen bogenförmigen Flankenschnitt und drängt man nach Durchtrennung der Muskeln und der Fascia transversalis das Peritoneum nach vorn und innen, so präsentirt sich im oberen Theil des lateralen retroperitonealen Raumes der untere Zipfel der von der Fascia renalis umhüllten Nierenfettkapsel. Der N. ileo-inguinalis läuft schräg über den unteren M. quadratus lumborum und am Darmbeinkamm entlang. Im Uebrigen erblickt man auf den Muskeln weder die Vasa spermatica noch den Ureter. Diese Gebilde haften dem Peritoneum fester als ihrer Unterlage an und werden mit dem Peritoneum abgelöst. Sie stellen sich gewissermassen im Spiegelbilde dar. An die Vasa spermatica gelangt man zuerst. Sie haben den Ureter, vor ihm gelegen, an der Grenze seines oberen und mittleren Drittels gekreuzt und bilden beim Manne mit 
dem Ureter einen spitzen Winkel, während sie beim Weibe nach der Kreuzung dicht am Ureter hinziehen.

Der Ureter tritt aus der Nierenfettkapsel hervor, bildet die Hauptspindel, läuft über den $\mathrm{N}$. genito-femoralis in einem spitzen Winkel hinweg und tritt in der Höhe der Synchondrosis sacroiliaca vor den Vasa iliaca in das kleine Becken. Median ist er dem N. sympathicus und den lumbalen Lymphdrüsen nicht fern. Vom Plexus lumbalis, welcher den M. psoas durchsetzt, wird nur schräg über dem M. iliacus der $\mathrm{N}$. cutaneus femoris lateralis sichtbar.

An dem Aufbau der vorderen Wand dieses Raumes betheiligen sich rechts nur im geringsten Grade das Peritoneum und das subperitoneale Gewebe, zumeist Intestina. Rechts liegt in der Rinne aussen vom M. psoas das Colon ascendens und, wenn kein Mesocoecum vorhanden ist, das Coecum. Um den unteren Nierenpol legt sich in einem nach oben offenen Bogen die Flexura coli dextra. Die Portio adrenalis des Ureters wird von der Flexura duodeni secunda bedeckt. Und endlich nimmt einen breiten Streifen der vorderen Wand des retroperitonealen Raumes die Radix mesenterii ein. Demzufolge liegen in dem subperitonealen Gewebe des rechten Spatium retroperitoneale zahlreiche dem Gebiete der $A$. und V. mesenteria superior zugehörige Gefässe, Lymphbahnen und Lymphdrüsen. Es können daher Mesenterialtum oren leicht sich im retroperitonealen Raum ausdehnen und umgekehrt retroperitoneale Tumoren in das Mesenterium hineinwachsen.

Links sind die Verhältnisse wesentlich einfacher. Hier besteht die laterale Hälfte der vorderen Wand aus dem Colon descendens, die mediale aus dem Peritoneum und dem subperitonealen Gewebe, welches die das Colon descendens mit Blut versorgenden Gefässe, die Lymphbahnen und die Lymphdrüsen enthält.

Die mittleren Lymphdrüsen dieser Gegend liegen entlang den grossen Gefässen, sie nehmen in sich die Lymphe vom Becken, von dem Plexus lymphaticus spermaticus internus und aus dem lateralen retroperitonealen Raum auf. Die lateralen Lymphoglandulae lumbales sind hinter dem M. psoas an den Processus transversi zu suchen. $\mathrm{Zu}$ ihnen gelangt der Lymphstrom von den Muskeln der hinteren Bauchwand.

Ueber das subperiton eale Geweb e hat William Anders on (4) auf dem Congress der British Medical Association im Jahre 1896 nach eingehenden Studien vom Standpunkt des Chirurgen vorgetragen. Nach ihm kann man in einem frühen Entwicklungsstadium das subperitoneale Gewebe als eine mesoblastische Masse die grossen 
Abdominalgefüsse umgeben sehen. Es wird mit den Gefässen in alle Abdominaleingeweide geschoben. Es besteht aus hochelastischem Bindegewebe mit verschieden grosser Menge Fett und einigen glatten Muskelfasern. Das subperitoneale Gewebe ist lose mit dem Peritoneum parietale und der Fascia transversalis verwachsen.

\section{Pathologische Anatomie.}

Schon der anatomische Aufbau der Regio lumbalis et iliaca deutet darauf hin, dass sie nicht nur eine Stätte für die Nieren- und Ureter-Pathologie und -Chirurgie ist. Sie birgt viele Gebilde in sich, welche die verschiedenartigsten pathologischen Producte liefern können, wenn auch neben der Niere es wohl am häufigsten Erkrankungen von den Organen der Wand sind, welehe diese Gegend in Mitleidenschaft ziehen. Es sei hier aber abgesehen von allen entzündlichen Vorgängen, für deren Producte gerade der laterale retroperitoneale Raum durch sein lockeres Gewebe und seine Ausdehnungsfähigkeit eine gute Sammelstätte darstellt. Unberücksichtigt seien ferner alle pathologischen Prozesse der Niere und der Nebenniere selbst und die Tumoren, welche sich von den Abdominalorganen aus entwickeln.

Hier sollen nur diejenigen $\mathrm{Tu}$ moren besprochen werden, welche im lateralen retroperitonealen Raum gelegen weder von der Niere noch von der Nebenniere selbst, noch von den Intestinis ausgehen.

Wie die histologische Structur des subperitonealen Gewebes, die Zusammensetzung der nicht durch Bauchorgane gebildeten Wandung und der Inhalt des lateral-retroperitonealen Raumes schon annehmen lassen, gehört die Mehrzahl der hier beobachteten Geschwülste der Reihe der Bindegewebsneubildungen an. Es sind indessen auch epitheliale Tumoren und Gebilde besonderer Art gefunden worden.

Es sei gestattet deren Aetiologie an der Hand unserer Fälle lateraler retroperitonealer Tumoren zu besprechen.

J.-Nr. 922/1900. 54 jähr. Landmannsfrau. Aufnahme am 1. Oct. 1900.

Anamnese: Nach den Angaben der Patientin sind die Eltern und 3 Geschwister an der Auszehrung gestorben. Ein Bruder ist an einer inoperablen Beckengeschwulst zu Grunde gegangen. Abgesehen von Dritsenschwellung in der Kindheit und Augenentzindung im 40. Lebensjahr will die Patientin nie ernstlich erkrankt gewesen sein. Sie hat einmal geboren, regelmässig menstruirt, niemals eine Fehlgeburt und seit der Menopause, welche etwa vor 4 Jahren eintrat, keine Blutung mehr gehabt. 
Seit 27 Jahren hatte die Patientin eine Geschwulst in der linken unteren Bauchgegend, welche früher beweglich war, aber niemuls starke Beschwerden bereitete. Eine Zeit lang hatte die Patientin eine Leibbinde getragen, sie dann aber wieder abgelegt, weil sie auch ohne Binde keine Beschwerden gehabt hatte. Seit dem Winter 1899/1900 hatte die Patientin Schmerzen in der linken unteren Bauchgegend. Im Juni 1900 wurde das linke Bein taub, die Schmerzen in der Geschwulstgegend wurden stärker. Der Stuhlgang war angehalten. Vor demselben traten häufig Schmerzen auf. Die Patientin wird vom behandelnden Arzt der Klinik zugewiesen.

Status: Die mittelgrosse, für ihr Alter mässig kräftige und mässig genährte Frau mit fleckiger Wangenröte, sonst normaler Haut, blassen Schleimhäuten und belegter feuchter Zunge hatte gesunde Brustorgane. Das Abdomen war links etwas aufgetrieben. Bei der Exspiration sah man zwischen linker Sp. oss. il, a. s. und Nabel sich eine von normaler Haut bedeckte Schwellung vorwölben. Bei Inspiration schoben sich die Intestina uber den oberen und medialen Rand der Schwellung, ohne dass letztere in ihrer Lage beeinflusst wurden. Der Schall uber dem Abdomen war tympanitisch. Die Leber und Milzdämpfung war nicht vergrössert. Zwischen Spina a. s. links und Nabel bestand eine handtellergrosse Dämpfung. In beiden hinteren und seitlichen Lendengegenden war tym. panitischer Schall. Man fuhlte in der linken Beckenschaufel einen nach unten und nach der Mitte zu von Darmschlingen bedeckten nach unten bis zur Mitte des Ligamentum inguinale, nach innen bis zur Mittellinie, nach oben bis ein Querfinger breit oberhalb des Nabels, nach aussen bis an die Spina oss. ilei a. s. sin. reichenden Tumor. Derselbe war an der Oberfläche leicht höckerig und fiel nach dem kleinen Becken zu steil ab. Er war von prallelastischer Consistenz, nicht druckempfindlich und zeigte im oberen, inneren Theil deutliche, sonst undeutliche Fluctuation. Der Tumor war seitlich nur in seinen vorderen Partieen wenig verschieblich, von unten nach oben gar nicht, er sass breitbasig und fest der Beckenschaufel auf. Zwischen dem Tumor und dem Rippen. bogen konnte man bis an die hintere Bauchwand eindringen. In der Nierengegend war nur eine undeutliche Resistenz zu fühlen.

Bei Aufblähung des Darmes vom Rectum aus lag das Colon descendens innen und vorn vor dem Tumor und zog oberhalb des Tumors etwas nach hinten, so dass der Tumor medial wie von einer Schleife (Flexura sigmoidea) umgeben zu sein schien.

Die Untersuchnng per vaginam ergab einen kleinen etwas nach hinten und rechts gelagerten Uterus, welcher gut verschieblich war und in keinerlei Beziehung zum Tumor stand. Die Adnexe waren anscheinend vorhanden. Von der Vagina und vom Rectum aus konnte man das kleine Becken abtasten. Der Tumor reichte nicht in dasselbe hinein.

Der Urin war vollständig normal ohne Eiweiss und Zucker, ohne mikroskopisch nachweisbare zellige Elemente, die Urinmenge normal. schaufel.

Diagnose: Retroperitonealer cystischer Tumor der linken Becken-

Beh and lung: 5. Oct. 1900. Chloroform-Narkose. Operation (Oberarzt Dr. Sick). Mit einem ausgedehnten lumbo-inguinalen Schräg- 
schnitt wurde zunächst nach Durchtrennung der vorderen Bauchwandmuskeln extraperitoneal auf den Tumor vorgegangen. Der M. iliacus bildete eine sehr dünne Platte und liess sich von dem Tumor sehr schwer trennen. Dabei wurde das Peritoneum eröffnet. Man fühlte durch das Loch im Peritoneum, dass der Tumor im Mesocolon der Flexura sigmoidea gelegen war. Zur besseren Orientirung wurde die Peritonealwunde erweitert.

Der kindskopfgrosse Tumor lag im Mesocolon der Flexura sigmoidea. Die Flexura zog an der Innen- und Vorderfläche im Bogen mässig gespannt an dem Tumor entlang. Die linke Niere war an normaler Stelle za fühlen. Der Uterus und seine Adnexe lagen im kleinen Becken. Der Tumor war nach vorn hin vom Peritoneum bedeckt. Zur Flexura zogen über den Tumor hinweg keine Gefässe. Es wurde deshalb das Peritoneum parietale nahe dem Colon abgetrennt and so transperitoneal die Exstirpation versucht. Dabei kam man aber in der Beckenschaufel in mit bräunlicher dunnbreiiger Flüssigkeit gefullte Cystenräume, welche zwischen erweichten Tumormassen und degenerirten Muskelfetzen gelegen waren. Dagegen gelang es eine tuber gänseeigrosse glattwandige Cyste, welche nur nach hinten und aussen fester verwachsen und nächst dem Colon gelegen war, herauszuschälen.

Um weiter extraperitoneal zu arbeiten, wurde die Darmserosa mit dem inneren Rande der zuerst gesetzten Peritonealwunde vernäht. Die Beckenschaufel wurde bis an das Periost ausgeräumt. Anf eine gründliche Entfernung musste indessen verzichtet werden, da harte knollige Massen mit den Vasa iliaca fest verwachsen waren. Bei der Inspection der Wunde fand sich im oberen Wundwinkel ein Gefässstrang und ein Lumen, welches fur das des abgerissenen Ureter gehalten wurde. Die Sondierung führte zur Nierengegend. Durch den Ureterkatheter wurde kein Urin entleert.

Da das Befinden der Patientin eine schnelle Beendigung der Operation verlangte, wurde der Sicherheit halber das Lumen in den hinteren Wundwinkel gelegt, die Wunde tamponirt und der untere Wundwinkel durch Naht geschlossen. Aseptischer Verband.

Der Verl a u f bestätigte zunächst die Annahme einer Ureterläsion insofern, als Verminderung der Urinmenge auf $530 \mathrm{ccm}$, leichte Benommenheit und Pulsbeschleunigung bis 132 Schläge in der Minute bei normaler Temperatur auftrat. Später aber, als kein Urin in die Wunde entleert wurde, die Urinmenge, wenn auch nicht bis zur Norm, so doch bis 1280 stieg, und keine Zeichen einer arteficiellen Hydronephrose auftraten, waren die Zweifel bezüglich der Verletzung des Ureters bestätigt, obwohl bei der cystoskopischen Untersuchung die linke Uretermündung ,todt" lag. Auf den einzig beweisenden Ureterenkatheterismus musste verzichtet werden. - Am 8. Tage nach der Operation hatte sich im unteren Wundwinkel eine Darmfistel ansgebildet.

Da dieser widernatürliche After der Patientin viele Beschwerden bereitete und eine Heilung der Wunde so nicht zu erzielen war, wurde 40 Tage nach der 1. Operation der Versuch einer Darmausschaltung durch Enteroanastomose gemacht, welcher aber an der gänzlichen Unbeweglichkeit des oberen Rectumabschnittes scheiterte. Es konnte nur ein 
A nus praeternaturalis am Colon transversum lege artis angelegt werden, welcher insofern bessere Dienste Ieistete wie die Darmfistel, als der Verschluss gut wirkte und nur täglich 1 mal Stuhl erfolgte. Die Frau ist dann unter immer mehr zunehmendem Kräfteverfall 2 Monate nach der ersten Operation gestorben.

Bei der Autopsie fand man folgendes:

S.-Nr. 649/1900. Wesentlicher Befund. Starker metastatischer Krebs der Leber, spärlicher der Nieren, geringer der Plenra und der Milz. Umschriebene Thrombose der unteren Hohlvene. Thrombose einer Milzvene dem Krebsknoten entsprechend. Metastatischer Krebs der retroperitonealen und -trachealen Lymphdrüsen. Ausgedehnter confluirender Krebs des Zwerchfell-Peritoneums. Anus praeternaturalis. Starke Atrophie und Emphysem der Lungen. Atrophie des Herzens. Geringe fettige Fleckung der Aorta. Kleine Kalkplatte am Ductus Botalli. Gallertkropf. Verkalkte Bronchialdriisen. Starke lockere Schwellung der Portio vaginalis des Uterus (beginnender Krebs ?). Hanfkorngrosser Knoten im Verlauf der linken Tube. Diphtheroide Entzündung der Vagina. Atrophie des Pankreas. Dermoidcyste des linken Ovarium.

Links war oberhalb der Spina ant. superior die bei der ersten Operation gesetzte granulirende Wunde vorhanden. Der Ureter lag stark comprimirt aber durchgängig in dem metastatischen Krebs der retroperitonealen Lymphdrusen eingebettet.

Die beiden Nieren und Nebennieren waren vorhanden, letztere normal, die Nieren parenchymatös nephritisch. Das Becken der linken Niere war kaum erweitert. Im Magendarmkanal war nirgends eine Geschwulst nachzuweisen. -

Der exstirpirte Tumor bestand aus zwei Theilen: einer äusserlich glattwandigen vielkammerigen Cyste von etwa $15 \mathrm{~cm}$ Durchmesser mit $\mathbf{3 - 5} \mathrm{mm}$ dicker geschichteter Wandung und bräunlichem atherombreiähnlichem Inhalt (keine Haare). An der äusseren und hinteren Fläche hingen einzelne Fetzen. Hier war die Cyste bei der Operation nur schwer von dem übrigen Tumor zu trennen.

Der andere Theil war weich, bräunlich, enthielt an einzelnen Stellen schleimenthaltende Hohlräume und hatte nach den Vasa iliaca zu ein mehr markiges Aussehen.

Die mikroskopische Untersuchung ergab:

I. Die Wand des cystischen Tumors ist aus fibrösem, kernarmem, im Zustand leichter Entzündung befindlichem Gewebe und einer dicken Plattenepithelschicht gebildet. An letzterer kann man ein Stratum mucosum, ein Stratum granulosum und ein sebr stark entwickeltes Stratum corneum unterscheiden. Die bindegewebige Unterlage zeigt papillenförmige Erhebungen. An einer Stelle konnte in ihr ein Schweissdrüsenkanal constatirt werden. Haarbälge und Talg- 
drüsen sind nicht zu sehen. In der Cyste liegen dichte Massen verhornter Epithelzellen.

Die Cystenwand hatte demnach einen cutisartigen Charakter.

Die kleineren Kammern sind mit einer etwas niedrigeren, aber noch stärker verhornten epidermisartigen Schicht ausgekleidet. Es fehlen in dem subepithelialen Bindegewebe die Papillen.

II. Der der Cyste angelagerte Tumor besteht aus:

1. der Grundsubstanz, zusammengesetzt aus einem dünnfaserigen Bindegewebsgerïst, und

dem Stroma, welches von durcheinander geschüttelten mittelgrossen rundlichen Zellen mit verhältnissmässig kleinen rundlichen Kernen und zahlreichen mit vielen oft central gelegenen Kernen, und körnigem Protoplasma versehenen Riesenzellen dargestellt wird.

2. kleinen cystischen Räumen. Dieselben tragen innen verschiedene Epithelsorten und zwar

a) geschichtetes hohes Cylinderepithel mit unregelmässiger nach dem Lumen gerichteter Contour, oder

b) eine einzellige fast kubische Zellschicht, oder

c) mehrschichtiges Cylinderepithel mit nach dem Lumen zugekehrtem Saum.

Die beiden letzten Epithelarten bilden Schleim.

III. Bei der Section wies die von der 1. Operation zurückgebliebene granulirende $W$ unde auf:

1. aus mittelgrossen rundlichen, einen verhältnissmässig kleinen rundlichen Kern führenden Zellen gebildete Geschwulstmassen,

2. z. Th. in letztere eingelagert und an dieselben angrenzend und dann in junges und älteres Bindegewebe eingebettet: zahlreiche mannigfach gestaltete Epithelnester, von denen viele ein deutliches Lumen aufweisen und einige aussehen wie ein Quersehnitt oder Schrägschnitt einer Darmdrüse. Das Epithel ist, wenn noch nicht atypisch gewuchert, cylindrisch $z$. Th. kubisch mit basalstehendem, länglich rundem Kern und nach dem Lumen zu gerichteter Protoplasmazone. Die Zellen bilden nach dem Lumen zu oft einen gleichmässigen Saum. Im Lumen liegen gequollene Zellen mit geschrumpftem Kern. Kubisch sind die Epithelzellen namentlich dann, wenn in dem Schlauch reichlicher Inhalt von abgestossenen hydropischen Zellen vorhanden ist. Nur selten besteht ein Nest ganz aus atypisch gewucherten Zellen. 
IV. Die Knoten in der Leber.

Umgeben von stark deformirten z. Th. verfetteten, z. Th. pigmentreichen Leberzellen liegt ein Tumor von fast skirrhusartigem Charakter. Zwischen breiten Bindegewebsbalken bilden verschieden gestaltete Epithelzellen Nester. Nur an einzelnen Stellen sind Lumina vorhanden. Hier kann man die ursprüngliche cylindrische Form der Zellen erkennen.

\section{Die Lunge und Pleura.}

Dicht unter der leicht verdickten, aber nicht mit Auflagerungen versehenen Pleura sieht man in kernarmem Bindegewebe, z. Th. zwischen Lungenalveolen gelegen, Drüsenlumina und -schläuche und Epithelzellennester. In den Drüsenschläuchen ist das Epithel cy. lindrisch und ähnelt dem Epithel des Magendarmtractus, in den Lumina oft kubisch. Die Nester enthalten atypische unregelmässig gestaltete mit bläschenförmigem Kern versehene epitheliale Zellen. Das Lungengewebe ist in geringem Grade kleinzellig infiltrirt.

VI. Die Niere.

Das Nierenparenchym giebt ein schönes Bild einer parenchymatösen Nephritis.

In der Rinde liegt bis unter die Kapsel und bis in das Gebiet der geraden Harnkanälchen reichend ein erbsengrosser Tumor. Derselbe hat die Harnkanälchen fast vollständig substituirt. Die noch erhaltenen Harnkanälchen sind stark verändert, die Kerne der Epithelien sind geschrumpft. Die Glomeruli sind z. Th. ihrer Form und Grösse nach normal, aber im Zustand chronischer Entzündung, z. Th. geschrumpft.

Das Bindegewebsgerüst des Tumors ist kleinzellig infiltrirt. In ihm liegen zahlreiche aus atypisch gewucherten Epithelzellen bestehende Nester. Die Epithelzellen lassen ihre Herkunft aus einigen im Mark gelegenen Stellen erkennen. Dort sieht man um eine kleine Vene herum mehrere kreisrunde Querschnitte, deren enges Lumen von hohem, schmalem, basalwärts liegende länglichrunde Kerne besitzendem Cylinderepithel umgeben ist. Dicht daneben liegen mehrere sehr lange von denselben hohen Cylinderzellen ausgekleidete Drüsenschläuche mit spaltförmigem Lumen.

VII. Cyste des linken Ovarium.

In der Cyste waren Haare und Zähne vorhanden. Die Wand war innen mit Plattenepithel besetzt. Neben zahlreichen mit Plattenepithel ausgekleideten Räumen, Schweissdrüsen und Talgdrüsen, waren in dem Theil, welchen ich zu untersuchen Gelegenheit hatte, keine entodermalen Organreste zu finden. 
VIII. Das rechte Ovarium ist reich an glatten Muskelzellen, zeigt aber sonst keine Abnormitäten.

Demnach war der cystische Tumor eine Dermoidcyste, - die anliegende Geschwulstmasse ein Riesenzellensarkom, welche mit entodermalem schleimproduzirenden Epithel ausgekleidete Cystehen umschloss. In der Wunde, in welcher wegen der Unmöglichkeit der Radicaloperation Geschwulstmassen zurückgeblieben waren, grenzte bei der Autopsie an das Sarkom ein Adenocarcinom. Nur das letztere hatte ausgedehnte Metastasen in Leber, Milz, Niere und Pleura gebildet.

Im Magendarmkanal war kein primärer Krebs vorhanden. Die Portio vaginalis uteri enthielt kein Carcinom. Der Krebs der Leber war kein primärer, sondern bestand nur aus Metastasen. ${ }^{1 \gamma}$

Damit war die Möglichkeit, dass das Adenocarcinom in der Iliacalgegend eine Metastase sei, ausgeschlossen.

Es handelte sich um einen höchst eigenartigen retroperitonealen Tumor der linken Iliacalregion, welcher 26 Jahre lang als gutartiger Tumor ärztlich beobachtet worden ist, ein Jahr vor dem Tode Schmerzen verursachte und 6 Monate vor dem Exitus durch feste Verwachsung mit der Unterlage und Schädigung der Nerven des linken Beines sich als maligne gewordener Tumor documentirte. Während aber der exstirpirte Theil der Geschwulst ein Sarkom enthielt, ging die Frau nicht an einer Sarkomatose zu Grunde, sondern an Krebskachexie. Der zurückgebliebene Theil des Tumors war in der Hauptsache ein Adenocarcinom, und die sehr zahlreichen Metastasen waren die eines Adenocarcinoms.

In der ganzen Geschwulst sind mithin alle drei Keimblätter vertreten, in der Dermoidcyste das Ektoderm, in dem Sarkom, den Gefässen, der Bindegewebssubstanz das Mesoderm, in dem Epithel der kleinen Cystehen und in dem Adenocarcinom das Entoderm. Sie ist somit aus einer dreikeimblätterigen Anlage hervorgegangen.

Dem klinischen Verlauf nach könnte man daran denken, dass 26 Jahre hindurch eine retroperitoneale Dermoideyste mit dreikeimblättriger Anlage bestanden hätte und dann erst die maligne Veränderung des mesodermalen und des entodermalen Theils eingesetzt hätte. Es ist mir indessen nicht gelungen, in der Wand der Dermoidcyste entodermale Organanlagen nachzuweisen. Es ist deshalb nicht

1) Herr Professor Döhle, welcher die mikroskopischen Präparate freundlichst durchgeschen hat, hatte die Liebenswürdigkeit, die Organe gerade hinsichtlich der Frage eines primären Krebses des Uterus und der Leber zu untersuchen. Ich gestatte mir ihm an dieser Stelle meinen verbindlichsten Dank auszusprechen. 
wahrscheinlich, dass die Cyste den Dermoidcysten des Ovarium gleichzusetzen ist.

Ferner hat man wohl die Entwicklung eines Plattenepithelkrebses in der Wand einer Dermoidcyste des Ovarium gesehen (Krukenberg (62) stellt 9 hierher gehörige Fälle zusammen), aber einen Drüsenzellenkrebs hat bis jetzt nur K. Yamagiwa (140) beschrieben. Es dürfte gewagt erscheinen, das Sarkom und das Carcinom von einer dreikeimblättrigen Dermoidcyste abzuleiten. - Es handelt sich wohl vielmehr um eine teratoide Geschwulst, in welcher das Ektoderm in Form einer vielkammerigen Dermoidcyste auftritt, das mesodermale Gewebe zum Theil sarkomatös ist, und vom Entoderm mit Cylinderepithel ausgekleidete Hohlräume abzuleiten sind. In diesem Teratom ist dem Entoderm entstammendes Drüsengewebe carcinomatös degenerirt und hat durch seine Metastasen den Tod herbeigeführt.

Wie ist das Vorkommen dieses Tumors in dieser Region zu erklären?

B onnet (143) hat neuerdings in einer Arbeit: „Zur A etiologie der Embryome" die verschiedenen zur Erklärung der Embryome, der Dermoide, der verschiedenen Mischgeschwïlste, der Teratome und der abortiven parasitären Bildungen aufgestellten Theorieen einer Kritik unterzogen. Er sieht mit Wilms (135) in den soliden Embryomen (Teratomen Pfannenstiel's) und den cystischen Embryomen (Dermoiden Pfannenstiel's) nicht principiell verschiedene Bildungen, sondern nur formell und quantitativ verschiedene Repräsentanten der Embryome.

"Die Embryome des Ovarium und des Hoden können nicht auf eine Eizelle im Ovarium oder eine Geschlechtszelle im Hoden zurückgeführt werden, weil nicht die geringste Berechtigung besteht, bei den Säugethieren und den Menschen von parthenogenetischen Vorgängen zu reden.

Bonnet nimmt an, dass eine befruchtete Polzelle sich in der Tiefe zwischen den Blastomeren weiter entwickele und damit zu einer Inclusion in den inneren Organen, also auch in den Keimstöcken, nicht nur in sich später schliessenden Rinnen- und Spaltbildungen der Embryonalanlage (Epignathus, Sacralparasit etc.) des Embryo Anlass geben könnte. - Es könnte sich auch um eine aus irgend welchen Gründen verzögerte Theilung einer oder mehrerer Blastomeren in früheren Furchungsstadien und um den Einschluss der nachträglich aus ihr gelieferten Organanlagen in schon weiter differenzirten Keimgebieten handeln. - „Ein Vergleich würde ergeben, dass bei der Be- 
fruchtung einer Polzelle ein abortives Ei -, bei der Entwicklung einer abgelösten abnorm langsam weiter getheilten Blastomere das Theilstück eines befruchteten und noch in der Furchung befindlichen Keimes die Veranlassung zur Entwicklung einer die Derivate aller drei Keimblätter enthaltenden Inclusion geben könne."

Bonnet nähert sich demnach der schon von Marchand in dieser Frage aufgestellten Hypothese, nach welcher schon bei den allerersten Theilungen des Eies ein befruchtetes Richtungskörperchen in die Embryonalanlage geräth und umschlossen wird. Er stimmt Marchand darin bei, dass zwischen echten fötalen Inclusionen und den Embryomen der Keimstöcke nur ein relativer, aber kein prinzipieller Unterschied besteht. Beide sind auf eine Art parasitärer Bildungen aber in verschiedenen Körperregionen resp. Organen zurïckzuführen.

Bonnet hält es aber für wahrscheinlicher, dass die parasitären Inclusionen und die Embryome der Entwicklung von gesonderten oder sich verspätet theilenden Blastomeren ihr Dasein verdanken.

Die letztere Theorie setzt voraus, dass sich der fötale Organismus normal weiter entwickelt, selbst wenn eine oder mehrere Blastomeren sich an dem Aufbau des Körpers nicht betheiligen. Dabei hält sie die gesonderten oder sich verspätet theilenden Blastomeren doch für so vollwerthig, dass sich aus ihnen fötale Inclusionen bilden können.

Wenn diese oder die Marchand'sche Hypothese richtig ist, so könnte man denken, bedarf es einer Erörterung der Frage, worauf die Localisation eines Teratoms an einer bostimmten Körperstelle beruht, nicht mehr. Dann könnten die Teratome oder Embryome überall gefunden werden, wo eben gerade das befruchtete Richtungskörperchen, die befruchtete Polzelle oder die abgelöste oder abnorm langsam weiterentwickelte Blastomere geblieben ist.

Es liegen aber Gründe vor, welche die obigen Hypothesen nicht bedingungslos annehmen lassen.

Denn wenn man auch nach Lexer (66), welcher für die einfach gebauten Teratome einen monogerminalen, für die complicirten, Organ. theile enthaltenden einen bigerminalen Ursprung annimmt, die nicht mit den Ovarien oder den Hoden zusammenhängenden Teratome und die fötalen Inclusionen durch Implantation entstehen lässt und sie wohl am besten durch die Marchand'sche oder Bonnet'sche Theorie erklärt, so liegt es anders bei den Dermoiden und Teratomen der Keimstöcke.

Schon daraus, dass gegenüber 77 Dermoidcysten und Teratomen in anderen Körperregionen und Organen 230 solche Tumoren der Ovarien und der Iloden in den Arbeiten von Wilms (134-136) aufgeführt werden, ergiebt sich, dass letzteren Geschwülsten eine Sonder- 
stellung zukommt. Denn man würde keine Erklärung dafür zu geben wissen, warum gerade so häufig (3 Mal öfter) das befruchtete Richtungskörperchen oder die befruchtete Polzelle oder die in der Theilung zurückgebliebenen Blastomeren sich in der Lendengegend, der Stätte der Entwicklung der Keimstöcke, localisiren. Ganz besonders ist mit dieser Theorie, und das hat Wilms schon nachdrücklich betont, nicht in Einklang zu bringen die Doppelseitigkeit dieser Tumoren. Mantel ${ }^{1}$ ) hat unter 191 Fällen 97 rechtsseitige, 67 linksseitige und 26 doppelseitige Dermoidcysten zusammengestellt. Und diese Statistik war es, welche Wilms veranlasste, sich gegen die Theorie der Inclusio foetus in foetu bei diesen Geschwülsten auszusprechen, "da man in der That nicht verstehen könne, wie ein Einschluss derartig symmetrisch stattfinden sollte".

In unserem Falle müssten dann 2 befruchtete Richtungskörperchen oder 2 befruchtete Polzellen angenommen werden, da sich rechts ein typisches Ovarialdermoid, links ein Teratom fand. Durch eine Verlangsamung der Theilung in 2 Blastomeren würde beider Aetiologie gut geklärt werden, aber die Frage nach den Gründen der Localisation an den betreffenden Stellen unbeantwortet bleiben.

Demnach kommt man zu dem Schluss, dass die Bonnet'sche Hypothese zwar für den Bildungsmodus aber nicht für die Localisation, insbesondere bei den betreffenden Keimstockgeschwülsten, eine Erklärung bietet. Umgekehrt begründet die Wilms'sche Theorie der Keimdrüsenembryome die Localisation gut, bleibt aber den Beweis für die Richtigkeit der Annahme, dass dreikeimblättrige Tumoren aus dem Keimepithel hervorgehen können, schuldig.

Für die in der Lendengegend beobachteten Dermoidcysten hat Wilms die ektoblastische Entwicklung des Wolff'schen Ganges verwerthet.

Lexer (66) hat entsprechend den neueren Ergebnissen der entwicklungsgeschichtlichen Forschungen als deren möglichen Ausgangspunkt Ektoderm reste im Wolff'schen Gange angenommen, weil an der Grenze des mittleren und hinteren Drittels des Wolff'schen Ganges bei Säugethieren ein vorübergehender Contact desselben mit dem Ektoderm nachgewiesen ist, indem sich Zellen an den Gang anlegen und vielleicht mit ihm verschmelzen.

Leider sind alle Dermoidcysten der Lendengegend, über welche in der Litteratur berichtet wird (Herrera (148), Zweifel (147), Bardenheuer (7), König) ${ }^{2}$ ) worauf Lexer selbst hinweist, nicht

1) cf. $W i l m s$ (134).

2) Citirt von Lexer l. c. 
hinreichend genau auf den Gehalt von Producten der 3 Keimblätter untersucht. Man weiss nicht, ob sie nicht doch deren besessen haben, und es ist deshalb ein Erklärungsversuch im obigen Sinne ohne positive Grundlagen.

Trotzdem darf die Frage, ob nicht gerade die Dermoidcysten und die Teratome der Lendengegend in der Entwicklungsgeschichte dieser Region ihre Erklärung finden können, nicht unerörtert bleiben.

Die Entwicklung des Urogenitalapparates gestaltet sich nach Bonnet (1.43) und Waldeyer (126) folgendermaassen:

Die erste Anlage des Urogenitalapparates ist auf das mittlere Keimblatt zurïckzuführen. Als solche entsteht im Zusammenhang mit der Vorniere der Urnierengang (Wolff'scher Gang) und zwar nach Graf Spee, Flemming, Bonnet und Strahl zum grössten Theil aus dem Mesoderm. An seinem hinteren Ende tritt er eine Zeit lang in so enge Beziehungen zu dem Ektoderm, dass die Grenze zwischen beiden vollkommen verschwindet. Wie weit etwa in dieser Zeit der Vereinigung des Urnierenganges mit dem Ektoderm ein Zuschuss ektodermaler Zellen stattfindet, lässt sich noch nicht beurtheilen. (Strahl.) $\left.{ }^{1}\right)$

Solange demgemäss die Frage der Betheiligung des Ektoderms am Aufbau des Wolff'schen Ganges offen ist, kann auch die Herkunft bisher noch nicht beobachteter, aber möglicher Weise zu beobachtender unzweifelbaft ektodermaler Cysten der Lendengegend unerklärt bleiben.

Während sich die Vorniere zurückbildet, baut sich aus dem Mesoderm unmittelbar hinter der Vorniere die Urniere (der Wolff'sche Körper) auf. Neben der Urniere stïlpt sich das Cölomepithel zum M üller'schen Gang aus, und an der anderen Seite des Organs tritt die Geschlechtsdrüse auf.

Dass aus eventuell bestehen bleibenden Resten der mesodermalen Vorniere Geschwülste hervorgehen können, ist möglich. Ein Beweis für diese Annahme steht noch aus.

Dagegen werden die sogen. mesonephrischen Tumoren von den Resten der Urniere, dem Epoophoron und Paroophoron abgeleitet. (Hartz) (149).

Da die bleibende Niere (Metanephros) dem Urnierengang nahe der Kloake entsprosst, so ist ungewiss, ob ihr Epithel ektodermaler oder mesodermaler Abstammung ist.

Uns interessirt hier besonders die Entwicklung der topographischen Anatomie des lateralen retroperitonealen Raumes, wie sie Strahl in Küster's (145) "Chirurgie der Nieren" zur Darstellung gebracht hat.j

1) 8. Küster (145). 
"In der letzten Hälfte des zweiten Monats ist beim menschlichen Embryo der ganze Raum zwischen Zwerchfell und Becken neben der Wirbelsäule von der Nebenniere, der Niere und der Geschlechtsdrüse eingenommen. Die Nebenniere und die Geschlechtsdrüse sind so gross, dass sie die Niere ganz verdecken. Während die Niere in ihrer ursprünglichen Lage verharrt, aber stetig an Grösse zunimmt, steigt die Nebenniere höher hinauf, bleibt aber gleichzeitig im Wachsthum zurück. Die Geschlechtsdrüse vollzieht ihren Descensus d. h. sie wird durch das Längenwachsthum des Körpers verschoben und nimmt ebenfalls nicht in dem Maasse an Volumen zu, wie die Niere, während sie sich gleichzeitig zum Hoden oder zum Eierstock differenzirt. Im 5. Monat liegt die Geschlechtsdrüse schon im Becken ausserhalb der Region, welche hier besprochen wird."

Aber diese Verschiebungen sind von Wichtigkeit. Denn es können während dieser Zeit sich abschnürende Theile der Nebenniere und der Geschlechtsdrüse sowohl im retroperitonealen Raume liegen bleiben als auch nach abwärts mitgeschleppt werden.

Dass dies bei der Nebenniere thatsächlich der Fall ist, wird unten erörtert werden. Ob bezüglich der Ovarien und Testikel dasselbe gilt, ist strittig. Accessorische Ovarien sind mehrfach beobachtet worden. Sie können nach Seitz (112) retroperitoneal, intraligamentär und intraperitoneal liegen.

Funke stellt den Satz auf: Alle retroperitonealen Dermoide der Becken- und der Bauchhöhle stammen aus abgesprengten Theilen des Keimepithels. Die intraperitonealen Dermoide sind anf Abschnürungen von Embryomen oder auf Neubildungen aus dritten Ovarien zurückzuführen. Und nach Seitz (112) steht soviel zweifellos fest, dass auch retroperitoneal Tumoren auftreten, die ihre Entstehung nur Ovarialkeimen oder accessorischen Ovarien verdanken können, und bringt als Beweis 3 Fälle von retroperitonealen Ovarialcystomen bei vorhandenen normalen Ovarien (Frank, Bassini und von Winkel). „Wenn beim Descensus ovariorum Keimepithel durch das von der Urniere hereinwuchernde Bindegewebe abgeschnürt oder abgekapselt worden sei, so könne dasselbe, falls es nicht zu Grunde gehe, im Zustande des Keimepithels verharren und unter günstigen Ernährungsbedingungen Follikel bilden, also ein accessorisches Ovarium entstehen."

Man könnte demnach die lateralen retroperitonealen Dermoide und Teratome von einem accessorischen Ovarium oder, da ein solches noch niemals im lateralen retroperitonealen Raume beobachtet worden 
ist, doch von abgeschnürtem und liegen gebliebenem Keimepithel ableiten.

Dazu fehlt aber die Berechtigung, so lange nicht der Beweis erbracht ist, dass das Keimepithel Dermoidcysten und Teratome zu produciren im Stande ist. So berechtigt die Seitz'sche Auffassung der Genese der retroperitonealen Ovarialcystome bei beiderseits vorhandenem Ovarium ist, so ist sie für die retroperitonealen Dermoide und Teratome vorläufig nicht annehmbar.

Wir kommen somit zu dem Schluss, dass auch unser Teratom auf einer bigerminalen Implantation beruhe, mag sie nun gemäss der Marchand'schen oder der Bonnet'sche Hypothese vor sich gegangen sein.

Für die Bildung des auf der andern Seite vorhanden gewesenen Ovarialembryoms aber müssen wir, wie für alle übrigen Keimdrüsenembryome und -teratome, diese Erklärung aus den oben angeführten Gründen ablehnen und abwarten, bis die Entwicklungsgeschichte und die Teratologie eine allen Anforderungen genügende Erläuterung liefert.

Bezüglich seiner Localisation und seiner histologisehen Beschaffenheit ist unser Fall wohl einzig in seiner Art und deshalb besonders bemerkenswerth, weil er neben einem Riesenzellensarkom ein Adenocarcinom enthielt, welches durch ausgedehnte Metastasen den Tod herbeiführte.

Unter den Abdominal-Teratomen, welche Lexer (66) zusammengestellt hat, lagen 2 lateral retroperitoneal. Dazu würden der obige und der von Helferich im Jahre 1898 operirte, von Gude (44) in seiner Dissertation beschriebene Fall hinzuzurechnen sein.

Wie man in der Geschichte der Lehre über die Nierentumoren eine Periode vor und nach der Grawitz'schen Entdeckung unterscheidet, wie man die vor dieser Zeit beobachteten Nierentumoren hinsichtlich der mikroskopischen Diagnose kritisch betrachten muss, so hat man dies auch bei den lateralen retroperitonealen Geschwülsten zu thun, welche vor Chiari's (21) Arbeit ,Zur Kenntnis der accessorischen Nebennieren des Menschen "untersucht worden sind.

Marchand (75) hatte im Jahre 1883 über das Vorkommen von accessorischen Nebennieren im freien Rande des Lig. latum in unmittelbarer Nähe des Ovarium bei Kindern bis zu 1/1/2 Jahren Mittheilung gemacht. Für die Vermuthung, aus solchen abgeirrten Nebennierenstückchen könnten Geschwülste hervorgehen, fand Mar- 
chand aber keine Beweismittel. Er nahm daher an, dass diese accessorischen Nebennieren allmählich zu Grunde gingen.

Chiari's Verdienst war es, dass er nicht allein Belege dafür brachte, dass accessorische Nebennieren zwischen Niere und Geschlechtsdrüse auch bei erwachsenen Personen, selbst reiferen Alters, nicht nur weiblichen sondern auch männlichen Geschlechts anzutreffen sind - er beobachtete auch zum ersten Male eine Geschwulst, welche sich mit grosser Wahrscheinlichkeit auf eine accessorische Nebenniere zurückführen liess.

Seit diesen Veröffentlichungen ist häufig über accessorische Nebennieren im Gebiet der Vena spermatica interna berichtet worden.

Dagouet(26) fand sie zuerst am Nebenhoden, Michael (79) am Samenstrang in wechselnder Höhe und Schmorl(109) in der Leber. Fassen wir die Beobachtungen von Marchand, Chiari, Dagouet, Michael, Schmorl, Friedland(153), Ajutolo(152) und Rossa(142) zusammen, so fällt ein Ueberwiegen des männlichen Geschlechts (15:11) und der rechten Seite $(21: 4)$ auf.

Als Fundorte werden verzeichnet:

1. Die Umgebung der Nebennieren,

2. Der Plexus solaris,

3. An der Vena spermatica interna,

4. Am Nebenhoden,

5. Am Ovarium,

6. Unter der Nierenkapsel und in der Nierenrinde.

Die accessorischen Nebennieren unterhalb der Niere sind in jedem Lebensalter gesehen worden.

Allmählich ist der Befund bei den Sectionen immer häufiger erhoben worden. Hat doch Wiesl(131) in der k. k. Gesellschaft der Aerzte in Wien mitgetheilt, dass $761 / 2$ Proc. der männlichen Neugeborenen accessorische Nebennieren am Nebenhoden hätten.

Aetiologisch bleibt die schon oben angedeutete Erklärung: Marchand's zu Recht bestehen. Danach wird eine frühzeitig abgeschnürte Zellengruppe der Nebenniere vermöge ihres innigen Zusammenhanges mit der Vena spermatica interna beim Descensus der Geschlechtsdrüse und der dadurch bedingten Verlagerung der Geschlechtsdrüse nach abwärts gezogen.

Glücklicher Weise ist die Neigung dieser accessorischen Nebennieren zu Geschw ul stbil d un g gering. Denn aus der mir zugänglichen Litteratur konnte ich nur 7 Fälle zusammenstellen, natürlich mit Ausnahme der Nierentumoren. Unter diesen 7 sind die 3 Fälle Schmorl's mitgerechnet, von denen der eine in der Leber, der 2. hülınereigross von 
einer fibrösen Kapsel umschlossen dicht unterhalb des Zwerchfelles neben der Wirbelsäule zwischen den Strängen des Plexus solaris seinen Sitz hatte und der 3. wallnussgross in einer divertikelartigen Ausstülpung des Bauchfelles zwischen Milz und Quercolon sich etablirt hatte. - Weiss' (129) sehr interessanter 2. Fall war ein maligner Tumor in Lig. latum in der Nähe des Ovarium, also an der Stätte, an welcher F. Marchand zuerst accessorische Nebennieren nachgewiesen hatte.

Unter den hier in Betracht kommenden Lendengeschwülsten sind nur zwei, welche mit grösster Wahrscheinlichkeit auf accessorische Nebennieren zurückzuführen sind.

1. Chiari (21) secirte einen 44jährigen Mann, welcher 6 Monate vor dem Tode laparotomirt und von einer retroperitonealen Geschwulst in der rechten Hälfte des Unterbauchraumes befreit worden war, und nun in Folge der wegen schnellwachsenden Recidivs nothwendig gewordenen 2. Laparotomie gestorben war.

Bei der Autopsie lagerte an der rechten Seite der Lendenwirbelsäule vor dem M. quadratus lumborum und M. iliacus internus hinter dem Coecum und Colon ascendens und dem Peritoneum parietale der Fossa iliaca zwischen der stark nach aufwärts verdrängten rechten Niere und dem Ligamentum Pouparti eine im Ganzen eiförmige Geschwulst, welche aussen und hinten noch mit einer Kapsel versehen, sonst nicht scharf begrenzt war. Die Geschwulstmasse war von gelblich-weisser Farbe und medullarer Consistenz. Das Neoplasma verhielt sich abgesehen von dem mit Kapsel versehenen Theil wie etwa carcinomatöse Tumoren medullären Charakters, Metastasen waren nicht zu finden. Nierenabscesse wurden auf die durch die Compression des rechten Ureters bedingte Harnstauung der rechten Niere zurïckgeführt. Ein genetischer Zusammenhang mit einem Organ der Bauchböhle oder eine etwaige Entwicklung der Geschwulst aus einem bestimmten Bindegewebslager war nicht nachzuweisen.

Histologis $\mathrm{ch}$ bestand die Hauptmasse der Nenbildung aus ziemlich grossen bis $50 \mu$ in Durchmesser haltenden epithelioiden Zellen mit grossen Kernen, die dicht in eine sehr zarte theils schleimige, theils feinfaserige $Z$ wischensubstanz eingelagert waren. Dabei war das Protoplasma nicht scharf von der Zwischensubstanz abgegrenzt, so dass die Conturen der einzelnen Zellen nicht immer genau festgestellt werden konnten. Wo dies der Fall war, erschienen die Zellenleiber meist poly. gonal. Die Kerne färbten sich intensiv und zeigten zahlreiche Mitosen. An vielen Stellen waren jedoch ausserdem noch kleinere und grössere z. T. einen centralen Hohlraum enthaltende Gruppen von Zeilen in um. fänglichere Maschenränme des Zwischengewebes eingeschlossen, wodurch an solchen Stellen das Neoplasma einen drusigen Charakter bekam. Die einzelnen Zellen waren in diesen Gruppen nur undeutlich von einander getrennt, enthielten in sich hie und da bräunliches körniges Pigment und oft eine grosse Zahl von Fetttropfen, so dass das Bild derartiger Abschnitte 
sofort an das Aussehen der Nebennierenrinde und zwar der Zona glomerulosa oder der quergeschnittenen Zona fasciculata derselben erinnerte. Am reichsten fanden sich diese Zellgruppen in der Nähe der noch erhaltenen Kapsel, während sie in den centralen Partieen des Tumors und namentlich in den in die angrenzenden Organe hineingewucherten $A b$ schnitten nur sehr spärlich waren.

Auf Grund dieses Befundes nahm Chiari als Ursprung eine accessorische Nebenniere an und erklärte die Geschwulst für ein Carcinom derselben.

2. Weiss (129) batte Gelegenheit, einen von von Eiselsberg exstirpirten maligne entarteten Tumor eines versprengten Nebennierenkeims, welcher der linken Niere und Nebenniere eines 27jährigen Mädchens angelagert war, mikroskopisch zu untersuchen.

Bei der 27jähr. Patientin war 21/2 Jahre vor der Aufnahme der Leib ohne Schmerzen allmählich stärker geworden und grosse Müdigkeit in den Beinen und Abmagerung aufgetreten, ausserdem Veränderung der Urinmenge und Eiweiss im Harn. Schon 2 Jahre vor dem Eintritt in die Klinik war wegen linksseitigen mannskopfgrossen Tumors eine Probelaparotomie und, weil eine radikale Entfernnng nicht möglich schien, eine Probeexstirpation gemacht worden. Damals latte man mikroskopisch eine gutartige Hyperplasie von Nierengewebe festgestellt. 11/2 Monate nach der Laparotomie ging das Mädchen ihren Beschäftigungen nach und kam wegen Zunehmens der Beschwerden 2 Jahre nach der 1. Operation in aie Klinik.

Das Abdomen war halbkugelig vorgewölbt. In der linken Seite des Abdomens war eine starke Resistenz nachzuweisen, welche noch rechts bis über die verlängerte Parasternallinie reichte. Nach oben erstreckte sich die Resistenz bis zum linken Rippenbogen, nach links bis zur Wirbelsäule. Der 'Tumor war ziemlich hart. Per vaginam und rectum nihil. Der Urin war eiweissfrei, klar und von normaler Menge. Stuhlgang normal.

Bei der Operation wurde ein mässig grosser Tumor gefunden, über welchen rechts schräg von oben nach unten das Colon descendens führte. Letzteres wurde nach unten zurilckgeschoben und der Tumor herausgewälzt. Nach oben sass helmartig die stark ausgezogene linke Niere auf, deren Parenchym blass und verdünnt erschien. Die Niere wurde abgelöst und exstirpirt, der Tumor aus seiner Kapsel herausgeschält. Naht des Peritoneum, Wundversorgung. Peritonitis. Tod nach 6 Tagen.

Die Section zeigte, dass die linke Niere an normaler Stelle gesessen hatte. Sie war durch eine $\mathrm{K}$ apsel vom Tumor scharf getrennt. Die Oberfäche des Neoplasma war glatt flachhöckrig, von einer bindegewebigen, isolirt nicht abziehbaren Kapsel begrenzt.

Die Schnittfäche war überall gleichmässig gebaut. Es traten zahlreiche grössere und kleinere Höcker hervor. Die Farbe war gleichmässig hellgelb, fast schwefelgelb und dabei stark getrübt undurchsichtig. Von der Oberfläche lässt sich ein hellgelber fettiger Brei reichlich abstreichen. Erweichungshöhlen bestehen nicht. Nach der Oberfäche hin buntscheckiges Aussehen, mehr grauroth, weniger getrilbt. Ferner aus- 
gedehnte hämorrhagisch zerfaline Theile, die theils dunkelschwarzroth, theils bräunlich oder braungelb aussehen. Die frische mikroskopische Untersuchung liess Zellen vom Typus der Nebennierenzellen mit reichlichen Fetttröpfchen erkennen.

Ueberall sah man Stellen, die im Aussehen und in der Anordnung der Zellen vollkommen ubereinstimmen mit dem histologischen Bau der Rinde der gleichseitigen Nebenniere. Es waren eine Zona reticularis Fascikel und Glomeruli wiederzufinden. Das Stroma war von einem äusserst dichten Capillarmaschenwerk gebildet. An anderen Stellen waren die Geschwulstzellen alveolär angeordnet, aussen Cylinder, innen runde, geblähte und polygonale centrale Zellen. Eine Anzahl der centralen Zeilen waren Riesenzellen. An manchen Punkten war Neigung zu Zerfall sichtbar, und Blut war zwischen die Follikel getreten.

Es handelte sich um einen malignen Nebennierentumor, denn der Ileopsoas und die Lymphdrusen enthielten Metastasen.

$\mathrm{Zu}$ diesen beiden bisher beschriebenen Tumoren accessorischer Nebennieren dieser Region würden hinzuzurechnen sein 2 Fälle, welche in der hiesigen chirurgischen Klinik beobachtet worden sind.

3. Fall. 25 jähriger Patient, welcher an einer lumbalen, nicht mit der Nebenniere und nicht mit der Niere in Zusammenhang stehenden Nebennierengeschwulst zu Grunde ging.

Krankengeschichte (J.-Nr. 1899/915).

A. J. aus B., 25 Jahre alt.

Anamnese: Die Eltern und Geschwister des Patienten leben und sind gesund.

Pat. selbst hat vor etwa 5-6 Jahren einen leichten Typhus durchgemacht und ist im Uebrigen bis zum Herbst 1897 gesund gewesen.

Im October 1897 erlitt Pat. einen Unfall. Er fiel beim Durebgehen der Pferde rückwärts vom Wagen auf den Rücken und zog sich eine Quetschung des linken Fusses zu. Letztere heilte, und Pat. hatte mit dem Fuss nur geringe Beschwerden, über den Rücken hatte er gar nicht zu klagen. Im Mai 1899 hatte Pat. in hartem Grunde sebr schwere Feldarbeit zu verrichten. Dabei traten Schmerzen in der linken Seite des Leibes auf, die gegen Abend und Nachts sehr heftig wurden. Nach 3 Wochen suchte Pat., da die Schmerzen weiter bestanden, einen Arzt auf, welcher ihn 5 Wochen behandelte, bis die Schmerzen nachliessen. Pat. wandte sich trotzdem an einen anderen Arzt, weil der erste Arzt gesagt hatte, es bestände eine Darmgeschwulst. Der zweite consultirte Arzt stellte die Wahrscheinlichkeitsdiagnose auf Wanderniere und wies den Pat. an die hiesige chirurgische Klinik, welche Pat. am 20. September 1899 aufsuchte.

Status: Mittelgrosser, kräftig gebauter, gesund anssehender Mann mit gut entwickelter Musculatur und von gutem Ernährungszustand. Haut normal, etwas blass, ebenso Schleimhäute. Zunge belegt, feucht. Brustorgane ohne bemerkenswerthen Befund. Wirbelsäule gerade, kein 
prominirender Processus spinosus, kein Druckschmerz, kein Stauchungsschmerz. Puls kräftig regelmässig, 80 in der Minute.

Abdomen: Die linke untere Regio epigastrica ist ein wenig voller als die rechte. Die Haut des Abdomen ist normal. Die Leberdämpfung ist nicht verbreitert, die Milz nicht vergrössert. Man fühlt links neben der Mittellinie oberhalb Nabelhöhle unter verschiebbarer, leicht abhebbarer Haut einen harten derben Tumor, welcher sich nach links oben, bis unter den linken Rippenbogen verfolgen lässt. Der Tumor ist ungefähr $9 \mathrm{~cm}$ breit und reicht nach unten bis etwa 3 Finger breit unterbalb des Nabels, mit der Hauptmasse links von der Mittellinie bleibend. Die Aorta erscheint durch den Tumor nach rechts und nach vorn gedrängt. Man fühlt sie nahe der Bauchwand pulsiren. Der Tumor ist gar nicht verschieblich und wird durch die Athmung nicht beeinflusst. Bei starkem Druck ist der Tumor empfindlich. Der Percussionsschall über der Geschwulst ist wechselnd je nach der Luftfüllung des Darmes. Bläht man den Dickdarm per rectum auf, so liegt vor dem Tumor und aussen oben Dickdarm. Die Nierendämpfung ist links hinten nicbt verbreitert. Der Urin ist frei von Eiweiss und Zucker und frei von zelligen Elementen. Die Urinmenge ist nicht vermindert. Der Stuhl ist auf Abführmittel sehr dünnbreiig, braungelblich, ohne Beimengung von Blut, Eiter und Schleim. Der Pat. wurde längere Zeit beobachtet, mit Laxantien, Diät und feuchten Umschlägen behandelt. Er war tagsüber meist ohne Schmerzen. Sie stellten sich gewöhnlich gegen Abend ein und waren nicht sehr heftig.

Die Consistenz des Tumors schien 5 Tage nach der Aufnahme etwas weicher geworden zu sein. Anfang October 1899 trat leichtes Fieber auf. Pat. klagte über stärkere Schmerzen in der linken Bauchseite, und der Tumor war druckempfindlicher geworden.

Es wurde die Wahrscheinlichkeits diagnose auf eine chronisch entzündliche retroperitoneale unter dem Mesocolon gelegene Geschwulst gestellt und am 9. October 1899 zur Operation geschritten.

Chloroformnarkose: Operation (Geheimrath Helferich). Laparotomie. $10 \mathrm{~cm}$ langer in der Regio epigastrica 2 Finger breit links von der Mittellinie gelegener Schnitt eröffnet die Bauchhöhle. Das vorliegende Colon transversum und Netz werden nach oben geschoben. Das Mesocolon ist von einem gänseeigrossen fest verwachsenen fluctnirenden Tumor vorgewölbt und leicht entzündlich geröthet. Im Mesecolon läuft tiber die Geschwulst eine fingerdicke Vene hinweg. Das Mesocolon wird nach Verschiebung der Vene mit der Scheere uber dem Tumor durchtrennt. Letzterer liegt unterhalb einer kapselartigen Gewebsschicht. Beim Anschneiden der Geschwulst entleert sich dünnflüssiger Eiter. In die Wunde des Tumors wird ein Jodoformtampon eingelegt. Dann wird der Mesocolonwundrand mit dem Peritonealwundrand durch Catgutknopfnähte vereinigt und so der Tumor eingestellt. Naht der Fascie in dem übrigen Theil der Wunde. Jodoform-Gazetamponade. Verkleinerung der Hautwunde. Verband.

Am 20. October 1889 wurde der II. Act der Operation ausgefuihrt und die Schwellung, welche für einen Abscess angesehen wurde, incidirt. Nach breiter Spaltung der Kapsel entleeren sich weiche, gelbliche, z. Th. graurosa gefärbte Massen. Mit einem grossen scharfen Löffel 
werden weiche, sehr blutreiche graurosa aussehende sarkomartige Geschwulstmassen zu Tage gefördert. Die mässig starke Blutung wird durch Jodoformgazetamponade gestillt. Verband. Die mikroskopische Untersuchung ergiebt, dass es sich um einen Nebennierentumor handelt.

Da die Geschwulst an der hinteren Bauchwand fest verwachsen war, so war nicht anzunehmen, dass sie mit Aussicht auf Erfolg exstirpirt werden könnte.

Die Behandlung konnte nur eine symptomatische sein. Es wurde zwar eine Arsenkur durchgeführt, aber ohne dass auf irgend welchen Erfolg gerechnet worden wäre.

Der beim Verbandwechsel öfters stark blutende Tumor wuchs weiter. Am 28. November 1899 klagte Pat. über starke nach dem linken Bein ausstrahlende Schmerzen.

Am 8. December 1899 erhob sich die Geschwulst uber die Haut. Ein Gang führte ca. $12 \mathrm{~cm}$ in die Tiefe. Nur durch Laxantien oder Klystiere war noch Stuhlgang zu erzielen. Klagen über starke Schmerzen im Rücken, im Leib, die nach dem linken Bein ausstrahlen.

Am 30. December 1899 war die Neubildung kindskopfgross, erhob sich pilzförmig ca. $6 \mathrm{~cm}$ über die Bauchdecken, war zerklüftet und blutete leicht. Nach oben aussen lag der Dickdarm. Der Magen war stark nach oben gedrängt, die untere Grenze der Herzdämpfung lag im 5. Intercostalraum. Die Leber war unter dem Rippenbogen verschwunden.

Der Urin war frei von Eiweiss und zelligen Elementen. Die Urinmenge wechselte sehr stark.

Am 12. Januar 1900 trat hohes Fieber auf. Am 13. Januar war der Tumor, soweit er oberhalb der Bauchdecken lag, kindskopfgross und nahm fast den ganzen Raum zwischen Spina ilei a. s. und Rippenbogen ein. Man konnte oberflächlich grosse Fetzen abbrökeln, ohne dass eine Blutung entstand.

Unter atypischem Fieber verfiel Pat. immer mehr. Am 19. Januar 1900 Exitus letalis.

Sectionsbericht. ${ }^{1}$ )

Wesentlicher Befund: Grosser Tumor der linken Nierengegend pilzartig durch das Mesocolon descendens und die Banchwand herauswuchernd. Thrombose (Geschwulst) der linken Nierenvene. Compression des linken Ureters durch die Geschwulstmasse. Starke linksseitige Pyelitis, zahlreiche feine Abscesse der linken, wenige der rechten Niere. Frische Milzinfarkte. Leichte Compression der linken Unterlappen. Verwachsung zweier Aortenklappen. Starke Trübung und fettige Degeneration des Herzens. Massenhafte hämorrhagische Erosionen des Magens. Umschriebene Peritonitis des Douglas'schen Raumes, sehr starke allgemeine Anämie.

Sectionsprotokoll: Kopf: Dura auf der Innenfäche glatt, Pia zart und durchsichtig. Gefässe wenig gefüllt. In den Hemisphären und den Ganglien wenig Blutpunkte.

Brust: Sämmtliche Organe stark anämisch, links geringer seröser Erguss im Pleuraraum. Die linke Pleura zeigt vereinzelte Petechien,

1) S. Nr. 31. 1900. 
rechts ist sie ausgedehnt mit der Costalpleura verwachsen und von kleineren und grösseren Blutungen durchsetzt. Die linke Lunge zeigt im Oberlappen etwas Emphysem, im Unterlappen Oedem und unter der Pleura vereinzelte kleine erweichte Herde, im unteren Rande Atelektase. Rechter Unterlappen etwas ödematös. Herz blass, etwas verfettet, am Aortenostium 2 Klappen mit einander verwachsen, Noduli verdickt. Im Oesophagus kleine strichförmige Blutungen.

Abdomen: An der linken Seite Haut von einem bis $9 \mathrm{~cm}$ breiten, ca. $5 \mathrm{~cm}$ hohen pilzartig überwuchernden Tumor durchbrochen. Derselbe zieht durch die Bauchwand in die Bauchhöhle, geht dann durch das Mesocolon descendens hindurch in eine nach unten und innen von der linken Niere liegende Geschwulstmasse über. Diese fest an der Wirbelsäule anliegende Geschwulstmasse misst von oben nach unten $14 \mathrm{~cm}$, drängt den linken Psoas auseinander, ist auf dem Durchschnitt von sebr buntem Aussehen, theils blass grauroth, theils weisslich-gelblich gescheckt, theils dunkel-grauroth durchblutet, z. Th. auch trockengelb in nekrotischem Zerfall begriffen. In der Bauchhöhle nur wenig Flüssigkeit, das Peritoneum allenthalben zart, nur im Douglas'schen Raume nach rechts eine rostfarbene Verdickung.

Leber sehr gross, derb, Durchschnitt dunkelbraun, Gallenblase klein, enthält nur wenig stark fadenziehende dunkelgrüne Galle. Milz grösser, besonders verbreitert, an der Oberfläche mit etwas Fibrinbelag, dunkelgrauroth, mit einzelnen scharf umschriebenen grösseren und kleineren dunkelgraurothen Infarkten.

Rechte Niere: normal gross, Kapsel glatt ablösbar, Oberfläche blassgelblich, mit ziemlich zahlreichen kleinen gelblich-weissen Abscessen durchsetzt. Auf dem Durchschnitt Substanz sehr blassgelb, von ziemlich zahlreichen, punkt- und streifenförmigen gelblichweissen Herden durchsetzt. Nierenkelche und Nierenbecken sehr bleich, leer.

Linke Niere: etwas hochliegend, ihre Kapsel glatt ablösbar, im Ganzen wie rechts, nur im oberen Ende mit sehr viel zahlreicheren Abscessen, die Nierenkelche erweitert and wie das Nierenbecken mit trubber eitriger Flüssigk eit gefüllt. Schleimhaut blass, mit kleinen hämorrhagischen Flecken. Der Ureter im oberen Theil ziemlich weit, ringsum in schwieliges Gewebe eingebacken. Etwa in der Mitte ist er durch ihn von hinten nach vorn vollkommen umgreifende Geschwulstmassen in etwa $4 \mathrm{~cm}$ Länge vollkommen comprimirt.

Linke Nebenniere in schwieliges Gewebe eingebettet, sonst anscheinend normal, die rechte normai.

Harnblase, Hoden nichts Besonderes. Magen mässig ausgedehnt, enthält wenig bräunliche Flüssigkeit, Schleimhaut sehr bleich, von ausserordentlich zahlreichen hämorrhagischen Erosionen durchsetzt.

Vena cava inferior: entbält flussiges Blut und Blutgerinsel, zeigt in etwa $11 / 2 \mathrm{~cm}$ Ausdehnung um die Mündung der linken Nierenvene herum einen ganz zarten, röthlichweissen, leicht festhaftenden Belag. Die Nierenvene sehr weit, bis zum Nierenhilus $61 / 2 \mathrm{~cm}$ messend, die Nebennierenvene mündet $11 / 2 \mathrm{~cm}$ von der Hohlvene, $3 \mathrm{~cm}$ von der Hohlvene ist die Vene durch andrängende Tumormassen zu einem schmalen Schlitze comprimirt, in die untere Umschlagsstelle mündet eine grössere und eine kleinere 
Vene, welche in die Geschwulstmasse führen. Die hintere Wand der Nierenvene ist daselbst mit einem gelblichweissen, unregelmässig dicken Belag versehen. $5 \mathrm{~cm}$ von der unteren Hohlvene geht dieser Belag in eine die schlitzförmige Lichtung vollkommen verlegende, an der Wand festhaftende Thrombusmasse über.

Mikroskopischer Befund

der bei der Operation entfernten Geschwulstmassen:

Frisch untersucht enthielt der Tumor sehr viel Fett. Die Zellen waren gross, mit rundlichem grossen Kern und enthielten Fetttröpfchen.

In gefärbten Schnitten ist das Stroma wabenartig und wird von Bindegewebszellen gebildet. Es ist reich an dünnwandigen Gefässen und zahlreichen, nur von einem Endothelschlauch gebildeten z. Th. sehr stark erweiterten Capillaren. Ausserdem findet man zahlreiche Hämorrhagieen. An vielen Stellen sind die Maschenräume ganz dicht mit Zellen gefüllt. Dann sind die Zellen polyedrisch, enthalten einen grossen rundlichen oder länglich runden Kern und Kernkörperchen. Das Protoplasma ist mässig entwickelt. In den Zellen oft Vacuolen. Zahlreiche Mitosen, Zellen mit sehr grossem Kern und Riesenzellen in ziemlich homogene Grundsubstanz eingebettet.

Andere Stellen bieten fast das Aussehen wie Schleimgewebe, sie sind aus sternförmigen aber mit grossem Kern versehenen Zellen und schleimiger Grundsubstanz zusammengesetzt. Wiederum in anderen Partieen sind das Maschenwerk und die Zellen so vertheilt, dass je eine Zelle in einer Lücke liegt. Vielfach kleinzellig infiltrirte Herde. Coagulationsnekrotische Herde.

Die dicht zusammenliegenden Zellen ähneln ausserordentlich den Zellen der Zona fasciculata der normalen Nebenniere.

4. Fa 11. 67 Jahre alter Mann mit grossem retroperitonealem Tumor der linken Iliacal- und Iumbalregion.

Krankengeschichte (J.-Nr. 1899/1324).

D. M., 67 Jahre alt, aus Sch.

Anamnese: Vater starb an Krebs des Penis, Mutter an Altersschwäche. Die Frau lebt und ist gesund, von 7 Kindern sind 2 an Tuberculose gestorben, die übrigen sind gesund. Die Frau hat einmal abortirt. Pat. will nie besonders krank gewesen sein. Urinbeschwerden haben nie bestanden. Der Stuhlgang war in letzter Zeit etwas unregelmässig. Seit einem Vierteljahr hat Pat. Schmerzen in der linken Seite, zu gleicher Zeit bemerkte er eine Geschwulst daselbst, die allmählich mehr wuchs. Grössere Beschwerden hat Pat. nie davon gehabt, hat aber in der letzten Zeit etwas abgenommen.

Status: Mittelgrosser, wenig kräftiger, ziemlich gut genährter Mann. Lungen und Herz normal, Leberdämpfung beginnt am oberen Rand der 
5. Rippe, sie ist nur 2 Finger breit, darauf folgt sofort Darmschall. Der Leib ist nicht aufgetrieben.

Die linke Abdominalseite wird durch eine halbkugelige Geschwulst von etwa Mannskopfgrösse vorgewölbt. Die Geschwulst zeigt eine ziemlich glatte Oberfläche, ist von praller Consistenz, fluctuirt, ist nicht druckempfindlich. Der Tumor setzt sich in die Tiefe fort und füllt die ganze linke Abdominalseite aus. Der Percussionsschall über dem Tumor in der linken Nierengegend ist leer. Ascites ist nicht nachweisbar. Der Tumor bewegt sich nicht mit der Athmung, er reicht genau bis in die Mittellinie. Das Colon descendens verläuft vor ihm her, wie sich bei Aufblähung deutlich erkennen lässt. Die Untersuchung per rectum ergiebt nichts Abnormes. Beiderseits Leistenbrüche seit 5-10 Jahren. Stuhlgang von normaler Beschaffenheit, Urin klar, hellgelb, kein Albumen, kein Saccharum.

Bei der Untersuchung in Narkose (9. Januar 1900) fühlt man die mächtige, die Mittellinie überschreitende weiche Geschwulst. Dieselbe erscheint mit der linken Darmbeinschaufel fest verwachsen und ist nicht beweglich. Ein allabendlicher Temperaturanstieg nach der Untersuchung fällt zur Norm ab.

Nachdem Patient sich von der Narkose erholt hat,

am 15. Januar 1900 Operation (Geheimrath Helferich) in Chloroformnarkose. 4 Finger breit von der Mittellinie gelegener Laparotomielängsschnitt. Vor dem Tumor liegt das Colon descendens. Der Tumor ist an einigen Stellen durch das Peritoneum gebrochen. Erweiterung des Längsschnittes und Querschnitt nach links. Die hintere Wand des Colon descendens ist mit dem Tumor fest verwachsen und bereits ergriffen. Durchtrennung des Colon descendens unterhalb des Tumors. Die Geschwulst mit sammt dem Colon und zugehörigem Mesocolon zu exstirpiren, zeigt sich als unausführbar. Der Tumor hat seine Kapsel durchbrochen und ist breit in die Weichtheile der Lendengegend und besonders des Beckens hineingewachsen, hat auch bereits an mehreren Stellen das Mesocolon des Colon descendens nach der freien Bauchhöhle $\mathrm{zu}$ durchbrochen. Bei dieser Sachlage muss von der Exstirpation Abstand genommen werden und die Operation, welche in dem Gedanken unternommen war, dem sicher verlorenen Manne vielleicht eine Besserung zu verschaffen, wird auf folgende Weise vollendet:

a. Anlegen eines Anus praeternaturalis am Colon transversum etwas rechts von der Mittellinie,

b. Abschluss des Tumors von der iibrigen Bauchhöhle durch Vernähen des medialen Peritonealwundrandes mit der Basis des Mesocolon descendens. Lose Tamponade. Situationsnähte. Verband.

Am 17. Januar 1900. Exitus letalis.

Sectionsbericht. 1)

Wesentlicher Befund: Gesehwulst der linken Nierengegend mit Compression des Colon descendens. Metastasen in Lunge und Pleura. Atrophie der Lungen. Hyperämie der Unterlappen. Geringe Verdickung

1) S. Nr. 29. 1900. 
der Mitralis. Ganz geringe ehronische Endarteriitis der Aorta descendens, stärkere der descendens. Starke Erweiterung der Aorta descendens. Starke Trübung von Herz, Leber und Nieren. Schwellung der atrophischen Milz. Fettdurchwachsung und Trübung des Herzens. Thrombose eines Pulmonalarterienastes. Starke hämorrhagische Peritonitis im Douglas. Kleiner verkäsender Tumor des linken Leberlappens. Kleiner Polyp im Coecum.

Sectionsprotokoll. Bauch: Decken stark aufgetrieben, in der linken Seite breite T-förmige Operationswunde. In der Höhle geringe Mengen klarer Flüssigkeit. Därme stark aufgetrieben. In der linken Seite eine grosse etwa kindskopfgrosse Geschwulst, die vom unteren Rande der Rippen bis zur Darmbeinschaufel herunterreicht. Das Colon descendens ist fest mit ihr verwachsen und zu einem schmalen Schlitze verengt, die Schleimhaut wird an mehreren Stellen von dem Tumor stark ins Lumen vorgewölbt. Unterbalb des Tumors ist der Dickdarm operativ durchtrennt und vernäht. Nach unten zu ist der Tumor mit dem Ileopsoas und den Banchdecken verwachsen. Der obere Theil der Geschwulst ist nur lose an die Wirbelsäule angeheftet.

Der Tumor zeigt entsprechend der äusseren Operationswunde einen tiefen Einschnitt, der stark zerklüftet und missfarbig grauroth aussehend ist. Auf einem frischen Durchschnitt ist der Tumor sehr blutreich, von scheckig graurother Farbe mit einzelnen umschriebenen helleren Partieen stark bröcklich zerfallend, von weicher Consistenz.

Linke Niere: ziemlich hoch von der Geschwulst hinaufgedrängt, auf ihr reitend, ziemlich klein, Kapsel glatt lösbar, Oberfläche glatt, von braunrother Farbe, auf dem Durchschnitt Zeichnung verwaschen, Sub. stanz weich.

Linker Ureter: im oberen Theil stark ausgedehnt, zieht hinter dem Tumor, von dem er comprimirt wird und mit dem er lose verwachsen ist, nach dem Becken. Schleimhaut des Ureters glatt.

Linke Nebenniere: klein, weich, Rindensubstanz schmal.

Rechte Niere: an normaler Stelle, zeigt dieselbe Farbe wie die linke Niere. Rechte Nebenniere wie die linke.

Leber klein, braungelb, mässig fest, auf Durchschnitt Zeichnung gut erhalten. Im linken Leberlappen dicht neben dem Ligament am unteren Rande ein kirschkerngrosser, runder, stark gelblicher Tumor, der auf dem Durchschnitt in dilnner fibröser Kapsel einen kreidigen Brei enthält (abgestorbener Echinococcus?).

Gallenblase: klein, enthält wenig schleimigen, dunkeln Inhalt.

Milz: klein, von weicher Consistenz mit geringer umschriebener Verdickung der Kapsel. Im Douglas sind die Serosablätter fest mit einander verklebt, nach Lösung ergiebt sich eine stark blutige, fleckige Durchtränkung der gesammten Douglasserosa. Die Venen der linken Bauchseite stark comprimirt. Innenfläche glatt.

B lase, Hoden: nichts Besonderes. Magen mässig ausgedehnt, enthält wenig Schleim. Schleimhaut blass, Wandungen dün. Darm ziemlich aufgetrieben. Schleimhaut blass, Wandungen dünn, im Coecum eine umschriebene gestielte Verdickung der Schleimhaut. 
Brust: Lungen klein, stark emphysematös, schlaff, von blassgraurother Farbe, mit zahlreichen schwärzlichen Punkten durchsetzt. Oberlappen wenig, Unterlappen stärker blutreich. In linker Lunge und linker Pleura viele bis kirschkerngrosse, weisslichgelbe weiche umschriebene Knoten. In rechter Lunge nur im Unterlappen einige ebensolche Knoten. Herz normal gross, mit sehr reichlicher subpericardialer Fettentwicklung, welche die Wandung des rechten Ventrikels in ausgedehnter Weise durchsetzt. Ventrikel weit, enthalten flüssiges und geronnenes Blut. Herzfleisch braunroth mit reichlichen gelblich scheckigen Flecken. Klappen zart, nur an Mitralis geringe Verdickung der Klappenränder. Aorta ziemlich weit, im aufsteigenden Theil auf Intima geringe weisslichgelbe beetartige Erhebungen, im absteigenden Theil zahlreichere.

Bronchialdrüsen klein, schiefrig. Kehlkopf und Trachea: Schleimhaut leicht geröthet.

Oesophagus: Schleimhant blass.

Bei der frischen mikroskopischen Untersuchung fand man grosse rundliche Zellen mit grossem Kern und reichlichem Fettgehalt in Tumor und Metastasen.

Es wurde im hiesigen pathologischen Institut die Diagnose gestellt, dass es sich mit grösster Wahrscheinlichkeit um eine aus einer accessorischen Nebenniere hervorgegangene Geschwulst gehandelt habe.

Pathologisch-anatomisch haben die Tumoren der eben beschriebenen 4 Fälle folgendes Gemeinsame:

1. Sie sind retroperitoneal zwischen der Niere und dem Beckeneingang in dem Gebiet gelegen, welches von den Vasa spermatica durchzogen wird.

2. Sie sind von einer Kapsel umgeben oder haben doch eine solche besessen.

3. Sie haben eine weiche z. Th. bröcklige gehirnähnliche Consistenz, sind auf dem Durchschnitt gelblich, sehr blutreich und oft von zahlreichen Hämorrhagieen durchsetzt. Sie erhalten dann ein mehr buntscheckiges Aussehen oder eine mehr grauröthliche Färbung.

4. Sie besitzen grosse Neigung zu Nekrose und auch zu schleimiger Entartung.

Vergleichen wir damit die grobanatomischen Eigenschaften, welche nach Lubarsch (72) den von Nebennierenkeimen ausgehenden Nierengeschwülsten zukommen:

1. Die Tumoren sind stets subcapsulär nnd scharf gegen die Nierensubstanz getrennt.

2. Sie bestehen fast stets aus multiplen Knoten,

3. Sie sind auf dem Durchschnitt graugelb bis schwefelgelb und nur durch Blutungen und reichlichen Blutgefässgehalt stellenweise grauröthlich. 
4. Sie sind weich und deutlich gelappt und zeigen

5. grosse Neigung zu myxomatöser Erweichung (Cystenbildung) Nekrosen und Blutungen. tastasen.

6. Sie bilden leicht durch Einbruch in das Venensystem Me-

$\mathrm{H}$ i s to logis c h enthielten unsere Geschwülste z. Th. Partieen, deren Zellen den Nebennierenzellen in ihrer Form und Anordnung gleich waren - z. Th. grosse polygonale Zellen mit grossem Kern, und kleinere cylinderförmige Zellen, welche nicht selten alveolär angeordnet waren und centrale Riesenzellen umschlossen. Die Zellen enthielten meist Fetttröpfchen. Das Stroma war reich an feinen dünnwandigen Gefässen.

Lubarsch entwirft als charakteristisch für die Nebennierentumoren der Nieren folgendes mikroskopische Bild:.

Das Stroma besteht vielfach nur aus dünnwandigen und weit klaffenden Gefässen, um welche nur selten noch eine Bindegewebshülle vorhanden ist. Das Endothel der Gefässe ist deutlich oft reichlich gewuchert. Die Tumorzellen sind meistens polygonal gestaltet, wie Nebennieren- und Leberzellen, doch sind sie auch cylindrisch und unregelmässig mehrkernig. Der Kern ist scharf rundlich mit deutlichem Kernkörperchen. Der Zellleib ist angefüllt

a) mit grösseren und kleineren Fetttröpfchen,

b) mit glänzenden Körnern und Kugeln (Glykogen).

Letzteres liegt auch als Schollen und Streifen zwischen den Zellen. Die Geschwulstzellen sind meist in 2 Reihen ohne Intercellularsubstanz angeordnet, manchmal ohne Lumenbildung.

Somit bieten die 4 Neubildungen sowohl makroskopisch wie mikroskopisch viele den als Strumae suprarenales renis beschriebenen Nierentumoren ähnliche, manche fast gleiche Eigenschaften. Man kann annehmen, dass auch sie aus Nebennierenkeimen hervorgegangen sind.

Das nicht seltene Vorkommen von accessorischen Nebennieren entlang der Vena spermatica interna ist oben dargethan. Es dürfte daher gestattet sein, die Entwicklung dieser Neoplasmen aus accessorischen Nebennieren als höchst wahrscheinlich hinzustellen.

Es müsste bei dem häufigen Vorkommen der accessorischen Nebennieren doch Wunder nehmen, dass nur 7 mal Tumoren derselben beschrieben worden sind.

Thatsächlich sind unter den in der beigefügten Casuistik aufgefülurten Sarkomen manche, welche ihrem makroskopischen und mikroskopischen Bilde nach auch sehr gut Tumoren der acces- 
sorischen Nebennieren sein könnten, z. B. die von Rauschoff (98), Rogowski (101) und Pilliet und Veau (95). Da eine mikroskopische Nachuntersuchung nicht stattgefunden hat, so ist es nicht erlaubt, die Diagnose dieser Geschwülste anzuzweifeln. Man darf aber wohl die Vermuthung aussprechen, dass mehr aus accessorischen Nebennieren entstandene Neubildungen vorgekommen, aber als solche nicht erkannt sind.

Als gutartige epitheliale Geschw ü Iste seien die primären Harnleiterpapillome erwähnt, welche sehr selten sind und für uns nicht in Betracht kommen.

Choostek (22), Monti (81) und Duplay (32) beschrieben Carcinome, welche von den retroperitonealen Lymphdrüsen ausgegangen sein sollten, und bei welchen kein primärer Herd nachzuweisen war. Alle diese Untersuchungen stammen aus älterer Zeit. Man wird gut thun, wenn man der Richtigkeit der Diagnose gegenüber Kritik übt.

So sah Ellis (35) ein Carcinom, welches als encephaloide Masse die linke Niere umgab. Von der Nebenniere wird nichts erwähnt. Der Tumor scheint ein Nebennierentumor gewesen zu sein. - Nicht mindèr merkwürdig ist $\mathrm{P}$ el eg rini's (90) Carcinom der retroperitonealen Lymphdrüsen.

Ein unbestreitbares Carcinom ist kürzlich von J. Israel (46) als papilläres z. Th. cystisches Adenocarcinom der Nierengegend exstirpirt worden. Die Frage nach der Abstammung dieser seltenen Neubildung ist noch offen.

Leichter zu deuten sind die retroperitonealen Geschwülste, welche secundäre Metastasen eines primären Carcinoms eines Beckenorganes darstellen. (Beispiele bei Köhler (61)).

Unsere Fälle haben uns somit Gelegenheit gegeben, die Entwicklungsgeschichte des lateralretroperitonealen Raumes, das Vorkommen von epitbelialen Gebilden (Dermoidcysten, Teratomen, Ovarialkystomen) und deren Aetiologie zu besprechen und als fast möchte ich sagen für diese Gegend charakteristisch die aus accessorischen Nebennieren entstehenden Epithelgeschwülste kennen zu lernen.

Wie die Tabelle 1 lehrt, stammt die überwiegende Mehrzahl der lateral-retroperitonealen Geschwülste vom Bindegewebe ab. Sie beweist aber gleichzeitig; dass die Sarkome nicht die retroperitonealen Neubildungen $x \alpha \tau^{\prime} \dot{\varepsilon} \xi_{0} \eta_{\eta} \nu$ sind, als welche sie von Dutton Steele (154) und Lockw o od (69) angesehen zu sein scheinen. Die Sarkome sind zwar häufiger als die einzelnen Geschwulstarten, aber 
die homologen Neoplasmen stellen doch ein grösseres Contingent wie die heterologen.

Dutton Steele (154), Kereszeghy (56) stellten die retroperitonealen Sarkome, Latte(65) die retroperitonealen Tumoren zusammen. In den beigegebenen Tabellen sind von mir die in der mir zugänglichen Litteratur erwähnten lateral-retroperitonealen Tumoren eingetragen. Indem bezüglich der Statistik auf sie verwiesen wird, seien kurz die einzelnen Geschwulstarten charakterisirt.

\section{Die reinen Lipome.}

Das Fettgewebe im lateral-retroperitonealen Raum kann mächtig: entwickelt sein, ohne dass es zu einer eigentlichen Geschwulstbildung kommt. Diese starke Fettbildung kann die Theilerscheinung einer allgemeinen Abdominalkrankheit sein, bei welcher sich im subserösen Gewebe eine sehr dicke Fettschicht ablagert (die subseröse Lipomatosis nach Ogston).

Reine Lipome dieser Region sind immer als Besonderheiten angesehen worden, und deshalb ist die spärliche Casuistik wohl doch sehr vollständig.

Je nach dem Ort der primären Entstehung scheinen die Verhältnisse der Geschwulst zur Niere verschieden zu sein: In den aus der Nierenfettkapsel hervorgehenden Tumoren ist die Niere meist eingebettet, die Lipome der Massa adrenalis lateralis und des retroperitonealen Zellengewebes drängen die Niere nach innen und oben, doch können auch sie die Niere umwachsen. Bei grossen Lipomen ist es oft unmöglich, den Ausgangspunkt genau zu bestimmen. Sie erreichen oft eine enorme Grösse. Sie kommen meist bei älteren Leuten zur Beobachtung, bei Frauen häufiger als bei Männern $(6: 1)$. Sie entwickeln sich langsam. Sie können abgekapselt bleiben, aber auch sich im subperitonealen Gewebe fortsetzen, neue Tumoren bilden und dif Intestina umschliessen.

4 Iipome lagen rechts, 2 links, 3 lumbal, 1 iliacal, 2 iliacal und lumbal.

\section{Die reinen Fibrome.}

Unter den 6 reinen Fibromen, über welche Mittheilungen zu finden sind, bildete für 3 (Möricke (47), J oubert (55)), das subperitoneale Gewebe, für 2 die Nierenkapsel den Mutterboden. Bei Beveridge's (11) grossem Fibrom ist es zweifelhaft, ob nicht die Nervenscheide die Zellen zu dessen Aufbau geliefert hat, und die Geschwulst nicbt zu den solitären Neurofibromen zu zählen wäre. Alle diese retroperitonealen Fibrome waren abgekapselt und hatten die 
charakteristischen Eigenschaften der reinen Fibrome. Sie hatten eine bedeutende Grösse erreicht, hatten aber nur durch ihre Grösse und Schwere pathologische Zustände hervorgerufen. Sie wuchsen sehr langsam. Die kürzeste Zeit der Beobachtung betrug 6 Monate, die längste 15 Jahre. Abgesehen von Beveridge's Patient handelte es sich nur um Frauen im Alter von 21 bis 42 Jahren. 4 lagen rechts, 2 links, 4 iliacal, 2 iliacal und lumbal.

\section{Die reinen Myxome.}

Eine besondere Eigenthümlichkeit der lateral-retroperitonealen Region ist es, dass sich hier relativ häufiger als anderswo Schleimgewebe an dem Aufbau der Tumoren betheiligt. Reine Myxome sind allerdings nur von dem perirenalen Gewebe, aber doch ohne Betheiligung der Niere ausgegangen und je eins von Hulke (52) und Gould (43) exstirpirt worden. $O b$ sich diese Tumoren primär, als Myxome entwickelt haben, im Hulke'schen Falle könnte man es annehmen, oder ob es sich, wie es bei dem Myxom Gould's (43) wahrscheinlicher ist, um eine myxomatöse Degeneration einer anderen Geschwulst handelt, lässt sich nicht sicher entscheiden. Jedenfalls liegt der Gedanke, diese Neubildungen als ein Product schleimiger Entartung aufzufassen, nahe, weil sie bei vielen Tumoren dieser Gegend eine grosse Rolle spielt. Lage: 1 rechts, 1 links, 1 lumbal, 1 iliacal und lumbal.

Ueberhaupt sind die reinen nur aus einer Gewebsart bestehenden Neubildungen hier selten. Van der Veer (123) hat die Mischtumoren geradezu als charakteristisch für das Retroperitoneum hingestellt. Für die homologen Neoplasmen dürfte diese Anschaung richtig sein. Dass es sich bei dem Sarkom anders verhält, werden wir später sehen.

Die lipomatösen Mischtumoren.

Die Fibrolipome und Myxolipome haben stets durch enorme Grösse imponirt. Man hat Menschen gesehen, die Geschwulstmassen bis zu 63 Pfd. in ihrem Bauche tragen mussten. Diese Neubildungen sind gelblich, gelappt, weich elastisch, meist mit einer Kapsel versehen, auf dem Durchschnitt fettig, aus verschieden grossen Knollen zusammengesetzt. Die Fibrolipome sind von derben weisslichen Streifen durchzogen, die Myxolipome mit gelatinösen oft zu Cysten sich umwandelnden Erweichungsherden oder mit glasigen Partieen durchsetzt. Auch sie sind bei weiblichen Individuen häufiger, die Fibrolipome wurden nur bei älteren Frauen, die Myxolipome im mittleren Lebensalter (bei beiden Geschlechtern gleich häufig) beobachtet. Uebergang in Sarkom und andere Combinationen fehlen nicht. 
Die Beobachtungszeit währte $1 / 2$ bis 15 Jahre. Der Ausgang war meistens der Tod, nur in einigen glücklichen Fällen konnte auf operativen Wegen eine Heilung erzielt werden. 4 lumbal.

Lage: Fibrolipome: 2 rechts, 1 links, 1 doppelseitig,

Myхolipome: 6 rechts, 3 links, 7 lumbal, 2 lumbal und iliacal.

\section{Die Chondrome. (Osteom.)}

J enner (54) war wohl der erste, welcher die interessante Mittheilung über ein abdominelles Enehondrom machte und die Hypothese aufstellte, dass diese Knorpelgeschwulst von der Synchondrosis sacroiliaca aus sich ihren Platz in der Bauchhöhle erobert habe. Beaudoux (8) hatte sogar das Glück, ein kindskopfgrosses Enchondrom von der rechten Fossa iliaca mit Erfolg entfernen zu können.

von Noorden's (86) ausserordentlich umfangreiches Chondrom war an der Linea terminalis in ea. $8 \mathrm{~cm}$ langer Ausdehnung verwachsen. Die glasig aussehenden knolligen Massen waren sehr blutarm. Das hyaline Chondrom war myxomatös degenerirt und recidivirte sehr bald, so dass nach einem Jahr eine radicale Exstirpation nicht möglich war. Auch Domke's (30) Enchondrom der rechten Beckenschaufel gehört hierher, während das von E. v. Bergmann (10) exstirpirte einen medianen Sitz hatte.

Vereinzelt steht in der Litteratur die Analyse eines 0 steoms des linken Hüftbeins und des M. psoas von Ebstein (33). In den pathologischen Sammlungen dürften Osteome und Osteochondrome der os ilei häufiger zu finden sein. Doch soll auch diese Beobachtung nicht unberücksichtigt gelassen sein, weil sie neben der Möglichkeit des Vorkommens auch die Symptome demonstrirt.

\section{Die Myome.}

Myome sind ausserordentlich seltene Befunde. Es seien deshalb die beiden einzigen bis jetzt operirten Fälle kurz mitgetheilt.

0 gston (88) erwähnt ein Myom, welches den linken Ureter in sich schloss. Deshalb war es nöthig, einen Theil des Ureters zu reseciren. Ogston pflanzte das proximale Ende in das distale und umsäumte die Ureterwunde rings mit vollkommenem Erfolg.

Pfannenstiel (92) demonstrirte auf dem deutsehen GynäkologenCongress 18972 Tumoren, welche er durch Operation gewonnen hatte. Der obere kindskopfgrosse lag hinter dem stark nach rechts verschobenen Colon descendens, welches enorm in die Breite ausgezerrt war. Die Appendices epiploicae waren infolge der Stauung zu 
kirschen- bis pflaumengrossen Anhängseln geschwollen. Der untere, grössere Tumor war hinten links von der Flexura sigmoidea und dem Rectum gelagert und ragte in das Becken hinein. Nach Spaltung des Peritoneum parietale wurde der obere Tumor ansgeschält und sein fleischiger Stiel, welcher zur hinteren Fläche des Colon bis nahe an die Mucosa führte, durchtrennt. Sodann wurde die untere Geschwulst nach Abtrennung der linken Adnexe exstirpirt. Mikroskopisch waren beide Myome.

Ein von Latte (65) besprochenes primär im retroperitonealen Raume entstandenes Adenomyoma myxosarcomatodes sei erwähnt, gehört aber nicht hierher, weil es median gelegen und gestielt war.

Pfannenstiel nahm als Ausgangspunkt für seinen Tumor die Muscularis des Colon descendens an. 0 gston erwähnte sein Myom bei der Discussion gelegentlich des von Anderson gehaltenen Vortrages über die Chirurgie des subperitonealen Gewebes und erwähnte die Aetiologie nicht besonders.

\section{Die Neurome.}

Während die äussere Hälfte des lateralen retroperitonealen Raumes arm an nervösen Elementen ist, birgt der mediale nicht nur den grossen Plexus lumbalis mit seinen Aesten, sondern auch den lumbalen Theil des N. sympathicus mit einer wechselnden Anzahl von Ganglien und den sympathischen Plexus spermaticus.

Man hat daher bei allgemeiner Neurofibromatosis auch hier Tumoren festgestellt (Generisch [156]). Ob man die Nervengeschwülste, welche secundär in der Lendenregion aufgetreten sind, als Metastasen oder als dieselbe Erkrankung an einem anderen Ort auffassen soll, ist zweifelhaft.

Thomson(119) musste erleben, dass bei allgemeiner Neurofibromatosis ein exstirpirtes schmerzhaftes Medianusfibrom immer wieder auch nach der Exarticulatio humeri als Sarkom recidivirte und dazu ein Sarkom am Plexus lumbalis auftrat. Er spricht sich gegen die Auffassung einer Metastasenbildung aus. Dagegen kann man den von $\mathrm{H}$ eymann und Fiedler (49) nach Enucleatio Bulbi wegen Netzhautglioms erhobenen Befund eines retroperitonealen Glioms nicht anders deuten, zumal noch andere Metastasen vorhanden waren. Das Gliom hatte die linke Niere nach oben gedrängt und sass breitbasig der hinteren Bauchwand fest auf.

Es sind indessen auch primäre Nervengeschwülste hier gefunden worden. Harrison, Cripps und Williamson (24) stiessen bei einer Laparotomie wegen eines vermutheten Ovarialtumors, welcher 
bei der Untersuchung links und hinten eine bis an die Beckenmitte reichende runde und feste Masse dargestellt hatte, auf eine vom Plexus sacralis sin. ausgehende Neubildung, welche stark myxomatös, weniger fibrös war und neben marklosen Nervenfasern einkernige multipolare Ganglienzellen enthielt.

Endlich gehört hierher ein Ganglienzellenneurom des linken dorso-Iumbalen Sympathicusstranges, dessen histologische Diagnose durch Buss e sicher gestellt wurde. Der von Kredel operirte 4 jährige Knabe mit Lähmungserscheinungen an den Beinen und Blasen- und Mastdarmstörungen, hatte links hinten neben der Wirbelsäule, zwischen Haut und 7. bis 12. Rippe einen etwa gänseeigrossen, sehr derben Tumor, welcher fast unverschieblich war und sich in die Lendengegend fortsetzte. Die Geschwulst füllte unten fast das ganze grosse Becken aus, reichte oben weit unter den Rippenbogen in die Höhe und legte sich medial dicht an die Wirbelsäule an. Die Oberfläche war glatt und rund, die Consistenz derb. Im Urin war kein Eiweiss und kein Zucker. Als man bei der Operation die im Rücken gelegene Geschwulst zuerst angriff, überraschte die ungemein geringe Blutfülle; da man Stïck für Stück herunterschneiden konnte, ohne dass eine stärkere Blutung auftrat, so wurde die weisse Geschwulst allmählich bis auf einen gänseeigrossen Rest unter dem Rippenbogen exstirpirt. Es trat Heilung der Wunde, aber keine Aenderung des nervösen Zustandes ein.

Die Sarkome.

Während die eben erwähnten Neubildungen, die Myome und Neurome Raritäten darstellen, sind die lateral retroperitonealen Sarkome, wenn auch selten, doch immerhin so häufig, dass sie mehr Interesse beanspruchen.

Die Kenntnisse über die retroperitonealen Sarkome im Allgemeinen verdanken wir seit Lobstein vielen Forschern, aber besondere Verdienste haben sich die Amerikaner und Engländer um dieses etwas vernachlässigte Gebiet der pathologischen Anatomie und der Chirurgie erworben. Hauptsächlich sei hier J. Dutton-Ste ele (154) erwähnt, welcher in einer kritischen Zusammenstellung der Litteratur über retroperitoneales Sarkom das Wesentlichste über diese Neubildung brachte und 61 Fälle sammelte. (Da seiner Arbeit wohl eine Statistik, aber keine Casuistik beigegeben ist, so mussten meinerseits die retroperitonealen Sarkome noch einmal zusammengebracht werden und laterale, mediane und Beckensarkome geschieden werden. Einiger amerikanischen Fälle habe ich nicht habhaft werden können. Im übrigen ist die unten angefügte Statistik, hoffe ich, vollständig.) 
Unter den 30 lateralen retroperitonealen Sarkomen waren 5 Spindelzellensarkome, 10 Rundzellensarkome, 2 Rund- und Spindelzellensarkome, 4 Fibrosarkome, 6 Myxosarkome, und 3 andere Sarkomarten vertreten. Davon wurden 14 bei männlichen, 15 bei weiblichen Individuen, 10 rechts, 11 links, 16 lumbale, 5 iliacale, 6 ilialcale und lumbale beobachtet. Wie bei den übrigen überwiegen auch hier die rechtsseitigen Neubildungen. Während aber sonst das weibliche Geschlecht fast doppelt so häufig (59:36) befallen ist, stellen bei den Sarkomen die Männer fast das gleiche Contingent.

Für die Spindelzellen- und die Fibrosarkome werden die Fascien, das Periost des Darmbeins und die Nierenkapsel als Ursprungsstätte aufgeführt. Sie wachsen schnell, besitzen meist eine höckrige Oberfläche und verhalten sich sonst wie die anderen Körpersarkome gleichen Charakters.

Die Rundzellensarkome sind wohl durchweg Drüsengeschwülste, nur in dem Willutzki'schen(133) Falle soll der Ureter primär afficirt gewesen sein, doch liegen zu dieser Annahme wenig Beweise vor.

Die Rundzellensarkome dieser Region sind meist knollig, von verschiedener Consistenz, manche hart, manche weich, andere bröcklig, auf dem Durchschnitt oft markweiss, grauweiss oder grauröthlich, zuweilen blutreich oder weich zerfallen und cystisch.

Die Myxosarkome entstammen dem perirenalen und dem retroperitonealen Gewebe. Sie werden z. Th. als kugelige glatte Tumoren mit flachen Prominenzen oder als knollig beschrieben; sie erreichen bis Mannskopfgrösse, sind auf dem Durchschnitt röthlichgrau, fast weich bis gelatinös, oft cystisch erweicht, oder sie bilden weiche breiige Massen.

Bei den Neoplasmen Rans o h off's (98), Monnier's (80) und dem Sarkom, welches Pilliet und Veau (95) (cf. Tabellen) untersuchten, ist die Möglichkeit eines sog. Hypernephroms nicht ausgeschlossen.

Die Sarkome wachsen in die umgebenden Gewebe hinein, besonders in die Muskeln als die am wenigsten widerstandsfähigen Gebilde. Die Niere und Nebenniere sind vor ihnen durch ihre Kapseln gut geschützt. Nur einmal war die Ureterwand an einer Stelle ganz durch Geschwulstmasse ersetzt (Willutzki). Sie brechen in die Venen ein, bilden Geschwulstthromben und so Metastasen, aber selten. Einige Mal führte ein Durchbruch in das Peritoneum den Tod herbei.

Sonst war ihre schädigende Wirkung auf den Organismus wie bei den übrigen Neoplasmen durch die Compression auf die Gefüsse, 
Nerven, die Eingeweide und den Ureter bedingt. Häufig entstanden Nierenbeckenerweiterung und Pyelitis.

Sie wurden am häufigsten im 20-30. und im 50-60. Lebensjahr, am seltensten im 1-20. und jenseits des 60. Lebensjahres beobachtet.

Ueber die Cysten liegen eingehende Arbeiten von Przevoski (96), Obalinski (87), Frank(37) und Narrath (83) vor. Der Vollständigkeit halber seien sie kurz erwähnt. Die serösen Cysten besitzen eine dünne, feste, weissliche, faserige Wand mit glatter glänzender Innenfläche, einen klaren, dünnflüssigen und gelblichen oder wasserklaren Inhalt. Wenn man bei der Operation oder Section auf sie stösst, machen sie den Eindruck eines bläulichen Sackes. Sie werden bis mannskopfgross und liegen vor und hinter der Niere (P a w li ck (89).

Unter den 9 zur Operation gelangten Chyluscysten lagen 2 rechts (Frank (37), Killian (158), eine links (Narath (83) von der Wirbelsäule. Sie enthielten chylusartige Flüssigkeit und gingen vom Lymphsystem aus. Sie sollen innerhalb 8 Tagen entstehen können.

Schönwerth (110) fübrte seine Blutcyste auf ein Trauma, Lockwood (69) eine ähnlich gebaute auf Reste des Wolff'schen Körpers zurück. Doch scheint diese Blutcoagula enthaltende Cyste auch eine einfachere Aetiologie, etwa wie die von Schönwerth angegebene zu gestatten.

$$
\text { Symptomatologie. }
$$

Die Patienten, bei welchen ein lateral-retroperitonealer Tumor constatirt wurde, haben oft gar keine Beschwerden gehabt. Sie kamen zum Arzt, weil der Leib in für sie etwas beunruhigender Weise angeschwollen war. Manche Frawen hielten sich für schwanger, und die geringen Leibschmerzen oder Störungen der Darmfunktion führten sie auf diesen Zustand zurïck.

Andere hatten ein Gefühl der Schwere im Leib oder Schmerzen und eine Geschwulst im Leibe bemerkt. Wieder andere waren durch eine Schwellung eines oder beider Beine, Schmerzen in einem Fuss oder Bein beunruhigt, und der herbeigerufene Arzt constatirte eine grosse unbemerkt entstandene Bauchgeschwulst.

Endlich fehlten unter den Patienten auch solche nicht, welche das Wachsthum einer Geschwulst beobachteten, aber erst als stärkere Abmagerung eintrat, ärztliche Hilfe in Anspruch nahmen.

Gerade bei den Lipomen wissen die Kranken oft weiter nichts anzugeben, als dass ihr Leib sehr stark an Umfang zugenommen habe. 
Man findet dann oft ein enorm, aber gleichmässig ausgedehntes Abdomen mit Striae, und die Untersuchung ergiebt in der einen Bauchseite Dämpfung und anscheinende Fluctuation, welche zur Annahme eines abgekapselten Ascites verleiten kann. Mehrmals sind in solchen Fällen Punctionen, natürlich ohne Erfolg, ausgeführt worden. Ein anderes Mal gelingt es, einen weichen schlechtbegrenzten, dem Finger ausweichenden Tumor nachzuweisen, welcher retroperitoneal gelegen ist. Der Urin ist meist normal, bei Frauen ist kein Zusammenhang mit der Gebärmutter festzustellen. Die Fibrolipo me sind fester als die reinen und die Myxolipome, sie sind grosslappig und entgehen dem tastenden Finger weniger leicht. Die Lipome und Fibrolipome wachsen langsam und gleichmässig, die Myxolipome schneller. Oft heisst es von den letzteren, dass sie Anfangs langsam, dann in kurzer Zeit rapide an Grösse zugenommen hätten.

Die derbelastischen Fibrome entstehen auch allmählich, aber sie werden meist früher bemerkt, weil ein harter Knoten selbst dem Laien eher auffällt. Ausserdem wölben sie die Bauchwand mehr circumscript vor, wenn sie ein gewisses Volumen erreicht haben. Sie sind oft sehr beweglich, glatt oder unregelmässig.

Während die Myxome sehr elastisch sind, zweifelhafte oder deutliche Fluctuation aufweisen und bei der Punction derselben viscide oder mucoide Flüssigkeit entleert wird, sind die Chondrome sehr hart. Da sie meist vom Becken ausgehen, hängen sie mit dem Knochen zusammen. Bei der Punction lassen sich zuweilen Knorpelzellen nachweisen. Die Myxome entwickeln sich sehr rasch, die Chondrome langsamer.

Die Dermoideysten befanden sich als völlig schmerzlose Geschwulzt z. Th. lange Zeit in Beobachtung. Bei dicken Wandungen war keine Fluctuation nachzuweisen, die Ovarialky stome dagegen zeigten dentliche grosswellige Fluctuation. Die serösen Cysten unterschieden sich von ihnen nur durch die noch dïnnere Wand und die Punctionsflüssigkeit, welche bei den serösen Cysten gelblich oder wasserklar, bei den Ovarialkystomen und den Chyluscysten in bekannter Weise charakteristisch ist.

Die Geschw ülste accessorischer Nebennier en sind meist verwachsen, weich elastisch, of fluctuirend, die Teratome sind je nach Art sehr verschieden. Die Spindelzellen- Rundzelien- und Fibrosarkome sind grosse rundliche, unebene vielknollige, derbe, harte, an manchen Stellen fluctuirende Tumoren, meist schon so mit der Umgebung verlöthet, dass sie nicht verschieblich sind. 
Durch ein geradezu rapides Wachsthum zeichnen sich die Myxosarkome aus, welche prall elastisch, hart und unbeweglich sind.

Für alle lateral-retroperitonealen Neubildungen sind am wichtigsten die Symptome, welche dureh ihre Lage und ihre Bezieh ungen zu den Nachbarorganen bedingt sind.

Durch ihr Wachsthum verdrängen sie die umgebenden Organe. Das Bauchfell wird abgehoben, und die Därme werden verschoben. Das hauptsächlichste Symptom für die retroperitoneale Localisation bleibt immer das, dass man den Darm, bei lateralen Geschwülsten insbesondere den Dickdarm vor ihnen durch Aufblähung nachweisen kann. Indessen besteht für die Lagerung des Darmes an einer bestimmten Seite des Tumors keine Regel. Man kann nicht sagen alle rechten lumbalen Geschwülste verschieben den Dickdarm nach innen unten und vorn oder alle rechten iliacalen haben den Dickdarm vor sich und an der median gerichteten Fläche. Ersteres gilt wohl für die kleineren Geschwülste, welche lumbal dicht an der rechten Niere auftreten.

Im Uebrigen ergiebt eine Zusammenstellung aus den Krankengeschichten, in welchen sich diesbezügliche Angaben finden, folgendes:

Rechts lag der Diekdarm

bei 7 lumbalen Tumoren 5 mal vorn unten und innen,

2 mal hinten und aussen,

bei 6 iliacalen Tumoren $3 \mathrm{mal}$ innen und vorn,

2 mal aussen und

1 mal lag das Coecum oben rechts

( $\mathrm{J}$ o u b e r t $)$,

bei einem Tumor der Lenden und Beckenregion quer vor der Gesehwulst.

Links fand sich der Dickdarm

bei 6 lumbalen Tumoren 5 mal innen und vorn,

1 mal aussen,

bei 3 iliacalen Tumoren 2 mal innen und vorn,

1 mal aussen,

bei 4 iliacal- u. lumbalen 3 mal innen und vorn,

1 mal gerade vor der Geschwulst hinabsteigend.

Wenn es sich hier leider auch nur um kleine Zahlen handelt so beweisen sie doch, dass man aus der Lage des Darms nur die retroperitoneale Entwicklung, sonst aber nichts Besonderes schliessen kann. 
Viel Werth ist von Steele auch den sogenannten Drucksymptomen beigelegt worden. Sie sind zwar häufiger bei manchen der hier besprochenen lateralen retroperitonealen Tumoren. Aber sie können durch jede andere von der Niere, Nebenniere, dem Mesenterium und median gelagerte retroperitoneale Tumoren hervorgerufen werden.

Als Drucksymptome sind anzusehen:

1. Anschwellung und Oedem der Beine. Es hat z. B. Beveridge angegeben, dass sein Patient 1 Monat, bevor eine Anschwellung des Unterleibes beobachtet wurde, eine solche des rechten Beines bemerkt habe.

2. Stauung im unteren Venengebiet, sei es nun dass einseitig oder beiderseits die Bauchvenen stark geschwollen waren, oder Krampfadern an den Unterschenkeln sich zeigten, sei es, dass sehr starke Hämorrhoiden oder eine Varicocele die Patienten veranlassten, einen Arzt zu consultiren. Bei grösseren Tumoren ist manchmal ein Verschluss der Vena cava inferior angenommen worden, weil colossal erweiterte und geschlängelte Bauchvenen wie ein Medusenhaupt sich entwickelt hatten und auch sonst sehr starke Stauungserscheinungen im unteren Venengebiet vorhanden waren.

3. Verschiedentlich localisirte Schmerzen und Parästhesieen. Ausstrahlende Schmerzen im Gebiet eines einzelnen Nerven z. B. des N. cruralis oder stechende Schmerzen in einem Fuss, welche allmählich sich über das ganze Bein hinerstreckten, endlich Schmerzen im Rücken, welche in den Testikel ausstrahlten.

4. Die Symptome einer intermittirenden Hydronephrose, das heisst soweit es die Urinmenge betrifft. Z. B. wechselte die Urinmenge sowohl in unserem Fall I, wie in Fall II sehr stark. Im Fall I schwankte sie innerhalb je 3 Tagen zwischen $500 \mathrm{ccm}$ und $1500 \mathrm{ccm}$ hin und her, während in Fall II die Urinverminderung mit stärkeren Schmerzen in der betreffenden Seite, die Urinvermehrung mit Befreiung oder doch Linderung einherging. Dieses Symptom ist wohl so zu erklären, dass erst ein gewisser Füllungsgrad des Nierenbeckens erreicht werden musste, ehe der Druck so gross wurde, dass der Widerstand des den Ureter comprimirenden Tumors überwunden werden konnte. Auf diese Weise ist es auch möglich, dass sich bei Fall I kein Hydronephrosensack entwickelte, obwohl ich bei der cystoskopischen Untersuchung die linke Uretermündung "todt" liegen sah und der linke Ureter auch bei 10 Minuten langer Beobachtungsdauer nicht agirte. Ein Ureterdauerkatheter würde diesen Widerspruch gelöst haben, doch gestattete der Zustand der Patientin keine längeren Manipulationen. 
Endlich ist die Qualität des Urins bei den lateral-retroperitonealen Tumoren auch wohl als Symptom nicht ausser Acht zu lassen.

Da stehen wir nun vor der bemerkenswerthen Thatsache, dass eine Veränderung des Urins selbst bei grossen Tumoren sehr selten bemerkt worden ist. Allerdings war bei den 101 Geschwülsten nur 25 mal der Urinbefund notirt. Unter diesen ist nur 2 mal von Eiweiss und Eitergehalt berichtet worden. Blutungen findet man niemals verzeichnet.

\section{Diagnose.}

Bei kleinen und mittelgrossen Tumoren wird die Diagnose, ob es sich um eine retroperitoneale Geschwulst handelt, immer leicht sein. Besonders gilt dies von den meisten iliacalen Tumoren. Doch finden sich auch unter ihnen solche, bei welchen die Differentialdiagnose zwischen retroperitonealem und Ovarialtumor mit Recht Schwierigkeiten gemacht hat.

Liegen sehr grosse Geschwülste vor, so ist die Entscheidung der Frage, ob intra- oder retroperitoneal, manchmal nicht leicht, dann trägt die Entstehungsgeschichte, der Nachweis der Fixirung an der hinteren Bauchwand unter Berücksichtigung der oben erwähnten Symptome zur richtigen Beurtheilung bei.

Die Differentialdiagnose einer lumbalen Geschwulst ist oft ausserordentlich schwierig. In keinem Gebiet der chirurgischen Diagnostik sind wohl so viel Fehl-Diagnosen gestellt worden.

Besonders häufig sind die Geschwülste als Nieren- und Ovarientumoren angesehen worden. Letztere gelingt es wohl meist auszuschliessen, wenn man durch Aufblähen des Dickdarms sich über retro- und intraperitoneale Lage klar werden kann.

Kann man aber einen Nieren- oder Nebennierentumor von einem lumbalen Tumor unterscheiden.?

Manche Teratome haben eine solche vielgestaltige Form, dass sie wohl erkannt werden können. Die Lipome bieten wohl zuweilen auch einmal einen solch klaren Befund, dass ein geübter Diagnostiker ein Lipom richtig constatirt, und unter den cystischen Tumoren lässt die Angabe sehr langen Bestehens bei fehlenden Nierensymptomen vielleicht an eine Dermoidcyste denken, sonst ist die Richtigkeit der Diagnose doch immer recht zweifelhaft.

Nehmen wir z. B. einen retroperitonealen lumbalen cystischen Tumor an. Wenn der Ureterenkatheterismus beiderseits normalen Urin und gleiche Urinmengen ergiebt, so spricht die Wahrscheinlichkeit für eine laterale retroperitoneale Cyste. Doch ist wiederum zu berücksichtigen, dass offene Hydronephrosen normalen Harn, was 
Qualität und Quantität anlangt, secerniren können. Auch kann eine paranephritische mit dem Nierenbecken communicirende Cyste vorhanden sein (Israel). Es bestehen also abgesehen davon, dass auch Myxome und Myxolipome Fluctuation und Cysten vortäuschen können, mancherlei Möglichkeiten. Doch wird dann eine Punction, welche unmittelbar vor der Operation erlaubt ist, Aufklärung verschaffen und vielleicht auch einen Echinococcussack ausschliessen.

Was die übrigen Tumoren anlangt, so spricht eine durch das Cystoskop festgestellte Blutung aus der mit der Geschwulst gleichseitigen Niere für eine Nierenaffection, Fehlen der Blutung, ja vollständig normaler Urin nicht gegen dieselbe. Letzteres bewies uns erst kürzlich ein Hypernephrom der linken Niere. Ein zweifäustegrosser Tumor hatte sich im untersten Nierenpol entwickelt. Der Urin war normal. Alle Symptome sprachen ebenso sehr für einen lateral-retroperitonealen Tumor wie für eine Nierengeschwulst. Die Geschwulst war sehr leicht nach aufwärts zu drängen. Letzteres wäre vielleicht gegen die Annahme eines lateralen retroperitonealen Tumors verwerthbar gewesen, aber doch auch nur mit Einschränkung.

Ein Hilfsmittel bei der Diagnosenstellung können bei Vorhandensein eines nicht fluctuirenden Tumors auch sein die oben beschriebenen starken Schwankungen in der Urinmenge.

Ferner sind sicher die Drucksymptome bedeutungsvoll insofern, als sie bei Nierentumoren seltener beobachtet werden und Nierentumoren, welche Drucksymptome hervorrufen, sicher mehr Nierensymptome aufzuweisen haben.

Da die Sarkome mehr infiltrirend wachsen, als die übrigen, könnte man annehmen, sie riefen eher Drucksymptome hervor. Eine Durchsicht der Fälle bestätigt die Annahme nicht. Dagegen ist die Schnelligkeit der Entwicklung wohl geeignet, unsere Entscheidung für diese oder jene Geschwulst zu beeinflussen.

\section{Prognose.}

Die Prognose bei den cystischen Tumoren ist gut. Nach der Operation trat in fast allen Fällen Heilung ein. Sonst ist die Prognose der lateral-retroperitonealen Geschwülste, wenn sie nicht frühzeitig. zur Operation kommen, absolut schlecht. Das lehrt folgende Tabelle: 


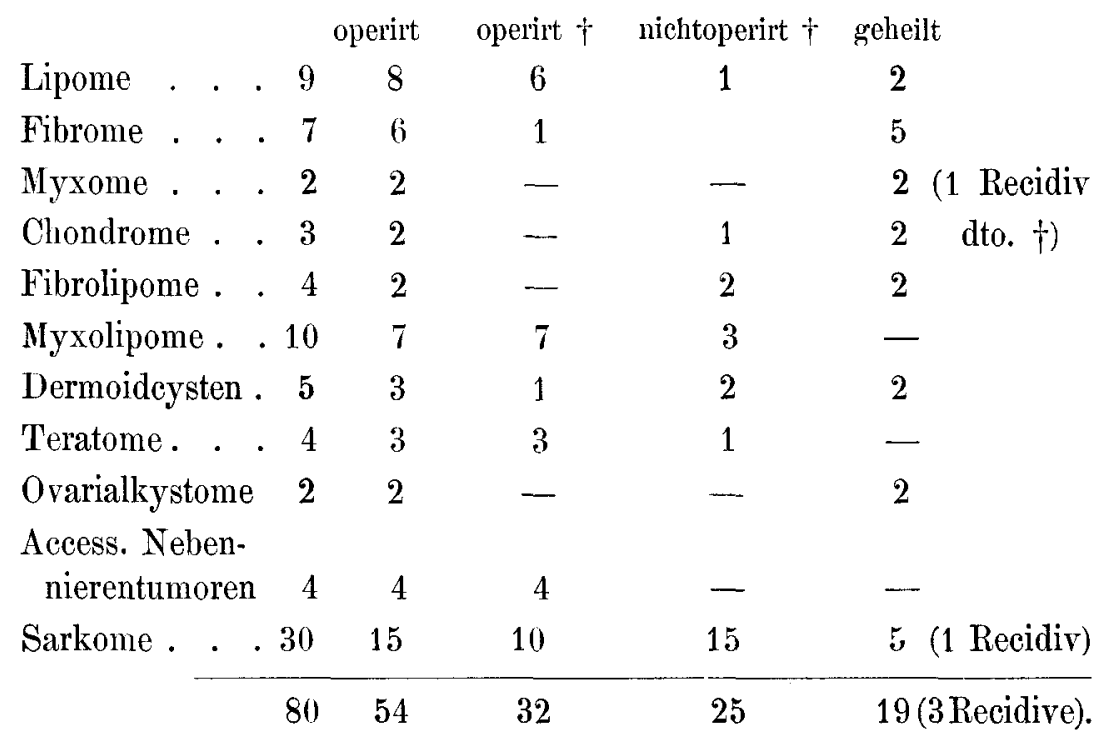

Die Zahlen zeigen die schlechteste Prognose bei den Lipomen und den lipomatösen Mischgeschwülsten, bei den Sarkomen und den Geschwïlsten der accessorischen Nebennieren, bessere bei den übrigen Tumoren.

$$
\text { Behandlung. }
$$

Die Behandlung kann nur in möglichst frühzeitiger Exstirpation bestehen. Bei der geförderten Erkenntniss der Bauchtumoren und den Fortschritten der Nierenchirurgie kann man hoffen, dass die Tumoren früher diagnosticirt werden, und die Pat. den Chirurgen eher zur Behandlung zugewiesen werden.

Die grösste Anzahl der Geschwülste ist per laparotomiam freigelegt worden, meist, weil man ein intraperitoneales Gebilde vermuthete. Als man sie dann retroperitoneal liegen sah, wurden sie transperitoneal entfernt. Von 36 Tumoren standen mir genaue Operationsberichte zur Verfügung; $28 \mathrm{mal}$ wurde transperitoneal, 8 mal extraperitoneal vorgegangen.

Dem extraperitonealen Verfahren ist bei kleineren und mittelgrossen Geschwülsten der Vorzug zu geben. Bei der transperitonealen Exstirpation ist die Orientirung leichter. Aber abgesehen davon, dass das Bauchfell 2 mal verletzt wird, muss sehr häufig das Mesocolon durchtrennt werden. Die Gefässe desselben erschweren das Vordringen, und der Darm wird durch das Abschneiden der Blutzufuhr leicht gefährdet. 
Will man die Vortheile des intraperitonealen Vorgehens nicht missen, so ist zu empfehlen, sich über die Lage des Colon Gewissheit. zu verschaffen, und wenn angängig aussen vom Darm einzugehen. Dass selbst dann noch Darmgangrän und eine Fistel auftreten kann, beweist unser Fall I.

Im Allgemeinen ist das extraperitoneale Vorgehen aber die Regel. Um sich über die Topographie des Tumors genaueren Aufschluss zu verschaffen, eröffnet man von dem extraperitonealen Schnitt aus das Peritoneum und stellt die Beziehungen des Tumors zu den Abdominalorganen fest.

Vor der Exstirpation sehr grosser retroperitonealer Tumoren hat Billr o th eindringlich gewarnt, und die Operationsresultate geben ihm Recht. Doch sind immerhin einige Operationen glïcklich zu Ende geführt worden und von Erfolg begleitet gewesen, meist bei relativ gutartigen Gesehwülsten. Die wichtigste Aufgabe bei grossen ;Geschwülsten ist deshalb, die Natur des Tumors festzustellen. Dazu kann man Bardenheuer's extraperitonealen Explorativschnitt anwenden. Viele Chirurgen werden aber zuerst eine Probelaparotomie machen. Hat man dann die Operabilität der Geschwulst festgestellt, so schliesst man die Bauchhöhle wieder und geht extraperitoneal vor. Für die Exstirpation der lumbalen und ileolumbalen Tumoren dürfte sich am besten der Schnitt eignen, welcher verschiedentlich zu Operationen am Ureter empfohlen worden ist. Er beginnt im Winkel zwischen M. sacro-lumbalis und der 12. Rippe, verläuft schräg nach abwärts und zieht an der Spina oss. ilei ant. sup. vorbei parallel dem Lig. inguinale. - Für die iliacalen Geschwülste genügt die untere Hälfte dieses Schnitts. Unter den 36 Operationen musste 16 mal eine Nephrectomie gemacht werden, weil der Tumor mit der Niere verwachsen war.

Daraus ergiebt sich die Forderung, dass man an keine Operation eines lateral-retroperitonealen Tumors herangehen soll, ohne über die Functionstïchtigkeit der anderen Niere unterrichtet zu sein. Man soll sich durch den Ureterenkatheterismus von dem Vorhandensein der andersseitigen Niere und deren Sufficienz überzeugen.

Ist nur der Ureter in geringer Ausdehnung mit der Geschwulst verwachsen, so ist das conservative Verfahren, Resection des Ureters und Naht desselben, das beste, wie es 0 gston(88) mit Erfolg ausgeführt hat. 
Tabelle I. Gesummt-Uebersicht.

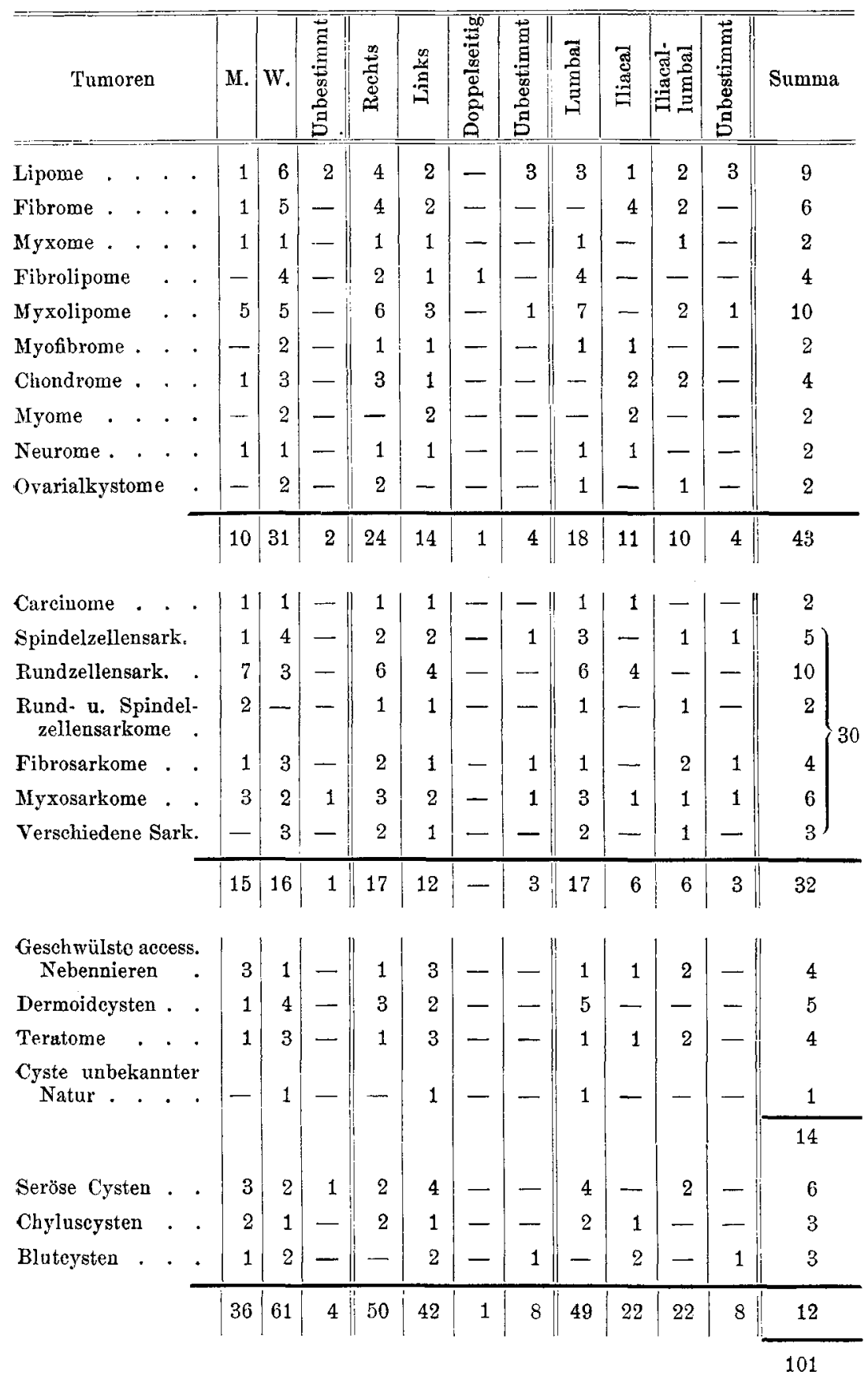


TABelle ]

\begin{tabular}{|c|c|c|c|c|c|c|c|}
\hline Nr. & $\begin{array}{l}\text { Autor, } \\
\text { Operateur }\end{array}$ & Alter & 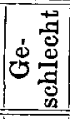 & Diagnose & Operation & Lage, Seite & Befund \\
\hline 1 & $\begin{array}{c}\text { Spencer } \\
\text { Wells (130). }\end{array}$ & $\begin{array}{c}43 \\
\text { Jahre. }\end{array}$ & W. & $?$ & $\begin{array}{c}\text { Probeincision, } \\
\text { später Exci- } \\
\text { sion transpe- } \\
\text { ritoneal. }\end{array}$ & R. lumbal. & $\begin{array}{l}\text { Fettmasse an } 0 \\
\text { rechten Seite, schl } \\
\text { die rechte Niere e } \\
\text { trieb das Colon de } \\
\text { nach links. Unt } \\
\text { fläche der Leber a } \\
\text { härent. } 11 \text { Pfd. }\end{array}$ \\
\hline 2 & $\begin{array}{c}\text { Kidd }(60) . \\
1877 .\end{array}$ & - & - & $?$ & $\begin{array}{c}\text { Operation } \\
?\end{array}$ & $?$ & $\begin{array}{l}\text { Grosses Lipom } \\
\text { zwischen den letzt } \\
\text { Rippen u. der Cri } \\
\text { ilei. } 7^{3} / 4 \text { Pfd. }\end{array}$ \\
\hline 3 & $\begin{array}{c}\text { Homans (51). } \\
1883 .\end{array}$ & $\begin{array}{c}60 \\
\text { Jahre. }\end{array}$ & W. & $\begin{array}{c}\text { Retroperiton. } \\
\text { Tumor. }\end{array}$ & $\begin{array}{l}\text { Transperiton. } \\
\text { Exstirpation. } \\
\text { Laparotomie. }\end{array}$ & $\begin{array}{l}\text { R. lumbal- } \\
\text { iliacal. }\end{array}$ & $\begin{array}{l}53 \text { Pfd. schwere } \\
\text { Fettgeschwulst, w' } \\
\text { che die Eingewei } \\
\text { nach vorn verdrän } \\
\text { Colon ase. vor de } \\
\text { Tumor. Coecum ei } \\
\text { geschlossen. }\end{array}$ \\
\hline 4 & $\underset{1886 .}{\text { Kümmell }(63) .}$ & $\begin{array}{c}38 \\
\text { Jahre. }\end{array}$ & M. & $\stackrel{?}{\text { Echinocoecus. }}$ & $\begin{array}{l}\text { Transperiton. } \\
\text { Exstirpation. }\end{array}$ & Links lumbal. & $\begin{array}{l}\text { Enormer Tumc } \\
\text { quer vor d. T. Colo } \\
\text { breit mit der Mi } \\
\text { verwachsen, von d } \\
\text { linken Niere an } \\
\text { gehend. }\end{array}$ \\
\hline 5 & $\begin{array}{c}\text { Saurenhaus } \\
(108) . \quad 1890 .\end{array}$ & $\begin{array}{c}42 \\
\text { Jahre. }\end{array}$ & W. & - & $\begin{array}{c}\text { Transperiton. } \\
\text { Exstirpation. } \\
\text { Nephrecto- } \\
\text { mie. }\end{array}$ & R. lumbal. & $\begin{array}{l}\text { Links v. d. Mitt } \\
\text { linie Col. ascender } \\
\text { rechts grosser retr } \\
\text { peritonealer Tum } \\
\text { (Lipom), Niere lie } \\
\text { hinten im Tumc } \\
\text { Nebenniere komr } \\
\text { zu Gesicht, Uret } \\
\text { nicht. } 13^{1 / 2} \text { Pfd. }\end{array}$ \\
\hline 6 & $\begin{array}{c}\text { Homans } \\
1891 .\end{array}$ & $\begin{array}{c}54 \\
\text { Jahre. }\end{array}$ & W. & Unbestimmt. & $\begin{array}{l}\text { Exstirpation. } \\
\text { Transperiton. } \\
\text { Laparotomie. }\end{array}$ & $\begin{array}{c}\text { Links iliacal- } \\
\text { median. }\end{array}$ & $\begin{array}{l}\text { Grosser Fetttum } \\
\text { retroperitoneal lin] } \\
\text { u. median. Dar } \\
\text { nicht gesehen. }\end{array}$ \\
\hline 7 & $\begin{array}{c}\text { Terrier u. } \\
\text { Guillemain } \\
(17) . \quad 1892 .\end{array}$ & $\begin{array}{c}40 \\
\text { Jahre. }\end{array}$ & W. & $\begin{array}{c}\text { Lipome } \\
\text { rétro-périton. }\end{array}$ & $\begin{array}{l}\text { Probelapa- } \\
\text { rotomie. }\end{array}$ & $\begin{array}{l}\text { Rechts iliacal- } \\
\text { lumbal. }\end{array}$ & $\begin{array}{l}\text { Autopsie: Tums } \\
\text { füllte } 3 / 4 \text { der Bauc] } \\
\text { höhle, haftete dı } \\
\text { r. Seite der Baucl } \\
\text { wand, Fossa iliac } \\
\text { lumb. d. Ureter nac } \\
\text { r. verdrängt. Rech } \\
\text { Niere gegen d. Wi } \\
\text { belsüule geschobe: } \\
7,850 \mathrm{~kg} \text {. }\end{array}$ \\
\hline
\end{tabular}


Seine Lipome.

\begin{tabular}{|c|c|c|c|c|}
\hline Symptome & $\begin{array}{l}\text { Mikrosk. } \\
\text { Befund }\end{array}$ & Resultat & Dauer & Ausgangspunkt \\
\hline - & Fett. & $\begin{array}{l}\text { † } 2 \text { Tage nach } \\
\text { der Operation. }\end{array}$ & - & Nierenfett. \\
\hline$?$ & Lipom. & Heilung. & $?$ & $?$ \\
\hline$?$ & Reines Lipom. & $\begin{array}{l}\text { I sofort nach } \\
\text { der Operation. }\end{array}$ & $?$ & $?$ \\
\hline $\begin{array}{l}\text { Gr. Abdominaltumor. Ha- } \\
\text { lnussgrosse Tumoren in der } \\
\text { ilz u. Lebergegend. Punction } \\
\text { gativ. }\end{array}$ & Lipom. & $\begin{array}{l}+2 \text { Tage nach } \\
\text { der Operation. }\end{array}$ & 3 Jahre. & Nierenfett. \\
\hline $\begin{array}{l}\text { Wie 7., 8. Monat der Gra- } \\
\text { dität. }\end{array}$ & Fett. & $?$ & 1 Jahr. & Nierenfettkapsel. \\
\hline $\begin{array}{l}\text { Wie 7., 5. Schwangerschafts- } \\
\text { onat. Dämpfung unter d. } \\
\text { abel, leicht gedämpft i. d. l. } \\
\text { endengegend. Runder, wei- } \\
\text { ler, nicht fluctuirend. Tumor, } \\
\text { hr wenig beweglich. Uterus } \\
\text { swärts gedrängt. }\end{array}$ & Fett. & Heilung. & 1 Jahr. & Retroperiton. \\
\hline $\begin{array}{l}\text { Abdomen aufgetrieben, rechts } \\
\text { 'weiterte Bauchvenen. Wei- } \\
\text { ler, schlecht begrenzter, dem } \\
\text { inger ausweichender, den } \\
\text { össten Theil der Bauchhöhle } \\
\text { nnehmender, mehr rechts ge- } \\
\text { gener, nach oben convex be- } \\
\text { enzter, nicht fluctuirender, } \\
\text { cht fester, nicht schmerz- } \\
\text { ifter, nicht druckempfind- } \\
\text { cher Tumor. Uterus normal, } \\
\text { rin normal. }\end{array}$ & Reines Lipom. & Tod. & 11 Jahre. & $\begin{array}{l}\text { Retroperiton. Zell- } \\
\text { gewebe in der Gegend } \\
\text { des Coecum. }\end{array}$ \\
\hline
\end{tabular}




\begin{tabular}{|c|c|c|c|c|c|c|c|}
\hline Nr. & $\begin{array}{l}\text { Autor, } \\
\text { Operateur }\end{array}$ & Alter & 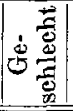 & Diagnose & Operation & Lage, Seite & Befund \\
\hline 8 & $\begin{array}{c}\text { Ogst on }(88) \\
1896 .\end{array}$ & $\begin{array}{c}20 \\
\text { Jahre. }\end{array}$ & W. & $?$ & $?$ & $?$ & $\begin{array}{l}\text { Lipom des subpe } \\
\text { tonealen Geweb } \\
\text { Intestina lagen ind } \\
\text { Substanz des Tumo: }\end{array}$ \\
\hline 9 & $\begin{array}{c}\text { Dalziel (27). } \\
1898 .\end{array}$ & $\begin{array}{c}8 \\
\text { Jahre. }\end{array}$ & Kind. & $?$ & $\begin{array}{c}\text { Exstirpat. } \\
?\end{array}$ & $?$ & $\begin{array}{l}13 \text { Pfund schwer } \\
\text { retroperitoneales I } \\
\text { pom. }\end{array}$ \\
\hline
\end{tabular}

Tabelle II

\begin{tabular}{|c|c|c|c|c|c|c|}
\hline $\mathrm{Nr}$. & $\begin{array}{l}\text { Autor, } \\
\text { Operateur }\end{array}$ & Alter & 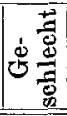 & Diagnose & Symptome & Operation \\
\hline 1 & $\begin{array}{l}\text { Beveridge } \\
\text { (11). } 1870 .\end{array}$ & $\begin{array}{c}29 \\
\text { Jahre. }\end{array}$ & M. & $\begin{array}{l}\text { Abdominal. } \\
\text { tumor. }\end{array}$ & $\begin{array}{l}\text { Anschwellung des rechten } \\
\text { Beines seit 5, des Unterleibs } \\
\text { seit } 4 \text { Monaten. }\end{array}$ & Keine. \\
\hline 2 & $\begin{array}{l}\text { Buschmann } \\
\text { (17). Bill- } \\
\text { roth. } 1880 .\end{array}$ & $\begin{array}{c}35 \\
\text { Jahre. }\end{array}$ & W. & $?$ & $\begin{array}{l}\text { Seit } 3 \text { Jahren Zunahme des } \\
\text { Leibes. Abdomen im ganzen } \\
\text { Umfang d. Wölbung Dämpfung, } \\
\text { derb elastisch, ohne deutl. Fluct. } \\
\text { fast unbeweglich. Norm. Uterus, } \\
\text { Stuhl und Harn. Beschwerden } \\
\text { durch Grösse. A bm a gerung. }\end{array}$ & $\begin{array}{l}\text { Laparotomie } \\
\text { Nephrectomi }\end{array}$ \\
\hline 3 & $\begin{array}{c}\text { Brunzel } \\
1882 .\end{array}$ & $\begin{array}{c}33 \\
\text { Jahre. }\end{array}$ & w. & $\begin{array}{l}\text { Mit Genita- } \\
\text { lien zusam- } \\
\text { menhängen- } \\
\text { der Tumor. } \\
\text { Stieltorsion. }\end{array}$ & $\begin{array}{l}\text { Vor } 5 \text { Jahren zuerst schmerz- } \\
\text { lose Geschwulst, langsam zu- } \\
\text { nehmend bis zu Manneskopfgr. } \\
\text { Median gelagerter Tumor mit } \\
\text { s. unt. Pol. bis zum Becken- } \\
\text { eingang reichend, schwer be- } \\
\text { weglich, rechts und links } \\
\text { Darmton. Uterus frei beweg- } \\
\text { lich. Dünner Strang v. d. linken } \\
\text { Seite des Tumors zum Becken- } \\
\text { eingang. Später linker Fu s } \\
\text { intensive Sehmerzen. Abmage- } \\
\text { rung. Kein Ascites. Urin frei. }\end{array}$ & $\begin{array}{c}\text { Laparotomie } \\
\text { Exstirpation } \\
\text { Nephrectc } \\
\text { mie. }\end{array}$ \\
\hline 4 & $\begin{array}{c}\text { Möricke (77) } \\
1882 .\end{array}$ & $\begin{array}{c}24 \\
\text { Jahre. }\end{array}$ & W. & $\begin{array}{l}\text { Solider rechts- } \\
\text { seitiger Ova- } \\
\text { rialtumor. }\end{array}$ & $\begin{array}{l}\text { Seit } 8 \text { Monaten Tumor im } \\
\text { Abdomen langsam wachsend, } \\
\text { grosse Beweglichkeit unbequem. } \\
\text { - Abd. durch mannskopfgros- } \\
\text { sen,ziemlich harten, nicht fluctui- } \\
\text { renden Tumor vorgewölbt, grosse } \\
\text { Beweglichkeit. Uterus normal, } \\
\text { beide Ovarien vorhanden, mit } \\
\text { dem Uterus kein Zusammenhang. } \\
\text { Geschwulst leicht in das linke } \\
\text { Hypochondrium verschiebbar, } \\
\text { nach rechts keine Beweglichkeit. } \\
\text { Uterus mit Museuz fixirt, Tu- } \\
\text { mor nach oben gedrängt: Span- } \\
\text { nung der Adnexe. }\end{array}$ & $\begin{array}{l}\text { Laparotomie } \\
\text { Exstirpation }\end{array}$ \\
\hline
\end{tabular}




\begin{tabular}{c|c|c|c|c}
\hline Symptome & $\begin{array}{c}\text { Mikrosk. } \\
\text { Befund }\end{array}$ & Resultat & Dauer & Ausgangspunkt \\
\hline $\begin{array}{c}\text { Enorm ausgedehntes Abdo- } \\
\text { nen. }\end{array}$ & - & - & - & - \\
- & - & - & - & -
\end{tabular}

Reine Fibrome.

\begin{tabular}{|c|c|c|c|c|c|}
\hline Lage, Seite & $\begin{array}{l}\text { Befund. Gestalt und } \\
\text { Grösse }\end{array}$ & $\begin{array}{l}\text { Mikrosk. } \\
\text { Befund }\end{array}$ & Resultat & Dauer & Ausgangspunkt \\
\hline $\begin{array}{l}\text { Rechts. } \\
\text { Iliacal. }\end{array}$ & $\begin{array}{l}37 \text { Zoll Umfang, coni- } \\
\text { sche Gestalt. Untere } \\
\text { Hälfte der Bauchhöhle } \\
\text { und das Becken ange- } \\
\text { füllt. }\end{array}$ & $\begin{array}{c}? \\
\text { Structur eines } \\
\text { Fibroms. }\end{array}$ & $\dagger$ & 6 Monate. & $\begin{array}{c}\text { Genitocruralis. } \\
\text { Obturatorius. } \\
\text { Plex. lumbo- } \\
\text { sacr. }\end{array}$ \\
\hline $\begin{array}{l}\text { Links. } \\
\text { Iliacal. }\end{array}$ & $\begin{array}{l}18 \text { Kilo schwer. Tu- } \\
\text { mor zwischen den Blät- } \\
\text { tern des Lig. lat. und } \\
\text { hinter d. Mesent. sitzend. } \\
\text { Linke Niere und Neben- } \\
\text { niere im Becken. }\end{array}$ & $\begin{array}{c}\text { My ofib rom } \\
\text { reich an glat- } \\
\text { ten Muskeln. }\end{array}$ & Heilung. & 3 Jahre. & $\begin{array}{l}\text { Lig. latum } \\
\text { oder Nieren- } \\
\text { kapsel. }\end{array}$ \\
\hline $\begin{array}{l}\text { Links. } \\
\text { Lumbal. } \\
\text { Iliacal. }\end{array}$ & $\begin{array}{l}37^{1 / 4} \text { Pfund schwerer, } \\
\text { gross. rundlich., prall ela- } \\
\text { stischer Tumor. Retro- } \\
\text { peritoneal. Colon descen- } \\
\text { dens zieht links vor dem } \\
\text { Tumor hinunter. Niere } \\
\text { mit dem Tumor ver- } \\
\text { wachsen. }\end{array}$ & $\begin{array}{l}\text { Fibrom mit } \\
\text { Fetteinlage- } \\
\text { rung. }\end{array}$ & Heilung. & 5 Jahre. & Nierenkapsel. \\
\hline $\begin{array}{l}\text { Iliacal. } \\
\text { Rechts. }\end{array}$ & $\begin{array}{l}\text { Tumor mannskopfgr., } \\
\text { mit Furche }(30 \mathrm{~cm}) \text {, für } \\
\text { das untere Ileum, } 1150 \mathrm{~g} \text {, } \\
\text { sehr harte Consistenz. } \\
\text { Nach hinten dünner Stiel. }\end{array}$ & $\begin{array}{c}\text { Sehr gefäss- } \\
\text { reicher fibrö- } \\
\text { ser Tumor. }\end{array}$ & Heilung. & 8 Monate. & $?$ \\
\hline
\end{tabular}

Deutsche Zeitschrift f. Chirurgie. LXI. Bd. 


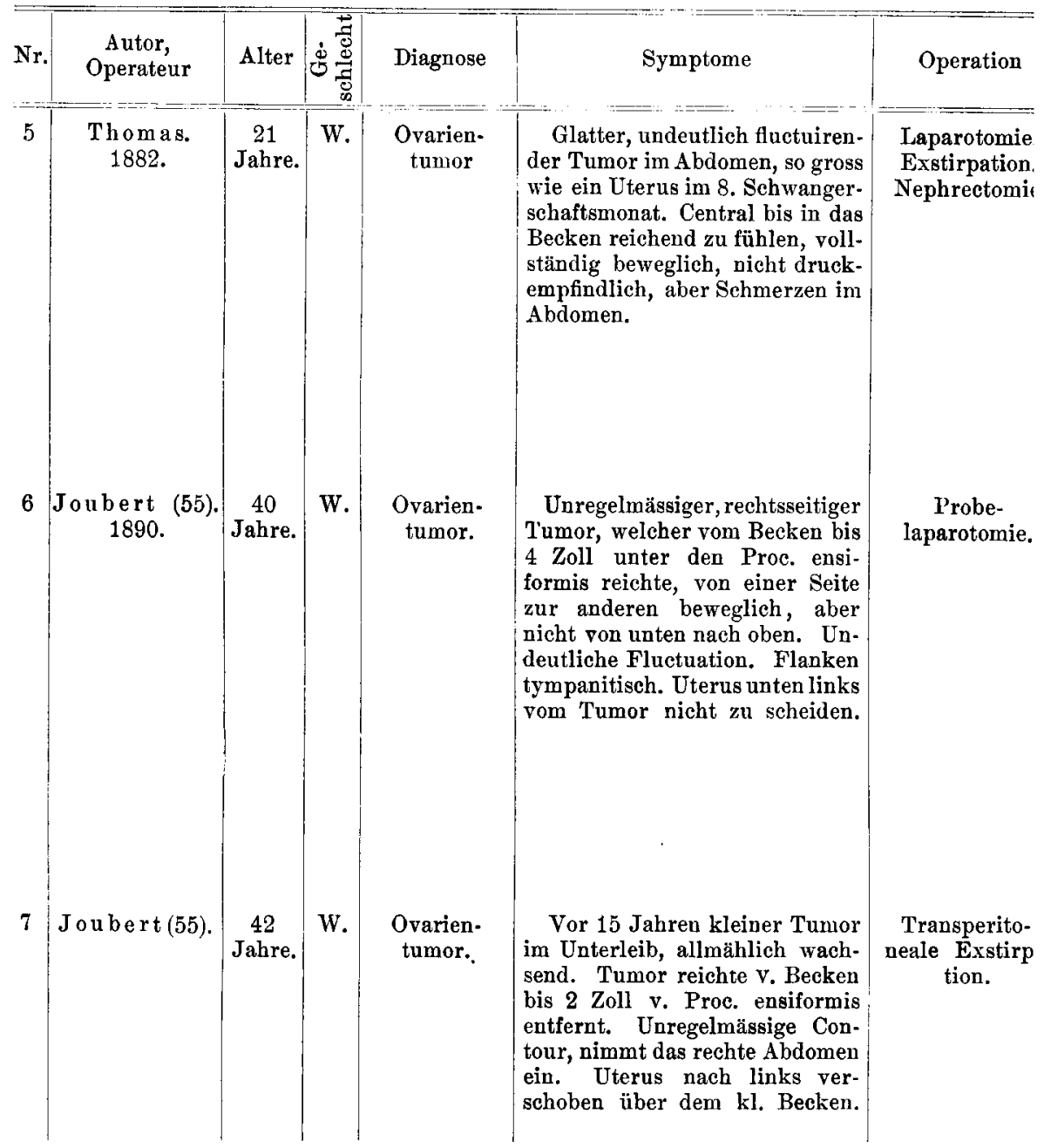

Tabelle II

\begin{tabular}{|c|c|c|c|c|c|c|}
\hline Nr. & $\begin{array}{c}\text { Autor, } \\
\text { Operateur }\end{array}$ & Alter & ن & Diagnose & Symptome & Behandlung \\
\hline 1 & $\begin{array}{c}\text { Hu l k e e (52). } \\
1887 .\end{array}$ & $\begin{array}{c}56 \\
\text { Jahre. }\end{array}$ & w. & Nierentumor. & $\begin{array}{l}\text { Im Abdomen Tumor, welcher } \\
\text { die linke Lenden- und Iliacal- } \\
\text { region einnahm, nach vorn bis } \\
\text { zum Nabel reichte, mässig be- } \\
\text { weglich, sehr elastisch, zweifel- } \\
\text { hafte Fluctuation. Ueber dem T } \\
\text { Uterus nach rechts und aufw } \\
\text { Kein Zusammenhang mit den } \\
\text { Urin obne Befund. }\end{array}$ & $\begin{array}{l}\text { Laparotomie. } \\
\text { Transperito- } \\
\text { neale Nephrec } \\
\text { tomie. } \\
\text { umor Dämpfun } \\
\text { ärts verschobe. } \\
\text { Beckenorgane. }\end{array}$ \\
\hline
\end{tabular}




\begin{tabular}{|c|c|c|c|c|c|}
\hline Lage, Seite & $\begin{array}{c}\text { Befund. Gestalt und } \\
\text { Grösse }\end{array}$ & $\begin{array}{l}\text { Mikrosk. } \\
\text { Befund }\end{array}$ & Resultat & Dauer & A usgangspunkt \\
\hline $\begin{array}{c}\text { Lumbal. } \\
\text { Iliacal. } \\
?\end{array}$ & $\begin{array}{l}\text { Zwischen Tumor and } \\
\text { Symphyse Darmschlinge. } \\
\text { Kein Ovarialtumor, vom } \\
\text { Peritoneum bedeokt. } \\
\text { Punction } 3 \text { Liter wasser- } \\
\text { helle Flüssigkeit. Kein } \\
\text { Urin. Am oberen Ende } \\
\text { Niere, welche so über } \\
\text { den Tumor gebogen war, } \\
\text { dass der Hilus convex, } \\
\text { die Convexität concav } \\
\text { war. Niere gesund. } \\
10^{1 / 2} \text { Pfund schweres } \\
\text { Fibrom mit Cystenbildg. }\end{array}$ & \begin{tabular}{|} 
Nierenkapsel- \\
fibrom. Cy- \\
stenbildung \\
dureh schlei- \\
mige Degene- \\
ration oder \\
Lymph- \\
stauung.
\end{tabular} & Heilung. & ? & Nierenkapsel. \\
\hline $\begin{array}{l}\text { Rechts. } \\
\text { Iliacal. }\end{array}$ & $\begin{array}{l}\text { Tunor breitbasig, von } \\
\text { der rechten Beckenschau- } \\
\text { fel bis zu den rechten fal- } \\
\text { schen Rippen reichend. } \\
\text { Peritoneum auf der Ober- } \\
\text { fläche verschieblich. } \\
\text { Uterus u. Anhänge nor- } \\
\text { mal. Tumor entsprang } \\
\text { dem subperitonealen Ge- } \\
\text { webe der rechten Seite } \\
\text { der Abdominalwand und } \\
\text { des Beckens, zusammen- } \\
\text { gesetzt aus reinem weis- } \\
\text { sen fibrösen Gewebe, } \\
\text { solide. } 15 \text { Pfd. schwer, } \\
\text { ausschälbar. }\end{array}$ & - & $\dagger$ & 2 Jahre. & $\begin{array}{c}\text { Subperitoneales } \\
\text { Gewebe. }\end{array}$ \\
\hline $\begin{array}{l}\text { Rechts. } \\
\text { Iliacal. }\end{array}$ & $\begin{array}{l}\text { Tumor mit einerdicken } \\
\text { Lage v. Periton. bedeckt, } \\
\text { zwischen Coecum, wel- } \\
\text { ches oben u. rechts lag, } \\
\text { und den Winkel zwischen } \\
\text { Tuba fallopii u. Lig. ro- } \\
\text { tundum. Uterus leicht } \\
\text { vergrössert. Ovarien v. } \\
\text { Tuben gesund. }\end{array}$ & $\begin{array}{l}\text { Fibröser } \\
\text { Tumor. }\end{array}$ & Geheilt. & 15 Jahre. & $\begin{array}{l}\text { Subperitoneales } \\
\text { Gewebe. }\end{array}$ \\
\hline
\end{tabular}

Myxome.

\begin{tabular}{c|c|c|c|c|c}
\hline \hline Lage, Seite & Befund & $\begin{array}{c}\text { Mikrosk. } \\
\text { Befund }\end{array}$ & Ausgangspunkt & Dauer & Resultat \\
\hline $\begin{array}{c}\text { Links. } \\
\text { iliacal. }\end{array}$ & $\begin{array}{c}\text { Retroperitonealer Tu- } \\
\text { mor, welcher die linke } \\
\text { Niere umschloss Colon } \\
\text { descendens vor dem Tu- } \\
\text { mor. Niere nicht be- } \\
\text { theiligt, nur comprimirt. }\end{array}$ & Myxoma. & $\begin{array}{c}\text { Perirenales } \\
\text { Gewebe. }\end{array}$ & 1 Jahr. & $\begin{array}{c}\text { Heilung. } \\
\text { Recidiv. } \\
\text { 1 Jahr nach } \\
\text { der Operation. }\end{array}$ \\
\hline
\end{tabular}




\begin{tabular}{|c|c|c|c|c|c|c|}
\hline Nr. & $\begin{array}{l}\text { Autor, } \\
\text { Operateur }\end{array}$ & Alter & 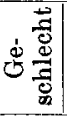 & Diagnose & Symptome & Behandlung \\
\hline 2 & $\begin{array}{c}\text { Gould (43). } \\
1888 .\end{array}$ & $\begin{array}{c}30 \\
\text { Jahre. }\end{array}$ & M. & Nierentumor. & $\begin{array}{l}\text { Vor } 2 \text { Monaten Stoss mit } \\
\text { einer Kuppelkette vor den Leib. } \\
\text { Vor } 1 \text { Monat Schwellung oran- } \\
\text { gengross unter dem Nabel, } \\
\text { schnell wachsend. Schmerzen } \\
\text { im Rücken, welche in den rech- } \\
\text { ten Testikel ausstrahlen. Urin- } \\
\text { beschwerden. Punction. Vis- } \\
\text { cide Flüssigkeit. Rechts im } \\
\text { Abdomen unter der Leber Sch } \\
\text { nicht druckempfindlich. Unter } \\
\text { Bei Athmung geringe Bewegung. } \\
\text { linie Fluctuation. Rechts Däm] } \\
\text { Samenstrang verdickt. Veneng }\end{array}$ & $\begin{array}{l}\text { Extraperito- } \\
\text { neale Nephre } \\
\text { tomie. Tumc } \\
\text { punctirt, } \\
\text { braune mucoid } \\
\text { Flüssigkeit. Es } \\
\text { stirpation. } \\
\text { wellung, weic] } \\
\text { rer Rand run } \\
\text { In der Achse } \\
\text { ipfung. Recht๘ } \\
\text { gefüllt. }\end{array}$ \\
\hline
\end{tabular}

Tabelle I

\begin{tabular}{|c|c|c|c|c|c|c|}
\hline Nr. & Autor & Alter & 通 & Diagnose & Symptome & Operation \\
\hline 1 & $\begin{array}{c}\text { J. Cooper } \\
\text { Forster (36). }\end{array}$ & $\begin{array}{c}63 \\
\text { Jahre. }\end{array}$ & w. & - & - & $\begin{array}{l}\text { Punction ohn } \\
\text { Erfolg. }\end{array}$ \\
\hline 2 & $\begin{array}{c}\text { Spencer } \\
\text { Wells (130). }\end{array}$ & $\begin{array}{c}48 \\
\text { Jahre. }\end{array}$ & W. & $\begin{array}{c}\text { Zwei solide } \\
\text { bewegliche } \\
\text { Tumoren im } \\
\text { Abdomen. }\end{array}$ & $\begin{array}{l}\text { Seit } 10 \text { Jahren Bauchbe- } \\
\text { schwerden. Seit } 6 \text { Jahren Leib } \\
\text { geschwollen. } 2 \text { feste, sehr be- } \\
\text { wegliche Tumoren im Abdomen } \\
\text { beiderseits. }\end{array}$ & $\begin{array}{l}\text { Transperito- } \\
\text { neale Exstirp } \\
\text { tion. Resectic } \\
\text { der linken } \\
\text { Niere. }\end{array}$ \\
\hline 3 & $\begin{array}{c}\text { Thiriar }(120) \\
1889 .\end{array}$ & $\begin{array}{c}63 \\
\text { Jahre. }\end{array}$ & w. & $\begin{array}{c}\text { Multiloculares } \\
\text { Ovarial- } \\
\text { kystom. }\end{array}$ & $\begin{array}{l}\text { Seit } 6 \text { Monaten in der linken } \\
\text { Bauchseite eine Geschwulst. } \\
\text { Rapides Wachsthum. Urin nor- } \\
\text { mal. Lipom der r. Stirngegend. } \\
\text { Im Abdomen sehr bewegliche, } \\
\text { anscheinend fluctuirende Ge- } \\
\text { schwulst. Becken frei. }\end{array}$ & $\begin{array}{l}\text { Laparotomie } \\
\text { Transperito- } \\
\text { neale Exstirp } \\
\text { tion mit Rese } \\
\text { tion der Nier }\end{array}$ \\
\hline 4 & $\begin{array}{c}\text { Mudd (82). } \\
1889 .\end{array}$ & $\begin{array}{c}71 \\
\text { Jahre. }\end{array}$ & W. & $?$ & - & $\begin{array}{l}\text { Explorativ- } \\
\text { schnitt. }\end{array}$ \\
\hline
\end{tabular}




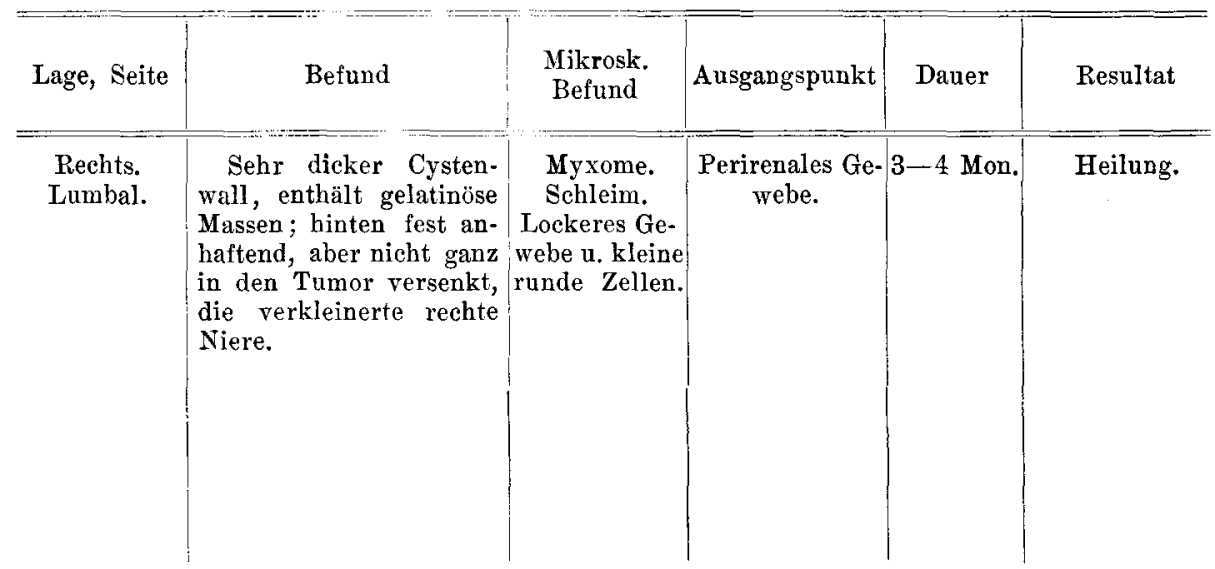

Fibrolipome.

\begin{tabular}{|c|c|c|c|c|c|}
\hline Lage, Seite & Befund & $\begin{array}{l}\text { Mikrosk. } \\
\text { Befund }\end{array}$ & Ausgangspunkt & Dauer & Resultat \\
\hline $\begin{array}{l}\text { Rechts. } \\
\text { Lumbal. }\end{array}$ & $\begin{array}{l}\text { Das ganze Abdomen, } \\
\text { ausgefüllt von e. enor- } \\
\text { men, } 55 \text { Pfd. schweren, } \\
\text { gelappten Lipom, wel- } \\
\text { ches retroperitoneal ge- } \\
\text { legen das Col. ascendens } \\
\text { nach vorn und links ge- } \\
\text { drängt hatte. }\end{array}$ & $\begin{array}{c}\text { Fett und } \\
\text { Bindegewebe. }\end{array}$ & $?$ & $?$ & $\dagger$ \\
\hline $\begin{array}{l}\text { Doppelseitig. } \\
\text { Lumbal. }\end{array}$ & $\begin{array}{l}\text { Links gewöhnliche } \\
\text { Fettgeschwulst vom Pe- } \\
\text { ritoneum bedeckt in einer } \\
\text { tiefen ITöhle der linken } \\
\text { Becken- und Lenden- } \\
\text { gegend. Am tiefsten Theil } \\
\text { die linke Niere. Rechts } \\
\text { ähnlich gelegener Tu- } \\
\text { mor. Niere nich ge- } \\
\text { sehen. 161/2 Pfund und } \\
\text { 141/2 Pfund. }\end{array}$ & Fibrolipom. & $\begin{array}{l}\text { Gewebe um } \\
\text { beide Nieren. }\end{array}$ & 6 Jahre. & Heilung. \\
\hline $\begin{array}{l}\text { Links. } \\
\text { Lumbal. }\end{array}$ & $\begin{array}{l}11 \text { Kilo sehweres, re- } \\
\text { troperitoneales Fibro- } \\
\text { lipom. Subserös. Ureter } \\
\text { im Tumor, welcher an } \\
\text { der linken Niere haftete. }\end{array}$ & Fibrolipom. & $\begin{array}{l}\text { Fett um die } \\
\text { linke Niere. }\end{array}$ & 6 Mon. & Geheilt. \\
\hline \multirow{2}{*}{$\begin{array}{l}\text { Rechts. } \\
\text { Lumbal und } \\
\text { medial. }\end{array}$} & $\begin{array}{l}63 \text { Pfd. schweres, re- } \\
\text { troperitoneales, zwischen }\end{array}$ & Fibrolipom. & $?$ & \multirow[t]{2}{*}{$?$} & \multirow[t]{2}{*}{$\dagger$} \\
\hline & $\begin{array}{l}\text { Leber und Beckenschaufel } \\
\text { darm und Colon nach links } \\
\text { vom Tumor umgeben. Re } \\
\text { abwärts gesenkt, die linke } \\
\text { Blase Uterus, I.ig. lata frei. }\end{array}$ & $\begin{array}{l}1 \text { gelegenes Fib } \\
\text { s gedrängt, hint } \\
\text { chte Niere fast } \\
\text { tief in der Subs } \\
\text { Kein A scites, } \mathrm{k}\end{array}$ & $\begin{array}{l}\text { rolipom. Dünn- } \\
\text { en. Beide Nieren } \\
1 \text { Fuss weit nach } \\
\text { tanz des Tumors. } \\
\text { eine Adhäsionen. }\end{array}$ & & \\
\hline
\end{tabular}




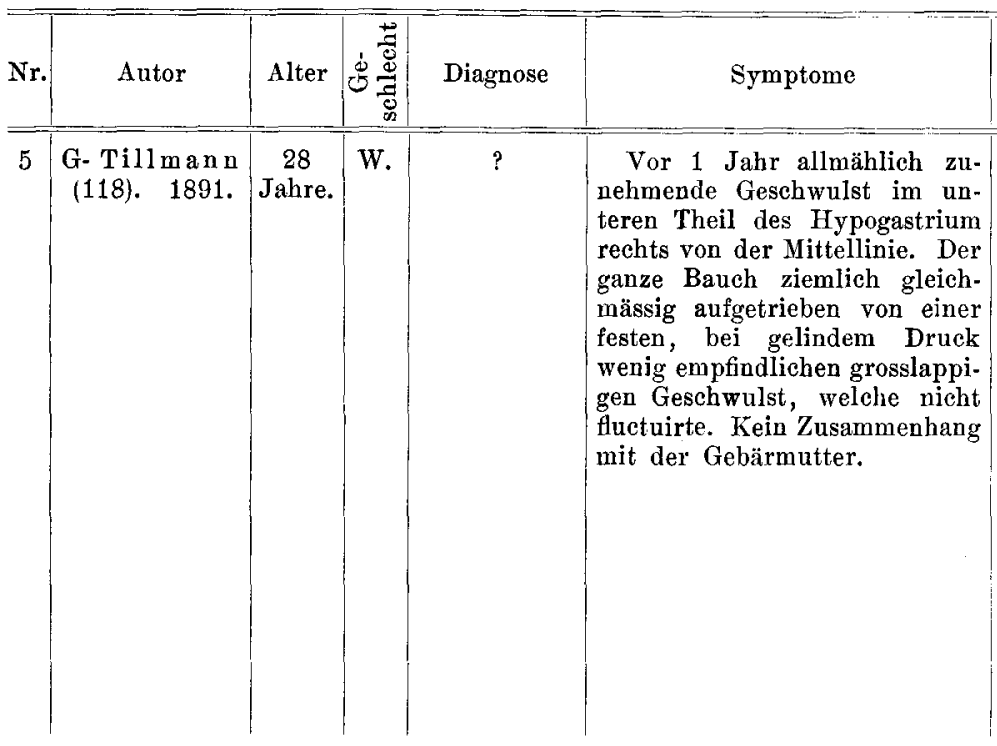

\begin{tabular}{|c|c|c|c|c|}
\hline $\begin{array}{c}\text { Walser }(127) \text {. } \\
1881 .\end{array}$ & $\begin{array}{c}44 \\
\text { Jahre. }\end{array}$ & W. & ? & $\begin{array}{l}\text { Tumor in der linken Seite } \\
\text { der Bauchhöhle, vorn beweg- } \\
\text { lich, hinten fixirt. Enorme Aus. } \\
\text { dehnung des Abdomen. }\end{array}$ \\
\hline$\underset{1883 .}{\operatorname{Homans}(51)}$ & $\begin{array}{c}39 \\
\text { Jahre. }\end{array}$ & M. & $?$ & Anschwellung des Leibes. \\
\hline $\begin{array}{c}\text { Strang }(115) \\
1883 .\end{array}$ & $\begin{array}{c}25 \\
\text { Jahre. }\end{array}$ & M. & Myxoma. & $\begin{array}{l}\text { Grosser Tumor in der rech- } \\
\text { ten Unterbauchgegend nach } \\
\text { plötzlicher Kolik. }\end{array}$ \\
\hline $\begin{array}{c}\text { Wiglesworth } \\
\text { (132). } 1883 .\end{array}$ & $\begin{array}{c}43 \\
\text { Jahre. }\end{array}$ & W. & Ovarialtumor. & $\begin{array}{l}\text { Drucksymptome auf die Vena } \\
\text { cava: Oedem der Beine, Bauch. } \\
\text { venenschwellung. }\end{array}$ \\
\hline$\left\{\begin{array}{c}\text { Vander Veer } \\
(123) .1891 .\end{array}\right.$ & $\begin{array}{c}42 \\
\text { Jahre. }\end{array}$ & W. & $\begin{array}{l}\text { Tumor der } \\
\text { Lende. }\end{array}$ & $\begin{array}{l}\text { Tumor am Rücken, rechts } \\
\text { von der Wirbelsäule seit } 15 \\
\text { Jahren, neben dem 1. Lenden- } \\
\text { wirbel begonnen, bis zum Schul- } \\
\text { terblattwinkel reichend. In der } \\
\text { letzten Zeit schnelleres Wachs- } \\
\text { thum. }\end{array}$ \\
\hline
\end{tabular}

\section{Operation}

Laparotomie. Transperitoneale Exstirp: tion mit par. tieller Nephre tomie.

TABELLE V]

Extraperitoneale Exstirpation.

Laparotomie. Transperitoneale Exstirpa. tion.

Punction (Spindelzellen) 


\begin{tabular}{|c|c|c|c|c|c|}
\hline Lage. Seite & Befund & $\begin{array}{l}\text { Mikrosk. } \\
\text { Befund }\end{array}$ & Ausgangspunkt & Dauer & Resultat \\
\hline $\begin{array}{l}\text { Rechts. } \\
\text { Lumbal. }\end{array}$ & $\begin{array}{l}\text { Fast die ganze Bauch- } \\
\text { höhle eingenommen von } \\
\text { einer colossalen roth- } \\
\text { grauen, grosslappigen, } \\
\text { retroperitonealen soliden } \\
\text { Geschwulst, deren serös } \\
\text { bekleidete vordere Wand } \\
\text { von einem groben Venen- } \\
\text { netze durchzogen er- } \\
\text { schien. Von oben nach } \\
\text { unten zog der vorderen } \\
\text { Geschwulstfläche adhä- } \\
\text { rent das Colon descen- } \\
\text { dens und die Flexura } \\
\text { sigmoidea, zwischen de- } \\
\text { ren Mosocolonblättern } \\
\text { die Geschwulst einge- } \\
\text { bettet lag. Nach oben } \\
\text { festere Adhäsionen. Nie- } \\
\text { renparenchym verhärtet. }\end{array}$ & $\begin{array}{r}\text { Myofibroma } \\
\text { lipomatosum. }\end{array}$ & $?$ & 1 Jahr. & Heilung. \\
\hline
\end{tabular}

\section{Myxolipome.}

Links.

Lumbal.

Rechts. Ileo-lumbal

Rechts. Lumbal.

Rechts.$$
?
$$

Gelappter, aus Fett | Myxolipom. gebildeter Tumor, welcher die ganze linke Bauchhöhle füllt und die Flexura sigmoidea um. schliesst.

Lipom (57 Pfd.schwer) mannskopfgross, sehr breitbasig. Rechts über und vor dem 'Tumor Colon.

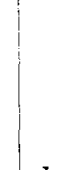

Eingeweide mit einem

elastischen Tumor durch Adhäsionen verbunden. Rechte Niere in die $41^{1 / 2}$ Pfd. schwere Geschwulst eingebettet.

Der Tumor ging vom Bindegewebe um die rechte Niere herum aus, war mit Kapsel versehen und leicht entfernbar, kleine Rund. reichliche Blutfüllung. | zelleninfiltraGewicht 8 Pfd. Auf dem tion im StroDurchschnitt anschei- ma der Genend ein Fibro-myxoma, schwulst. hier und da Lipom and cavernöse Stellen. Der Tumor hatte ohne Verletzung der Niere entfernt werden können. matöses Ge-

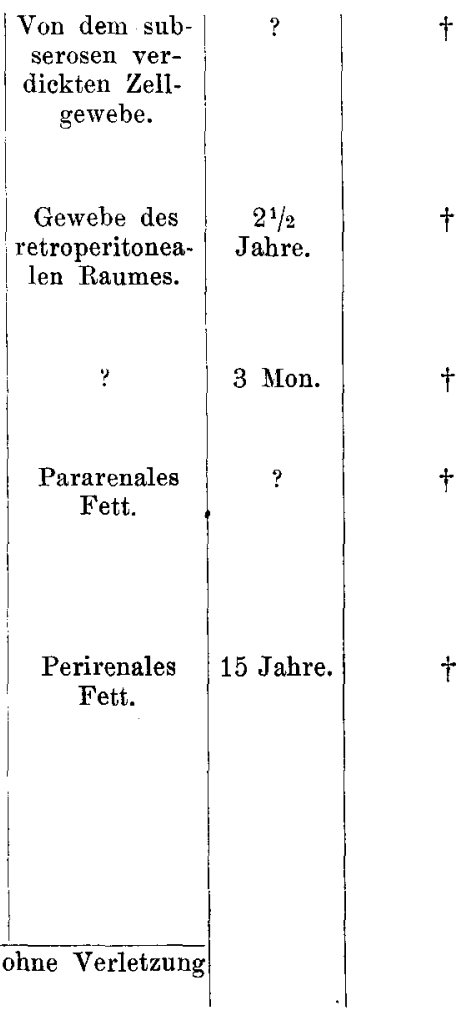

Fett, Myxowebe,

Fett. 
I. Göbetl

\begin{tabular}{|c|c|c|c|c|c|c|}
\hline Nr. & Autor & Alter & 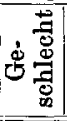 & Diagnose & Symptome & Operation \\
\hline 6 & $\begin{array}{l}\text { Vander } \\
\text { Veer (123). } \\
\quad 1891 .\end{array}$ & $\begin{array}{c}41 \\
\text { Jahre. }\end{array}$ & M. & $\begin{array}{l}\text { Lipom im } \\
\text { rechten } \mathrm{Ab} \\
\text { domen. }\end{array}$ & $\begin{array}{l}\text { Schmerzen in der rechten } \\
\text { Seite seit 5 Jahren. Seit } 3 \text { Mo- } \\
\text { naten Abdomen aufgetrieben. } \\
\text { Oedem an den Füssen. Ver- } \\
\text { stopfung. Rechts im Abdomen } \\
\text { lipomatöser Tumor. Keine } \\
\text { Fluctuation, von der Leber } \\
\text { durch tympanitischen Schall } \\
\text { getrennt. Urin normal. }\end{array}$ & $\begin{array}{c}\text { Laparotomie } \\
\text { Versuch deı } \\
\text { transperitones } \\
\text { len Exstirpa } \\
\text { tion (unvoll. } \\
\text { endet). }\end{array}$ \\
\hline 7 & $\begin{array}{c}\text { Rohaczek } \\
\text { (Kundrat) (64). } \\
1886 .\end{array}$ & $\begin{array}{l}40-50 \\
\text { Jahre. }\end{array}$ & M. & $\begin{array}{l}\text { Alter Echino- } \\
\text { coccussack. }\end{array}$ & $\begin{array}{l}\text { Seit längerer Zeit sehr lang. } \\
\text { sam wachsende Geschwulst im } \\
\text { Bauch, deutlich fluctuirend. } \\
\text { Bei Punction Fettdetritus. }\end{array}$ & $\begin{array}{l}\text { Bauchschnitt. } \\
\text { Einstellung d } \\
\text { Tumors. Inci } \\
\text { sion. }\end{array}$ \\
\hline 8 & $\begin{array}{c}\text { Rosmanit } \\
(103) . \quad 1888 .\end{array}$ & $\begin{array}{c}53 \\
\text { Jahre. }\end{array}$ & w. & $\begin{array}{l}\text { Solider Ova- } \\
\text { rialtumor. }\end{array}$ & $\begin{array}{l}\text { Grosse Unterleibsgeschwulst, } \\
\text { die als solider Ovarialtumor im- } \\
\text { ponirte. }\end{array}$ & $\begin{array}{l}\text { Laparotomie. } \\
\text { Lxstirpation. } \\
\text { Nephrectomie }\end{array}$ \\
\hline 9 & $\begin{array}{c}\text { Billroth } \\
\left(\begin{array}{c}\text { (Salzer) (105) } \\
1888 .\end{array}\right.\end{array}$ & $\begin{array}{c}40 \\
\text { Jahre. }\end{array}$ & M. & $\begin{array}{l}\text { Abdominal- } \\
\text { tumor? }\end{array}$ & $\begin{array}{l}\text { Abdomen symmetrisch colos- } \\
\text { sal ausgedehnt, Umfang } 126 \mathrm{~cm} \text {. } \\
\text { Rechts Tympanie, linke Flanke, } \\
\text { Epigastrium u. Hypogastrium } \\
\text { Dämpfung bis nach links hin- } \\
\text { ten. Abdomen gespannt, im } \\
\text { Epigastrium einzelne resisten- } \\
\text { tere Stellen. Deutliche Fluc- } \\
\text { tuation. Urin reichlich, Albu- } \\
\text { menmenge vermindert. }\end{array}$ & $\begin{array}{l}\text { Laparotomie. } \\
\text { Exstirpation. } \\
\text { Nephrectomie. }\end{array}$ \\
\hline
\end{tabular}




\begin{tabular}{|c|c|c|c|c|}
\hline Lage, Seite & $\begin{array}{l}\text { Mikrosk. } \\
\text { Befund }\end{array}$ & Ausgangspunkt & Dauer & Resultat \\
\hline $\begin{array}{l}\text { Rechts. } \\
\text { Lumbal. }\end{array}$ & 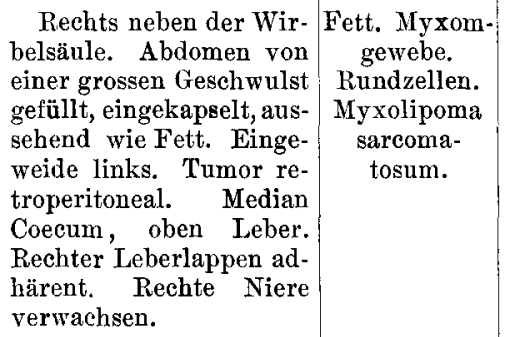 & $?$ & 5 Jahre. & $\dagger$ \\
\hline $\begin{array}{l}\text { Links. } \\
\text { Lumbal. }\end{array}$ & $\begin{array}{l}\text { Bei der Operation: } \\
\text { Theilweise erweichte Af- } \\
\text { termasse. } \\
\text { Section: Von der } \\
\text { Flexura coli sin. über- } \\
\text { lagerte Geschwulstmasse, } \\
\text { die die linke Hälfte des } \\
\text { Banchraums ausfüllte. } \\
\text { Linke Niere im oberen } \\
\text { Theil der Neubildung } \\
\text { medialwärts vollkom- } \\
\text { men eingebettet. Manns- } \\
\text { kopfgrosser Tumor,ziem- } \\
\text { lich gleichmässig gerun- } \\
\text { dete Oberfläche, Gewebe } \\
\text { sehr weich, leicht zer- } \\
\text { reisslich, stellenweise } \\
\text { Flüssigkeit und Detritus } \\
\text { enthaltende Erwei- } \\
\text { chungsherde. }\end{array}$ & $\begin{array}{c}\text { Perirenales } \\
\text { Fett. }\end{array}$ & $\begin{array}{l}\text { Längere } \\
\text { Zeit. }\end{array}$ & $\begin{array}{l}\text { Keine Ver- } \\
\text { kleinerungder } \\
\text { Geschwulst. } \\
\text { + einige Zeit } \\
\text { nach der Ope- } \\
\text { ration. }\end{array}$ \\
\hline $\begin{array}{l}\text { Rechts. } \\
\text { Lumbal. }\end{array}$ & $\begin{array}{l}\text { Grosse Geschwulst im Fibromyxyma } \\
\text { rechten Bauchraum, re- } \\
\text { troperitoneal gelagert, } \\
\text { leicht in } 3-4 \text { Partieen } \\
\text { zu zerlegen und auszuschälen; plötzlic } \\
\text { entblösst, die von der Fettmasse nach } \\
\text { mitten im Tumor lag. } \\
\text { welcher aus taubenei- bis mannskopfgro } \\
\text { ligrunden Knollen einer Aftermasse } \\
\text { durch die Geschwulst nach oben verd } \\
\text { Nebenniere nicht verändert. Nieren no }\end{array}$ & $\begin{array}{l} \\
\text { h rechte Niere } \\
\text { vorn gedrängt } \\
\text { fgrosser Tumor, } \\
\text { ssen, meist kug- } \\
\text { gestand. Leber } \\
\text { irängt. Rechte } \\
\text { ormal. }\end{array}$ & \multirow[b]{2}{*}{2 Jahre. } & \multirow{2}{*}{$\begin{array}{l}+ \text { bald nach } \\
\text { der Ope- } \\
\text { ration. } \\
\\
\dagger \text { ca. } 14 \text { Stun. } \\
\text { den nach der } \\
\text { Operation. }\end{array}$} \\
\hline $\begin{array}{l}\text { Links. } \\
\text { Lumbal. }\end{array}$ & $\begin{array}{l}\text { Vom Peritoneum über- } \\
\text { kleidete, gelbweisse ge- lipomatodes. } \\
\text { fässarme Geschwulst, Li- } \\
\text { porn. } 29 \text { Kilogr. schwer; } \\
\text { linke Niere mitten zwischen fettig glä } \\
\text { Geschwulstmassen nach vorn u. unten d } \\
\text { reicht bis auf den Psoas, das Pankreas } \\
\text { Colon desc. links vor der Geschwulst. N } \\
\text { blutreich nach der Fläche vergrössert. } \\
\text { aus bis mannskopfgrossen Knollen; blas } \\
\text { stenteren Stellen weiss. }\end{array}$ & $\begin{array}{l}\text { nzenden lichten } \\
\text { lislocirt. Tumor } \\
\text { s und die Milz. } \\
\text { ebenniere platt, } \\
\text { Tumor besteht } \\
\text { ssgelb, an resi- }\end{array}$ & & \\
\hline
\end{tabular}


Tabeile VI

\begin{tabular}{|c|c|c|c|c|c|c|}
\hline Nr. & Autor & Alter & 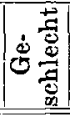 & Diagnose & Symptome & Behandlung \\
\hline 1 & $\begin{array}{l}\text { W. Jenner } \\
(54) .1870 .\end{array}$ & $\begin{array}{c}36 \\
\text { Jahre. }\end{array}$ & W. & $\begin{array}{l}\text { Abdominal- } \\
\text { tumor. }\end{array}$ & $\begin{array}{l}\text { Schmerzen in der r. Hüfte, } \\
\text { darnach im r. Knie. } 1 \text { Monat } \\
\text { lang, verschwanden } 3 \text { Monate } \\
\text { ante partum. Darnach Schmerze } \\
\text { der r. Seite zwischen Rippenkno } \\
\text { ilei von sehr harter Consistenz } \\
\text { eines Cricketballes. } 1 \text { Jahr kein } \\
\text { Schmerzen im r. Knie. Keine U } \\
2 \text { Jahre vor der Aufnahme rasc } \\
\text { Weicherwerden. Flexionscontra } \\
\text { schenkels. Objecti : Tumor d } \\
\text { domen, vollkommen unbeweglie } \\
\text { härtere und weichere Stellen, an } \\
\text { Fluctuation. Auf der r. Seite } \\
2 \text { faustgrosse Anschwellungen v } \\
\text { Consistenz. Eingeweide ganz in } \\
\text { des Abdomen verschoben. Au } \\
\text { Becken Tumor zu fühlen. Utert } \\
\text { links gedrängt. Oedem des recl }\end{array}$ & $\begin{array}{l}\text { und Tumor } \\
\text { rpel und Cris } \\
\text { und der Grös } \\
\text { Vachsthum, } \mathbf{n} \\
\text { rinbesehwerde } \\
\text { les Wachsthuj } \\
\text { tur des Obe } \\
\text { es ganzen r. A } \\
\text { h, versehiedel } \\
\text { der Mediansej } \\
\text { ler Wirbelsäu } \\
\text { on der gleich } \\
\text { die linke Hälf } \\
\text { ch im klein } \\
\text { is nach oben } \\
\text { ten Beins. }\end{array}$ \\
\hline 2 & $\begin{array}{c}\text { Beaudoux }(8) \\
1884 .\end{array}$ & $\begin{array}{c}34 \\
\text { Jahre. }\end{array}$ & W. & $?$ & $?$ & $\begin{array}{c}\text { Exstirpation } \\
\text { Abmeisselung } \\
\text { Extraperi- } \\
\text { toneal. }\end{array}$ \\
\hline \multirow[t]{2}{*}{3} & \multirow[t]{2}{*}{$\begin{array}{c}\text { W. v. Noor- } \\
\text { den }(86) \text {. } \\
1896 .\end{array}$} & \multirow[t]{2}{*}{$\begin{array}{c}46 \\
\text { Jahre. }\end{array}$} & \multirow[t]{2}{*}{ M. } & Chondrom. & \multirow{2}{*}{\multicolumn{2}{|c|}{\begin{tabular}{l|c} 
Seit 10 Mon. eigrosser harter & Exstirpation \\
Knoten in der linken Seite des & $\begin{array}{c}\text { Extraperi- } \\
\text { toneale. }\end{array}$ \\
Bauches, schmerzlos. Dauerndes & \\
Wachsthum. Keine Darm- und & \\
rden. Beinödem links. Linke Bauchseite sta \\
Haut verschiebbar. Derber Tumor mit fünfmar. \\
rweichter Stelle vorn oben, von der Regio lur \\
n die Regio suprapubica dext. u. epigastrica dex \\
rschieblich gegen das Becken und die Wirbelsäul \\
zung vom Darmbeinkamm möglich. Darm nic \\
or. Keine Urinbeschwerden. Regio sacroiliac \\
sbein frei. Probepunction zahlreiche Knorpelzelle
\end{tabular}}} \\
\hline & & & & $\begin{array}{l}\text { Blasenbeschwe } \\
\text { vorgetrieben, } \\
\text { stückgrosser e } \\
\text { balis sin. bis } \\
\text { reichend, unv } \\
\text { Keine Abgren } \\
\text { vor dem Tum } \\
\text { Kreuz- u. Steis }\end{array}$ & & \\
\hline
\end{tabular}

Tabelle VII

Eduard Frank (37). 1894.

37
Jahre.

W. Cyste im Abdomen.
Seit 6 Jahren stetige langsame Zunahme des Leibes, in den letzten 2 Jahren rascher, zeitweise stechende Schmerzen in der $r$. Lumbalgegend. - Stark ausgedehnter Hängebauch. Tumor füllt den grössten Theil des Bauches, reicht nach oben bis an den Rippenbogen, beiderseits in die Hypochondrien. Glatte Oberfläche, weich, elastisch, grosswellig fluctuirend. Im linken oberen Quadrauten des Tumors Coecum. Uterus leicht verschieblich, Adnexe beiderseits nachweisbar.
Laparotomie. Punction.

Transperiton Exstirpation. 
nchondrome.

\begin{tabular}{|c|c|c|c|c|c|}
\hline Seite, Lage & Befund & $\begin{array}{l}\text { Mikroskop. } \\
\text { Befund }\end{array}$ & Ausgangspunkt & Dauer & Resultat \\
\hline $\begin{array}{l}\text { Rechts. } \\
\text { Iliacal. }\end{array}$ & $\begin{array}{l}\text { Bei der Punction: zähes } \\
\text { eiweissartiges Fluidum, } \\
\text { enthält Blutkörperchen } \\
\text { und Körnchenzellen. Sec- } \\
\text { tion: Grosses Enchon- } \\
\text { drom, wahrscheinlich von } \\
\text { der Synchondrosis sacro- } \\
\text { iliaca ausgehend. Durch- } \\
\text { messer } 8^{1 / 2} \text { Zoll. Gewicht } \\
15 \mathrm{Pfd} \text {. }\end{array}$ & - & $\begin{array}{l}\text { Synchondrosis } \\
\text { sacroiliaca. }\end{array}$ & $\begin{array}{c}\text { Ueber } \\
3 \text { Jahre. }\end{array}$ & $\dagger$ \\
\hline $\begin{array}{l}\text { Rechts. } \\
\text { Iliacal. }\end{array}$ & $\begin{array}{l}\text { Kindskopfgrosser Tu- } \\
\text { mor der r. Fossa iliaca, } \\
\text { bis zur Crista ossis ilei } \\
\text { reichend. Grösster Durch- } \\
\text { messer } 25 \text { cm. }\end{array}$ & Chondrom. & $\begin{array}{l}\text { Syuchondrosis } \\
\text { sacroiliaca. }\end{array}$ & $?$ & Heilung. \\
\hline $\begin{array}{l}\text { Links. } \\
\text { Iliacal. }\end{array}$ & $\begin{array}{l}\text { Tumor, glasig aus- } \\
\text { sehende knollige Massen, } \\
\text { stückweise entfernt. Nur } \\
\text { an der Linea innominata } \\
\text { in ca. } 8 \mathrm{~cm} \text { langer Aus- } \\
\text { dehnung verwachsen. }\end{array}$ & $\begin{array}{l}\text { Hyalines } \\
\text { Chondrom- } \\
\text { gewebe mit } \\
\text { myxomatöser } \\
\text { Degeneration. }\end{array}$ & Os ilei sin. & 10 Monate. & $\begin{array}{l}\text { Heilung. } \\
\text { Nach } 1 \text { Jahr } \\
\text { Recidiv. } \\
\text { Abermalige } \\
\text { Operation. } \\
\text { Radicale } \\
\text { Exstirpation } \\
\text { nicht möglich. }\end{array}$ \\
\hline \multicolumn{6}{|c|}{ Jvarialkystome. } \\
\hline $\begin{array}{l}\text { Rechts. } \\
\text { Lumbal. }\end{array}$ & $\begin{array}{l}\text { Tumor mit glatter Ober- } \\
\text { fläche vom Periton. be- } \\
\text { deckt, Coecum im linken } \\
\text { oberen Quadranten des } \\
\text { Tumors, Col. ascendens } \\
\text { an der Hinterfläche des } \\
\text { Tumors. Periton. Ueber- } \\
\text { zug geht in das rech- } \\
\text { te parietale Peritoneum } \\
\text { über. 10 Liter gelblich- } \\
\text { grüne, klare Flüssigkeit. } \\
\text { glatte Innenflache mit } \\
\text { Leisten. }\end{array}$ & \begin{tabular}{|} 
Schleimhal- \\
tiges Cylinder- \\
epithel.
\end{tabular} & $\begin{array}{l}\text { Nach Seitz } \\
\text { von einem } \\
\text { accessorischen } \\
\text { Ovarium } \\
\text { ausgehend. }\end{array}$ & 6 Jahre. & Heilung. \\
\hline
\end{tabular}




\begin{tabular}{|c|c|c|c|c|c|c|}
\hline Nr. & Autor & Alter & 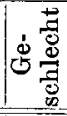 & Diagnose & Symptone & Behandlun \\
\hline 2 & $\begin{array}{c}\text { Ludwig } \\
\text { Seitz (112). } \\
1900 .\end{array}$ & $\begin{array}{c}29 \\
\text { Jahre. }\end{array}$ & W. & $\begin{array}{l}\text { Tumor des } \\
\text { r. Ovarium. }\end{array}$ & $\begin{array}{l}\text { Grosser, bis dicht unter den } \\
\text { Proc. ensiformis hinaufragender, } \\
\text { überall sehr deutlich fluctuiren- } \\
\text { der Tumor. Bauchdecken nicht } \\
\text { von der Geschwulst abzuheben. } \\
\text { Rechts in der Inguinalgegend } \\
\text { etwas vor dem Tumor eine fixirte } \\
\text { Darmschlinge. Uterus im oberen } \\
\text { Theil nach links und etwas nach } \\
\text { hinten gelagert, beweglich. Nur } \\
\text { bei kräftigem Druck von aussen } \\
\text { lässt sich ein kleines Segment } \\
\text { des Tumors im Becken fühlen. } \\
\text { Keine Geschwülste und keine } \\
\text { Ovarien im kleinen Becken zu } \\
\text { fühlen. }\end{array}$ & $\begin{array}{l}\text { Iaparotomi } \\
\text { Transperito } \\
\text { Exstirpatio }\end{array}$ \\
\hline
\end{tabular}

Cyste unbekann 1

\begin{tabular}{|c|c|c|c|c|}
\hline $\begin{array}{c}\text { Czerny } \\
1880 .\end{array}$ & $\begin{array}{c}57 \\
\text { Jahre. }\end{array}$ & W. & Ovarialcyste? & $\begin{array}{l}\text { Vor } 21 \text { Jahren strangförmige } \\
\text { Geschwulst in der } 1 \text {. Bauchseite, } \\
\text { langsames Wachsthum, seit zwei } \\
\text { Jahren rascher. - Linke Bauch- } \\
\text { seite gefüllt von einer glatten, } \\
\text { prallelastischen, undeutlich fluc- } \\
\text { tuirenden, etwas bewegliehen, } \\
\text { auf Druck nicht empfindlichen } \\
\text { Geschwulst. Dann und wann } \\
\text { eine Darmschlinge vor der Ge- } \\
\text { schwulst. Gegen das Becken } \\
\text { kann man unterhalb mit der } \\
\text { Hand eindringen, oberhalb nicht } \\
\text { unter die Rippen. Milzdämpf. } \\
\text { nicht abzugrenzen. Urin klar, } \\
\text { frei. BeigrossenVerschiebungen } \\
\text { wird der Uterus mitbewegt. }\end{array}$ \\
\hline
\end{tabular}

Laparotomi Transperito Exstirpatio

Tabelle ]

\begin{tabular}{|c|c|c|c|c|c|c|c|}
\hline $\mathbf{N} \mathbf{r}$. & $\begin{array}{l}\text { Operateur, } \\
\text { Autor }\end{array}$ & Alter & 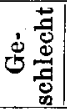 & Diagnose & $\begin{array}{l}\text { Operation } \\
\text { Nephrec- } \\
\text { tomie? }\end{array}$ & $\begin{array}{l}\text { Lage, } \\
\text { Seite }\end{array}$ & Befund \\
\hline 1 & Virchow (124). & $\begin{array}{c}42 \\
\text { Jahre. }\end{array}$ & M. & - & - & $\begin{array}{l}\text { Rechts. } \\
\text { Lumbal, } \\
\text { iliacal. }\end{array}$ & $\begin{array}{l}\text { Auf dem r. Psoas } \\
\text { kindskopfgrosse de } \\
\text { Geschwulst, welche } \\
\text { einer unebenen, } \\
\text { höckerigen Fläche } \\
\text { bis gegen die Wir } \\
\text { säule reichte. Aorta, } \\
\text { iliaca comm. nach lł } \\
\text { verschoben. V. cava } \\
\text { comprimirt. }\end{array}$ \\
\hline 2 & $\begin{array}{l}\text { Barden- } \\
\text { heuer (7). } \\
\quad 1879 .\end{array}$ & $\begin{array}{c}22 \\
\text { Jahre. }\end{array}$ & W. & $\begin{array}{l}\text { Nierensarkom } \\
\text { od. Steinniere } \\
\text { mit Perinephr. }\end{array}$ & $\begin{array}{l}\text { Nephrec- } \\
\text { tomie. }\end{array}$ & $?$ & $\begin{array}{l}\text { Der vorderen Nie: } \\
\text { fläche aufsitzendes } \\
\text { kom. }\end{array}$ \\
\hline
\end{tabular}




\begin{tabular}{|c|c|c|c|c|c|}
\hline jeite, Lage & Befund & $\begin{array}{c}\text { Mikroskop. } \\
\text { Befund }\end{array}$ & Ausgangspunkt & Dauer & Resultat \\
\hline $\begin{array}{l}\text { Rechts, } \\
\text { Lumbal, } \\
\text { iliacal. }\end{array}$ & $\begin{array}{l}\text { Tumor retroperitoneal. } \\
\text { Darmschlinge quer vor } \\
\text { dem Tumor. Beide Ova- } \\
\text { rien und Uterus normal. } \\
\text { Cystenwand gespalten. } \\
\text { Einstellung. Tamponade. } \\
\text { - Innenfläche Hervor- } \\
\text { ragungen, welche auf } \\
\text { eine multiloculäre Cyste } \\
\text { schliessen liessen. Cyste } \\
\text { dunkelbr. Inhalt } 4500 \text { g. } \\
\text { - Multiloculäres glan. } \\
\text { duläres Ovarialkystom. }\end{array}$ & $\begin{array}{c}\text { Flüssigkeit: } \\
\text { Blut, Chole- } \\
\text { stearinkry- } \\
\text { stalle. Wand: } \\
\text { Niederes Cy- } \\
\text { linderepithel } \\
\text { mit basal ge- } \\
\text { lagerten } \\
\text { Kernen. } \\
\text { Deutliche } \\
\text { Längs- und } \\
\text { Querdurch- } \\
\text { schnitte von } \\
\text { Drüsen. }\end{array}$ & $\begin{array}{l}\text { Accessor. } \\
\text { Ovarium. }\end{array}$ & 3 Wochen. & Heilung. \\
\hline
\end{tabular}

\section{[erkunft.}

Links.

Lumbal.
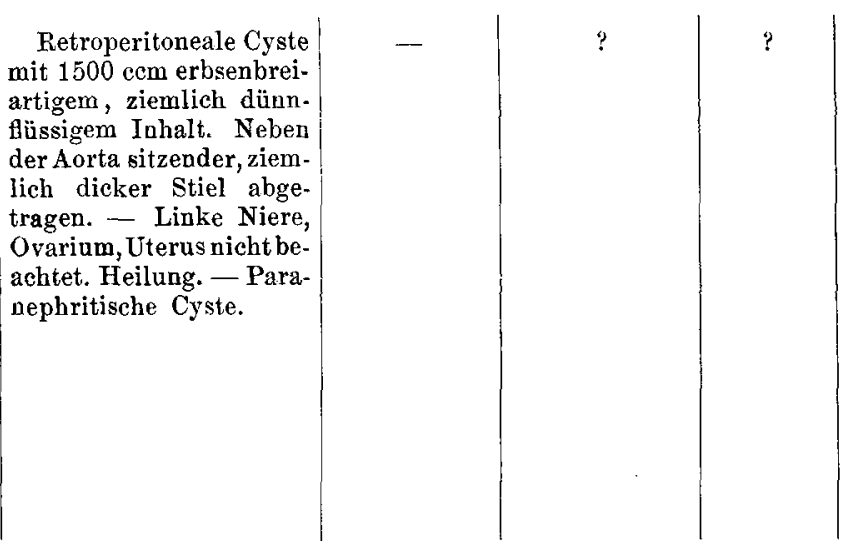

Heilung.

spindelzellensarkome.

\begin{tabular}{|c|c|c|c|c|}
\hline Symptome & $\begin{array}{c}\text { Mikroskop. } \\
\text { Befund }\end{array}$ & Resultat & Dauer & Ausgangspunkt \\
\hline - & $\begin{array}{c}\text { Sarkom } \\
\text { (Faserzellen). }\end{array}$ & $\dagger$ & $?$ & Fascie. \\
\hline- & $\begin{array}{l}\text { Spindelzellen- } \\
\text { sarkom. }\end{array}$ & $\stackrel{\dagger}{\dagger}^{+}$ & $?$ & $\begin{array}{c}\text { Fibröse } \\
\text { Nierenkapsel. }\end{array}$ \\
\hline
\end{tabular}




\begin{tabular}{|c|c|c|c|c|c|c|c|}
\hline Nr. & $\begin{array}{l}\text { Operateur, } \\
\text { Autor }\end{array}$ & Alter & 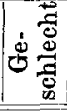 & Diagnose & $\begin{array}{l}\text { Operation } \\
\text { Nephrec- } \\
\text { tomie? }\end{array}$ & $\begin{array}{l}\text { Lage, } \\
\text { Seite }\end{array}$ & Befund \\
\hline 3 & $\begin{array}{c}\text { Witzel (138) } \\
1887 .\end{array}$ & $44 \mathrm{~J}$. & W. & $\begin{array}{l}\text { Retro- } \\
\text { peritonealer } \\
\text { Tumor. }\end{array}$ & $\begin{array}{l}\text { Exstirpation. } \\
\text { Splenectomie. }\end{array}$ & $\begin{array}{l}\text { Links. } \\
\text { Lumbal. }\end{array}$ & $\begin{array}{l}\text { Dickdarm i. e. Hack } \\
\text { Rinne des Tumors. } \\
\text { gmor ebuckelt, derb e } \\
\text { stisch, nirgends cyst } \\
\text { lateral vom Bauchfell } \\
\text { Colon, median v. N } \\
\text { bedeckt, unten zwisck } \\
\text { Tumor u. Beckenschau } \\
\text { Raum, oben Milz etv } \\
\text { verschieblich. Pankr } \\
\text { verwachsen. Niere } \\
\text { fühlt. Nebenniere inta }\end{array}$ \\
\hline 4 & $\begin{array}{l}\text { Thorn. } \\
\text { ton }(129) . \\
1890 .\end{array}$ & $36 \mathrm{~J}$. & W. & $\begin{array}{c}\text { Tumor in } \mathrm{Zu}- \\
\text { sammenhang } \\
\text { mit der linken } \\
\text { Niere. }\end{array}$ & $\begin{array}{c}\text { Nephrec- } \\
\text { tomie. } \\
\text { Transperiton. }\end{array}$ & $\begin{array}{l}\text { Links. } \\
\text { Lumbal. }\end{array}$ & $\begin{array}{l}20 \text { Pfund schwerer }] \\
\text { mor mit Milz und Pt } \\
\text { kreas verwachsen. Gro } \\
\text { Gefässe. }\end{array}$ \\
\hline 5 & $\begin{array}{c}\text { Bergh }(9) . \\
1897 .\end{array}$ & $52 \mathrm{~J}$. & W. & $\begin{array}{l}\text { Abdominal- } \\
\text { geschwulst. }\end{array}$ & $\begin{array}{l}\text { Transperiton. } \\
\text { Exstirpation. }\end{array}$ & $\begin{array}{l}\text { Rechts. } \\
\text { Lumbal. }\end{array}$ & $\begin{array}{l}\text { Kindskopfgrosse ret } \\
\text { peritoneale Geschwu } \\
\text { rechts. }\end{array}$ \\
\hline
\end{tabular}

\section{TAbelle}

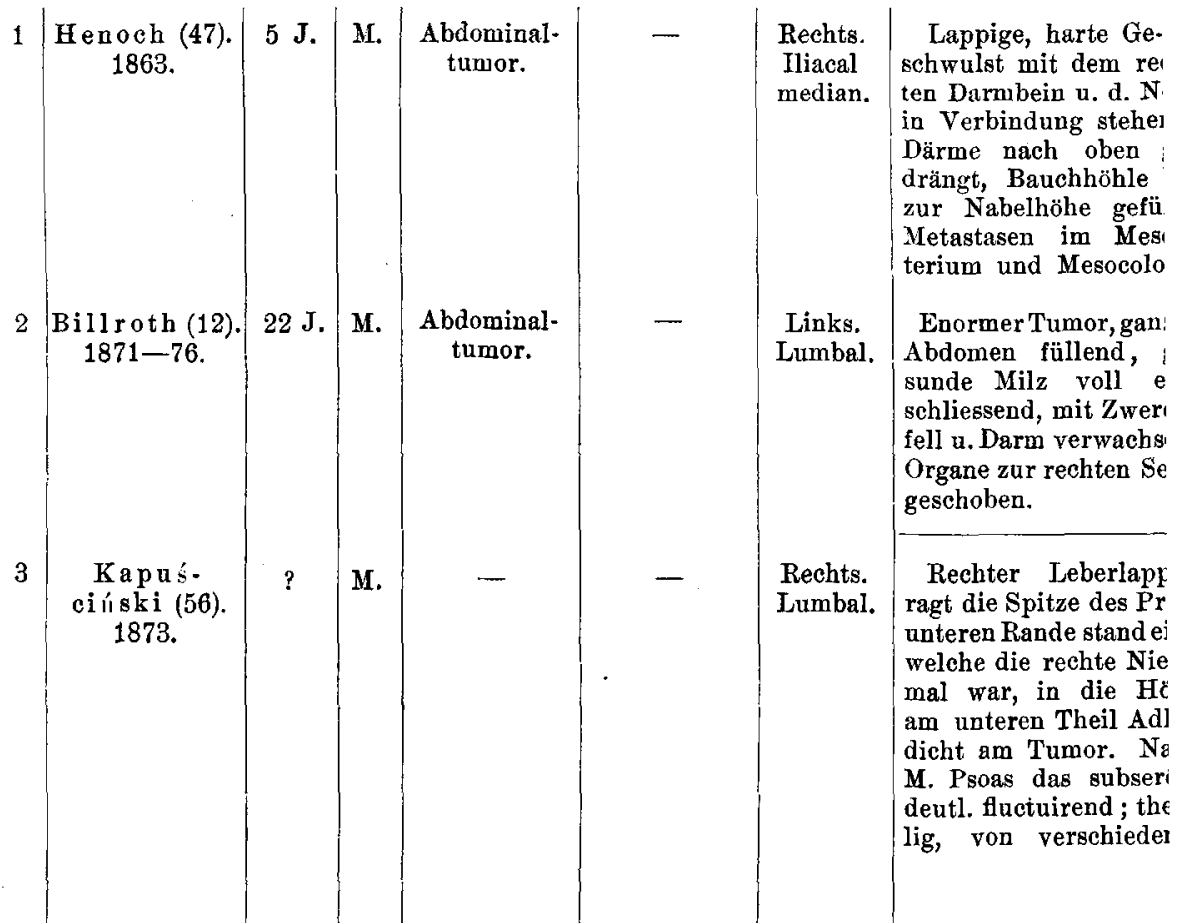




\begin{abstract}
Symptome
Vor 1 Jahre leichte Schmerzen in zr linken Seite. Tumor daselbst seine age wechselnd. -.-.. Grosse, runde unsene vielknollige, derbe Geschwulst, ir einzelne Stellen undeutlich flucirend. Verschieblichkeit in querer ichtung, abwärts nicht. Einziehung ubei im 9. I. C. R. in der Axillarlinie. orn rechts unten zu umgreifen. Links ssolute Dämpfung. Dickdarm vor dem teren Geschwulstrande. Urin normal.
\end{abstract}

Keine Nierensymptome. Grosser Ahminaltumor links.

Tumor in der rechten Bauchseite.

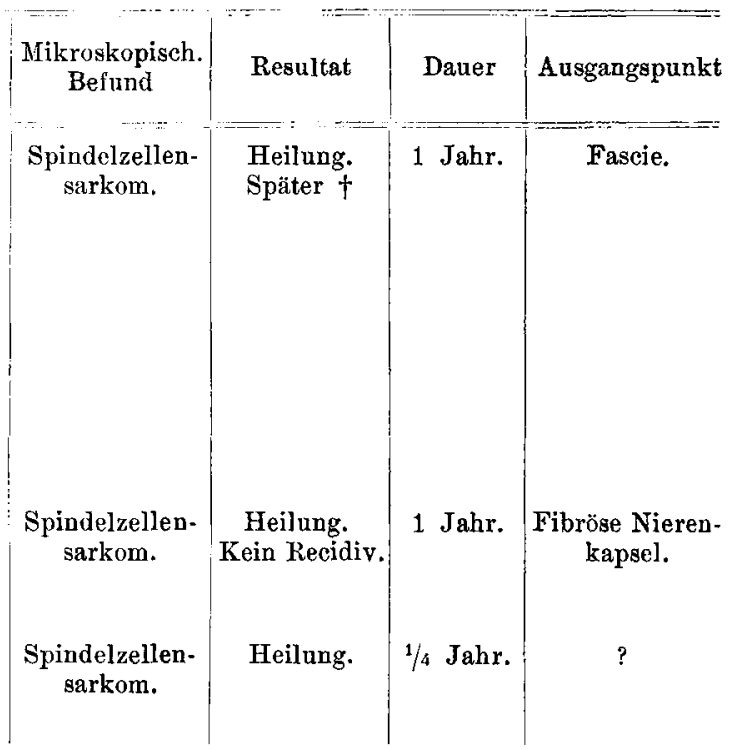

iundzellensarkome.

Vom Nabel gegen beide Darmbeine u sich eretreckende Geschwulst.

ch vorn und links dislocirt, überphoideus um $12 \mathrm{~cm}$. Mit seinem treiche Geschwulst in Verbindung, ren Parenchym blass, aber sonst norhoben hatte, und mit ihrer Kapsel nen bildete. Magen u. Duodenum ten bis zur r. Sp. a. s. und über dem ttgewebe ejnnehmend. Oberer Theil lugelb, theils mehr röthlich, bröckensistenz.

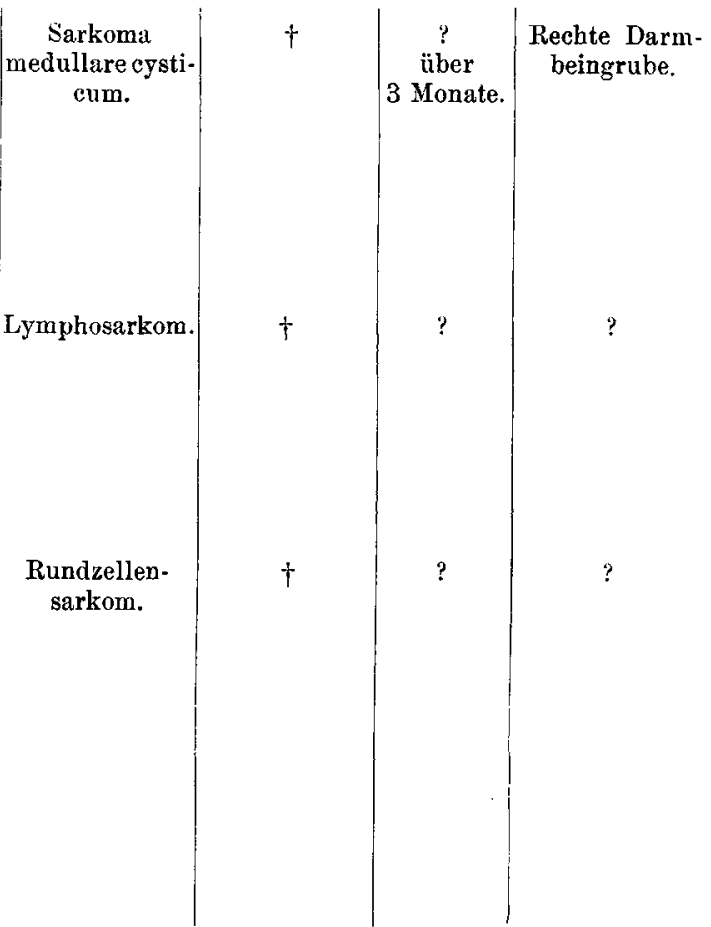




\begin{tabular}{|c|c|c|c|c|c|c|c|}
\hline Nr. & $\begin{array}{l}\text { Autor, } \\
\text { Operateur }\end{array}$ & Alter & 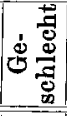 & Diagnose & Operation & $\begin{array}{l}\text { Seite, } \\
\text { Lage }\end{array}$ & Befund \\
\hline 4 & $\begin{array}{c}\text { Elli ot }(34) \\
1879 .\end{array}$ & $49 \mathrm{~J}$. & M. & Tumor & 一 & $\begin{array}{l}\text { Rechts. } \\
\text { Lumbal. }\end{array}$ & $\begin{array}{l}\text { Enormer Tumor, kn } \\
\text { lig, füllte den gröss } \\
\text { Theil der Bauchh., rec } \\
\text { unter die Rippen und } \\
\text { das kleine Becken } \\
\text { chend, links unten In } \\
\text { stina mit dem Darm v } \\
\text { wachsen. In der Ma } \\
\text { gehirnbreiähnliche Fl } \\
\text { sigkeit, hinten rechts } \\
\text { d. Wirbelsäule verwa } \\
\text { sen. Rechte Niere } \\
\text { schlossen, ebenso V, } \\
\text { cava inf. }\end{array}$ \\
\hline 5 & $\begin{array}{c}\text { Kelsch } \\
\text { und Wanhe. } \\
\text { broucqu (58). }\end{array}$ & $59 \mathrm{~J}$. & W. & Tumor. & - & $\begin{array}{l}\text { Rechts. } \\
\text { Iliacal. }\end{array}$ & $\begin{array}{l}\text { Colossaltumor, weic } \\
\text { graue, markähnl. Mai } \\
\text { welche durch binde } \\
\text { webige Stränge mit d } \\
\text { Peritoneum u. der h } \\
\text { Fläche des Mesenter } \\
\text { zusammenbing. }\end{array}$ \\
\hline 6 & $\begin{array}{c}\text { Barde. } \\
\text { leben }(61) \\
1881 .\end{array}$ & $23 \mathrm{~J}$. & W. & Beckentumor. & Probeincision. & $\begin{array}{l}\text { Links. } \\
\text { Iliacal. }\end{array}$ & $\begin{array}{l}\text { Linke Beckenhälfte } \\
\text { einem harten Tumor } \\
\text { gefüllt, vom Lig. Po } \\
\text { bis über die Darmb } \\
\text { schaufel reichend u. } \\
\text { kleineBecken ausfülle } \\
\text { Hauptmasse zerfal } \\
\text { verfettet, verkalkt. }\end{array}$ \\
\hline 7 & $\begin{array}{c}\text { Chadwick }(20) \\
1884 .\end{array}$ & $52 \mathrm{~J}$. & M. & $?$ & $\begin{array}{l}\text { Exstirpation. } \\
\text { Niere n. Ent- } \\
\text { fernung d. Tu- } \\
\text { mors reponirt. }\end{array}$ & $\begin{array}{l}\text { Links. } \\
\text { Lumbal. }\end{array}$ & $\begin{array}{l}\text { Colon zog über die } \\
\text { schwulst hinweg. N } \\
\text { selbst unverändert } \\
\text { oben an der Innenst }\end{array}$ \\
\hline 8 & $\begin{array}{l}\text { Helfe. } \\
\text { rich (104), } \\
\text { Ruge. }\end{array}$ & $19 \mathrm{~J}$ & W. & $\begin{array}{l}\text { Becken- } \\
\text { sarkom. }\end{array}$ & $\begin{array}{l}\text { Exstirpation. } \\
\text { Resection des } \\
\text { Beckens. }\end{array}$ & $\begin{array}{l}\text { Rechts. } \\
\text { Iliacal. }\end{array}$ & $\begin{array}{l}\text { Tumor mannskopfgr } \\
\text { zu beiden Seiten } \\
\text { Beckenschaufel, di } \\
\text { festanliegend, mit } \\
\text { Peritoneum verwach } \\
\text { Knochen nich t ron } \\
\text { Geschwulst durchs } \\
\text { nach oben bis an } \\
\text { Crista, nach unten bi } \\
\text { Tub. ischii, nach } \\
\text { zur Symphyse. Al } \\
\text { kapselt, von einer fib } \\
\text { Membran umgeben,g } \\
\text { knollig. Auf dem Du: } \\
\text { schnitt blutreich, z. } \\
\text { weich zerfallen; g } \\
\text { weiss, an anderen Ste } \\
\text { derb. }\end{array}$ \\
\hline
\end{tabular}


Symptome
Erst Tumor im Epigastrium, wel-
ler eine einfache Vergrösserung der ler eine einfache Vergrösserung der
eber vortäuschte, Oberfläche uueben. auchvenen colossal erweitert. Veua เva-Verschluss. Geringe Beschwerden.

Tumor. Symptome der Compression 3 Vena cava.

Vor 14 Tagen heftige Schmerzen im aken Bein. Vor 4 Tagen beträcht. che Schwellung des linken Oberhenkels. Linke Beckenhälfte von nem harten Tumor ausgefiillt. Haut call infltrirt.

$?$

Vor 5 Wochen Sehmerzen, die rom :chten Oberschenkel ausgingen bis zum uss. Seit 14 Tagen heftiger, bettgerig. - Abductions- und Flexionsintractur. Starke Druckempfindlichit des Troch. maj., Scarpa'schen reiecks und des $\mathrm{N}$. isch. Narkose. üftgelenk frei. Tumor in der rechten ossa iliaca bis zum Nabel, raube Oberiche. Deutl. fluctuirend. Probepuncon : gelbe, stark eiweisshaltige Flüssigit (grosse pigmenthaltende Rundllen, lange spiralförmige Zellen). Kein asammenhang mit den Genitalien.

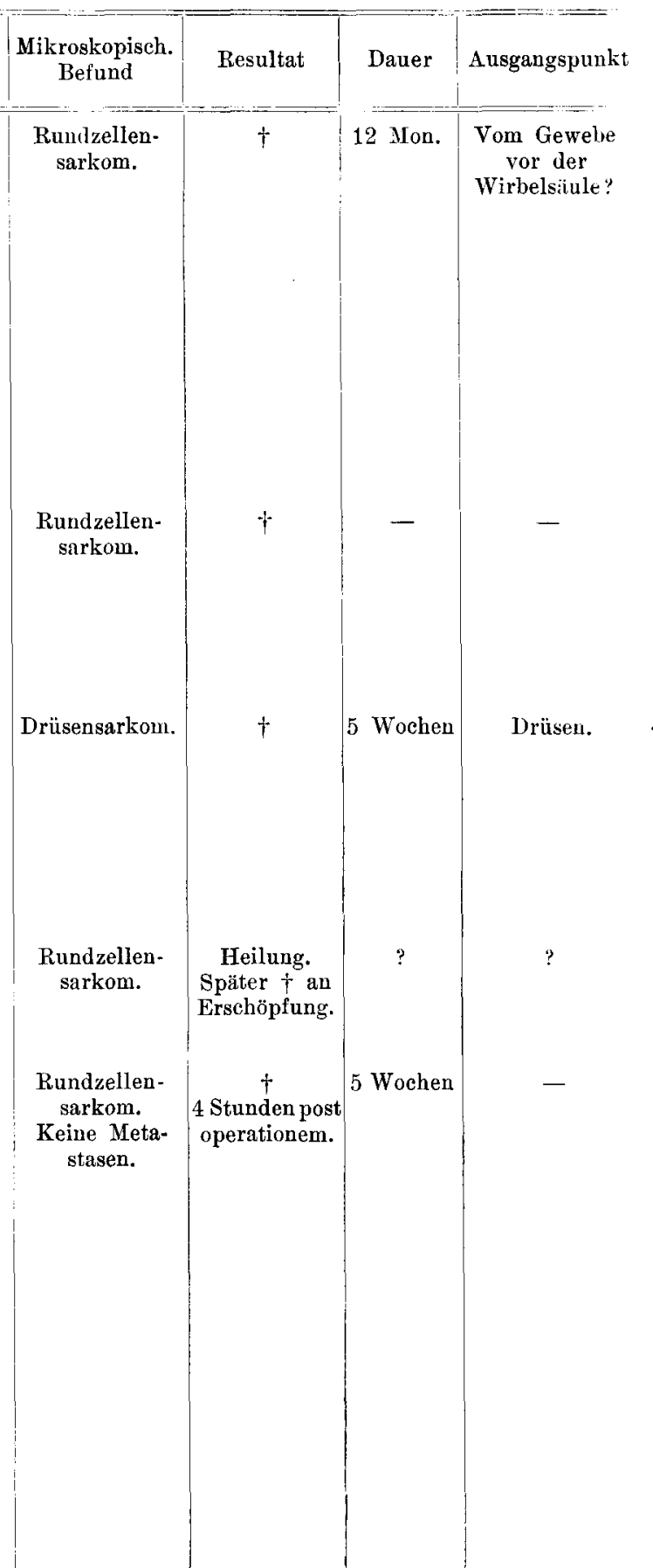




\begin{tabular}{|c|c|c|c|c|c|c|c|}
\hline Nr. & $\begin{array}{c}\text { Autor, } \\
\text { Operateur }\end{array}$ & Alter & 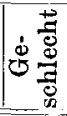 & Diagnose & Operation & $\begin{array}{l}\text { Seite, } \\
\text { Lage }\end{array}$ & Befund \\
\hline \multirow[t]{2}{*}{9} & \multirow[t]{2}{*}{$\begin{array}{l}\text { Willutzki } \\
\text { (133). } \\
1890 .\end{array}$} & \multirow[t]{2}{*}{$25 \mathrm{~J}}$. & \multirow[t]{2}{*}{ M. } & \multirow[t]{2}{*}{$\begin{array}{l}\text { Maligner } \\
\text { retroperiton. } \\
\text { Tumor. }\end{array}$} & - & $\begin{array}{l}\text { Links. } \\
\text { Lumbal. }\end{array}$ & $\begin{array}{l}\text { Linke Seite der Bau } \\
\text { höhle: flachhöckeri } \\
\text { weisslicher, vom Pe } \\
\text { neum überzogner Tu } \\
\text { der sich von der Nie }\end{array}$ \\
\hline & & & & & \multicolumn{3}{|c|}{$\begin{array}{l}\text { gegend bis zur Mitte zwischen Mammillarlinie } \\
\text { Nabel, nach aufwärts bis zur Milz und zum } \\
\text { gen (Collabirtes Colon descendens aussen vor } \\
\text { Tumor), nach abwärts bis zur Linea innomi } \\
\text { erstreckt. 2. Tumor füllt das ganze kleine Bec } \\
\text { aus, reicht bis zur Mitte zwischen Nabel und } \\
\text { physe. Därme nach rechts, Milz in die Zwe } \\
\text { fellkuppe gedrängt. Linke Ni er e liegt dem } \\
\text { mor hinten und oben dicht auf, kein Zusamr } \\
\text { hang. Nierenbecken u. -Kelche erweitert. Ur } \\
\text { zieht durch die Geschwulst. Nahe dem Nierenber } \\
\text { Ureterwand vom Tumor gebildet. Nebennieren } \\
\text { verändert. Durchschnitt undeutlich knollig, 1 } \\
\text { kig, weisslich, grauweiss oder grauröthlich. } \\
\text { Prävertebr. Lymphdrüsenmetastasen. }\end{array}$} \\
\hline 10 & \multirow[t]{2}{*}{$\begin{array}{c}\text { Kereszt- } \\
\text { szeghy } \\
1891 .\end{array}$} & \multirow[t]{2}{*}{$73 \mathrm{~J}}$. & \multirow[t]{2}{*}{ M. } & \multirow[t]{2}{*}{$\begin{array}{c}\text { Pyelo- } \\
\text { calculose, } \\
\text { später Hydro- } \\
\text { nephrose. }\end{array}$} & - & $\begin{array}{l}\text { Rechts. } \\
\text { Lumbal } \\
\text { median. }\end{array}$ & \multirow{2}{*}{$\begin{array}{l}\text { Dünndarmschlingen } \\
\text { labirt, verdrängt di } \\
\text { eine tumorartige Ma } \\
\text { welche, v. Mesenter } \\
\text { überzogen, von der } \\
\text { chfells bis an den } \\
\text { sich erstreckt. In } \\
\text { ini faustgrosse, das } \\
\text { sse. Tumor bedeck } \\
\text { h beiderseits bis an } \\
\text { lein, Becken nicht } \\
\text { adungen mit dem Tu } \\
\text { le zu lösen. Zusamr } \\
\text { chwülsten, von fibr } \\
\text { chnitt markweiss. B } \\
\text { naldrüse markig w } \\
\text {. }\end{array}$} \\
\hline & & & & & \multicolumn{2}{|c|}{$\begin{array}{l}\text { gend unterhalb des Zwerchfells bis an den } \\
\text { gang des kleinen Beckens sich erstreckt. In } \\
\text { Gegend der Valvula Bauhini faustgrosse, das } \\
\text { cum umfassende Tumormasse. Tumor bedeck } \\
\text { ganze Wirbelsäule, seitlich beiderseits bis an } \\
\text { Nieren. Rechte Niere klein, Becken nicht } \\
\text { weitert, keine festen Verbindungen mit dem Tu } \\
\text { Tumor von der Wirbelsäule zu lösen. Zusamr } \\
\text { gesetzt aus knolligen Geschwülsten, von fibr } \\
\text { Kapsel umgeben. Durchschnitt markweiss. B } \\
\text { Nebennieren frei. Inguinaldrüse markig w } \\
\text { Urin eitrig. Blasensteine. }\end{array}$} & \\
\hline
\end{tabular}

Tabelie XI. $R u$

\begin{tabular}{|c|c|c|c|c|c|c|c|}
\hline Nr. & Autor & Alter & (5) & Diagnose & Operation & $\begin{array}{c}\text { Seite, } \\
\text { Lage }\end{array}$ & Symptome \\
\hline 1 & $\begin{array}{c}\text { C. A. W eber } \\
(128) \text {. } \\
1859 .\end{array}$ & $29 \mathrm{~J}$. & M. & $\begin{array}{c}\text { Drüsen- } \\
\text { Geschwulst } \\
\text { der linken } \\
\text { Beckenhälfte. }\end{array}$ & - & $\begin{array}{l}\text { Links. } \\
\text { Iliacal, } \\
\text { lumbal. }\end{array}$ & $\begin{array}{l}\text { Grosse Geschwulst fi } \\
\text { den ganzen unteren T } \\
\text { der Bauchhöhle, hö } \\
\text { rige, schmerzlose,stel } \\
\text { weise weichere Ma } \\
\text { mit dem liuken Hüftl } \\
\text { zusammenhängenc } \\
\text { früher beweglich. A } \\
\text { sere Leistendrüsen } \\
\text { schwollen.-Neural } \\
\text { in Ischiadicus, Obt } \\
\text { torius. Oedemdes lin } \\
\text { Beins. Innere Rupt }\end{array}$ \\
\hline
\end{tabular}




\begin{tabular}{|c|c|c|c|c|}
\hline Symptome & $\begin{array}{l}\text { Mikroskopisch. } \\
\text { Befund }\end{array}$ & Resultat & Dauer & Ausgangspunkt \\
\hline $\begin{array}{l}\text { Vor } 4 \text { Monaten Kreuzschmerzen, } \\
\text { opfschmerzen, Magenbeschwerden. } \\
\text { tuhlverhaltung. Vor } 1 \text { Monat Ge- } \\
\text { 'hwulst unter d. linken Rippenbogen. } \\
\text { - Kein Ascites. Im linken Hypochon- } \\
\text { rium Tumor von Apfelgrösse, bis Fi } \\
\text { an Nabel reichend, lässt sich gut abgre } \\
\text { art, grobhöckrig. Geringe Beweglich } \\
\text { ierengegend verdrängbar. Magen und } \\
\text { umor. Urin o, wechselnde Urinmenge } \\
\text { onaten reicht der Tumor bis an die } \\
\text { nten wenig unter den Nabel, nach hir } \\
\text { ordere Axillarlinie, nach oben kann } \\
\text { ippenbogen und Tumor eindringen. Obe } \\
\text { arte Consistenz, druckempfindlich. - } \\
\text { berhalb der Symphyse bis zum Nabel } \\
\text { dm Lig. inguinale reichend. Colon lä } \\
\text { beren Tumor weg. Beide Tumoren fas } \\
\text { rinentleerung schmerzhaft, sehr häu } \\
\text { altung. }\end{array}$ & $\begin{array}{l}\text { Alveoläres } \\
\text { Rundzellen- } \\
\text { sarkom. } \\
\text { ngerbreit unter } \\
\text { enzen, knorpel- } \\
\text { keit. Von der } \\
\text { Colon vor dem } \\
\text { e. Nach drei } \\
\text { Aittellinie, nach } \\
\text { nten bis an die } \\
\text { man zwischen } \\
\text { erfläche höckrig, } \\
\text { Neuer 2. Tumor } \\
\text { nach links bis } \\
\text { äuft unter dem } \\
\text { st unbeweglich. } \\
\text { afig. Stuhlver- }\end{array}$ & $\dagger$ & 8 Monate. & Ureter. \\
\hline $\begin{array}{l}\text { Seit } 1 \text { Jahre Erkrankung der Harn- } \\
\text { 'ege. Kolikartige Schmerzen in der } \\
\text { zchten Nierengegend. Harnretention. } \\
\text { Pyelocalculose. Später Bauchge- } \\
\text { shwulst in der rechten Nierengegend } \\
\text { ut zu fühlen. Hydronephrose. }\end{array}$ & $\begin{array}{c}\text { Rundzellen- } \\
\text { sarkom } \\
\text { und Blutgefässe. }\end{array}$ & $\dagger$ & 1 Jahr. & Drüsen. \\
\hline
\end{tabular}

und Spindelzellensarkome.

\begin{tabular}{|c|c|c|c|c|}
\hline Befund & $\begin{array}{l}\text { Mikroskop. } \\
\text { Befund }\end{array}$ & $\begin{array}{c}\text { Ausgangs- } \\
\text { punkt }\end{array}$ & Dauer & Resultat \\
\hline $\begin{array}{l}\text { Section: Grosser Tumor. Eingeweide } \\
\text { anz nach oben gedrängt, blutig jau- } \\
\text { hige Flüssigkeit in der Bauchhöhle } \\
\text { tammte aus einer lateral-retroperito- } \\
\text { eal hinter dem Colon descendens ge- } \\
\text { egenen Geschwulst, welche z. Th. hä- } \\
\text { lorrhagisch die Muskeln zum Schwin- } \\
\text { en gebracht, den Knochen usurirt } \\
\text { atte. Zahlreiche, mit gallertartiger, } \\
\text { onigähnlicher Flüssigkeit gefüllte } \\
\text { Iöhlen in der markweissen und gelb- } \\
\text { ichen Masse. Metastasen in der Lunge. }\end{array}$ & $\begin{array}{l}\text { Rund- und } \\
\text { Spindelzellen- } \\
\text { sarkom. }\end{array}$ & $\begin{array}{l}\text { Linke Lumbal- } \\
\text { und Inguinal- } \\
\text { drüsen. }\end{array}$ & $1 / 2 \mathrm{Jahr}$ & $\dagger$ \\
\hline
\end{tabular}




\begin{tabular}{|c|c|c|c|c|c|c|c|}
\hline Nr. & Autor & Alter & 总 & Diagnose & Operation & $\begin{array}{l}\text { Lage, } \\
\text { Seite }\end{array}$ & Symptome \\
\hline \multirow[t]{2}{*}{2} & \multirow[t]{2}{*}{$\begin{array}{c}\text { Joseph Ran- } \\
\text { so of of }(98) . \\
1883 .\end{array}$} & \multirow[t]{2}{*}{$33 \mathrm{~J}}$. & \multirow[t]{2}{*}{ M. } & \multirow[t]{2}{*}{$\begin{array}{l}\text { Maligne } \\
\text { Leberge- } \\
\text { schwulst? }\end{array}$} & $\begin{array}{c}\text { Laparotomie. } \\
\text { Einstellung. } \\
\text { Incision mit } \\
\text { dem Thermo- } \\
\text { kauter. }\end{array}$ & $\begin{array}{l}\text { Rechts. } \\
\text { Lumbal. }\end{array}$ & $\begin{array}{l}\text { Vor } 2 \text { Jahren Sch } \\
\text { lung des linken Fus } \\
\text { nach } 1 \text { Woche auch } \\
\text { rechten, bis hinauf } \\
\text { Abdomen. Abdor } \\
\text { aufgetrieben. Schr }\end{array}$ \\
\hline & & & & & \multicolumn{3}{|c|}{$\begin{array}{l}\text { lung der Beine geringer. Vor } 1 \text { Jahr Verda } \\
\text { auf Ascites. Punction ohne Erfolg. Appe } \\
\text { losigkeit, vor } 6 \text { Monaten Hämorrhoiden. } \\
\text { magerung. Oberer Theil des Abdomen st } \\
\text { ausgedehnt, besonders im rechten Hypoch } \\
\text { drium. Varicöse epigastrische Venen. Man fi } \\
\text { im oberen Theil der Bauchhöhle eine feste Ma } \\
\text { die sich mit der Athmung bewegt, glatte Ol } \\
\text { fläche. Fluctuation. Auscultation ergiebt nic } \\
\text { Punction. Degenerirende Leberzellen, zahlrei } \\
\text { rothe und weisse Blutkörperchen. Tyrosin. } \\
\text { weiss. Keine primäre Geschwulst sonst nz } \\
\text { zuweisen. }\end{array}$} \\
\hline
\end{tabular}

Tabelle $\mathrm{X}$

\begin{tabular}{|c|c|c|c|c|c|c|}
\hline Nr. & $\begin{array}{c}\text { Autor, } \\
\text { Operateur }\end{array}$ & Alter & 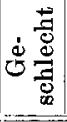 & Diagnose & Symptome & Behandlu \\
\hline 1 & $\begin{array}{l}\text { F. Winckel } \\
(137) . \quad 1874 .\end{array}$ & $37 \mathrm{~J}$ & W. & - & $\begin{array}{l}\text { Vor } 2 \text { Jahren ziemlich rasch } \\
\text { wachsende Geschwulst im Leibe. } \\
\text { Damals deutliche Fluctuation. Tu- } \\
\text { mor bis in den Beckeneingang von } \\
\text { rechts her hinabragend, verschieb- } \\
\text { lich gegen den Uterus. Bei der } \\
\text { Punction } 3 \text { Kannen gelblich serö- } \\
\text { ser Flüssigkeit. Erleichterung. } \\
\text { Vor } 4 \text { Monaten, seit Beginn der } \\
\text { 6. Schwangerschaft } 2 \text { mal Punctio- } \\
\text { nen. Bei der Aufnahme enorm } \\
\text { viele, fast fingerbreite Bauchvenen. } \\
\text { Tumor bis in die Herzgrube ra- } \\
\text { gend. Athemnoth, Harndrang, } \\
\text { starke Diurese. Appetit gut. Par- } \\
\text { tus. } 8 \text { Monats-Kind. }\end{array}$ & $\begin{array}{l}\text { Operatio } \\
3 \text { Wochen ] } \\
\text { partum. } \\
\text { stirpatio } \\
\end{array}$ \\
\hline 2 & $\begin{array}{c}\text { Thornton } \\
(121) . \quad 1883 .\end{array}$ & $43 \mathrm{~J}$ & W. & $?$ & Seit 6 Jahren bestanden. & $\begin{array}{c}\text { Nephrect } \\
\text { mie. }\end{array}$ \\
\hline 3 & $\underset{1890 .}{\text { Heyder }}$ & $37 \mathrm{~J}$. & W. & $\begin{array}{l}\text { Unentschie- } \\
\text { den. }\end{array}$ & $\begin{array}{l}\text { Allmähliches Stärkerwerden des } \\
\text { Leibes. Obstipation. Unterleib } \\
\text { gleichmässig vergrössert. Grosse, } \\
\text { derbe Geschwulst mit glatter Ober- } \\
\text { fläche. Haut über ihr verschieb- } \\
\text { lich. Geschwulst wenig verschieb- } \\
\text { lich. Im Epigastrium und in bei- } \\
\text { den Hypochondr. und in der r. } \\
\text { tympanitischer, sonst leerer Schal } \\
\text { klar, normal. Uterusanhänge nich }\end{array}$ & 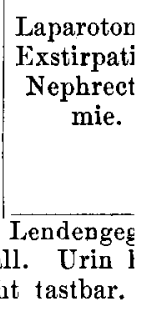 \\
\hline
\end{tabular}




\begin{tabular}{|c|c|c|c|c|}
\hline Befund & $\begin{array}{c}\text { Mikroskop. } \\
\text { Befund }\end{array}$ & $\begin{array}{c}\text { Ausgangs- } \\
\text { punkt }\end{array}$ & Dauer & Resultat \\
\hline $\begin{array}{l}\text { Bei der Eröffuung weiche, bröcklige } \\
\text { bstanz, wie Gehirnsubstanz, starke } \\
\text { atung. } \\
\text { Bei der Section : Leber enthält einen } \\
\text { sssen Tumor, der sich durch das } \\
\text { aze Abdomen erstreckt, } 2 \text { manns- } \\
\text { pfgross, unten an dem rechten Leber- } \\
\text { ypen cystischer Tumor. Kapsel des } \\
\text { mors mit Glis son'scher Kapsel so } \\
\text { lig verwachsen, dass keine Tren- } \\
\text { ng möglich. Tumor vom Periton. } \\
\text { deckt an der rechten Seite der Wir- } \\
\text { lsäule, in der rechten Nierengegend } \\
\text { legen. Unterer Theil fest, knollig, } \\
\text { grau-hämorrhagisch; Durchschnitt } \\
\text { uh, uneben, röthliche und graue } \\
\text { öcklige Substanz. }\end{array}$ & \begin{tabular}{|} 
Sarkom, kleine \\
u. grosse Rund- \\
zellen, Spindel- \\
zellen, homo- \\
gene Zwischen- \\
substanz. Blut- \\
gefässe mit \\
dünner Wand. \\
Blutexstra- \\
vasate.
\end{tabular} & $\begin{array}{c}\text { Von der Ge- } \\
\text { gend oberhalb } \\
\text { der rechten } \\
\text { Niere. Nicht } \\
\text { imZusammen- } \\
\text { hang mit Niere } \\
\text { und Neben- } \\
\text { niere. }\end{array}$ & 2 Jahre. & $\begin{array}{l}+67 \text { Stunden } \\
\text { post operatio- } \\
\text { nem. }\end{array}$ \\
\hline
\end{tabular}

ibrosarkome.

\begin{tabular}{|c|c|c|c|c|c|}
\hline $\begin{array}{l}\text { Seite, } \\
\text { Lage }\end{array}$ & Befund & $\begin{array}{l}\text { Mikroskop. } \\
\text { Befund }\end{array}$ & $\begin{array}{c}\text { Ausgangs- } \\
\text { punkt }\end{array}$ & Dauer & Resultat \\
\hline $\begin{array}{l}\text { Rechts. } \\
\text { umbal- } \\
\text { liacal. }\end{array}$ & $\begin{array}{l}\text { 10 Kilogr. schwere Ge- } \\
\text { schwulst, } 8-15 \mathrm{~cm} \text { dicke, } \\
\text { fibröse Kapsel, stellenweise } \\
\text { mit ödematösen Interstitien. } \\
\text { Kindskopfgrosses, leicht zu } \\
\text { isolirendes, ganz ausschäl- } \\
\text { bares, gemischtes, mässig } \\
\text { derbes Sarkom. }\end{array}$ & $\begin{array}{l}\text { Fibrom mit } \\
\text { centralem Sar- } \\
\text { kom. }\end{array}$ & $\begin{array}{l}\text { Retroperiton. } \\
\text { Stiel zur Sym- } \\
\text { physis sacro- } \\
\text { iliaca. }\end{array}$ & 2 Jahre. & Heilung. \\
\hline$?$ & $\begin{array}{l}11 \text { Pfund schweres Sar- } \\
\text { kom der Nierenkapsel. }\end{array}$ & $\begin{array}{l}\text { Fibrom mit } \\
\text { sarkomatöser } \\
\text { Entartung. }\end{array}$ & Nierenkapsel. & 6 Jahre. & $?$ \\
\hline $\begin{array}{l}\text { Links. } \\
\text { jumbal. }\end{array}$ & $\begin{array}{l}\text { Prall-elastische Geschwulst, } \\
\text { nach oben bis zum Brust- } \\
\text { bein, nach unten bis auf die } \\
\text { Beckenschaufeln reichend, } \\
\text { keine Verwachsung. Mässi- } \\
\text { ger Ascites. Ursprung linke } \\
\text { Nierengegend. Colon descen- } \\
\text { dens nicht bemerkt. Uterus } \\
\text { u. Adnexe normal. Wurzeld. } \\
\text { Geschwulst die ganzel. Niere. }\end{array}$ & Fibrosarkom. & Nierenkapsel. & 6 Woch. & Heilung. \\
\hline
\end{tabular}




\begin{tabular}{|c|c|c|c|c|c|c|}
\hline $\mathrm{Nr}$. & $\begin{array}{l}\text { Autor, } \\
\text { Operateur }\end{array}$ & Alter & 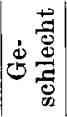 & Diagnose & Symptome & Behandlun \\
\hline 4 & $\begin{array}{c}\text { Dorn }(31) \\
1894 .\end{array}$ & $51 \mathrm{~J}$. & M. & $\begin{array}{c}\text { Periostales } \\
\text { Sarkom des } \\
\text { Darmbeins } \\
\text { mit Druck auf } \\
\text { d. N. cruralis. }\end{array}$ & $\begin{array}{l}\text { In der rechten Lumbalgegend } \\
\text { nach rechts von der Wirbelsäule } \\
\text { Weichtheile im Allgemeinen vor- } \\
\text { gebuchtet. Die Anschwellung er- } \\
\text { streckt sich vom hinteren Rand } \\
\text { der Crista ilei nach aufwärts bis } \\
\text { zur letzten Rippe, nach vorn bis } \\
\text { an die Sp. a. s. Weichtheile sehr } \\
\text { hart, infiltrirt, Tumor weder nach } \\
\text { oben von der 12. Rippe, noch } \\
\text { nach unten vom Darmbein abzug } \\
\text { gegen die Wirbelsäule Abgrenzur } \\
\text { Bis in die Scapularlinie Infiltratio } \\
\text { verfärbt, in der Mitte der Schwellu } \\
\text { Beweglichkeit der unteren Extre } \\
\text { leichte rechtsseitige Skoliose der } \\
\text { der Gegend des Tumors. }\end{array}$ & $\begin{array}{l}\text { Exstirpatic } \\
\text { mit Resecti } \\
\text { des Darm } \\
\text { beins, Rese } \\
\text { tion des I } \\
\text { cruralis ur } \\
\text { Eröffnung c } \\
\text { recht. Pleu } \\
\text { höhle. } \\
\text { grenzen, au } \\
\text { ng unmögli } \\
\text { on. Haut niı } \\
\text { ing eingezog. } \\
\text { emität norm } \\
\text { Wirbelsäule }\end{array}$ \\
\hline
\end{tabular}

Tabelle XI

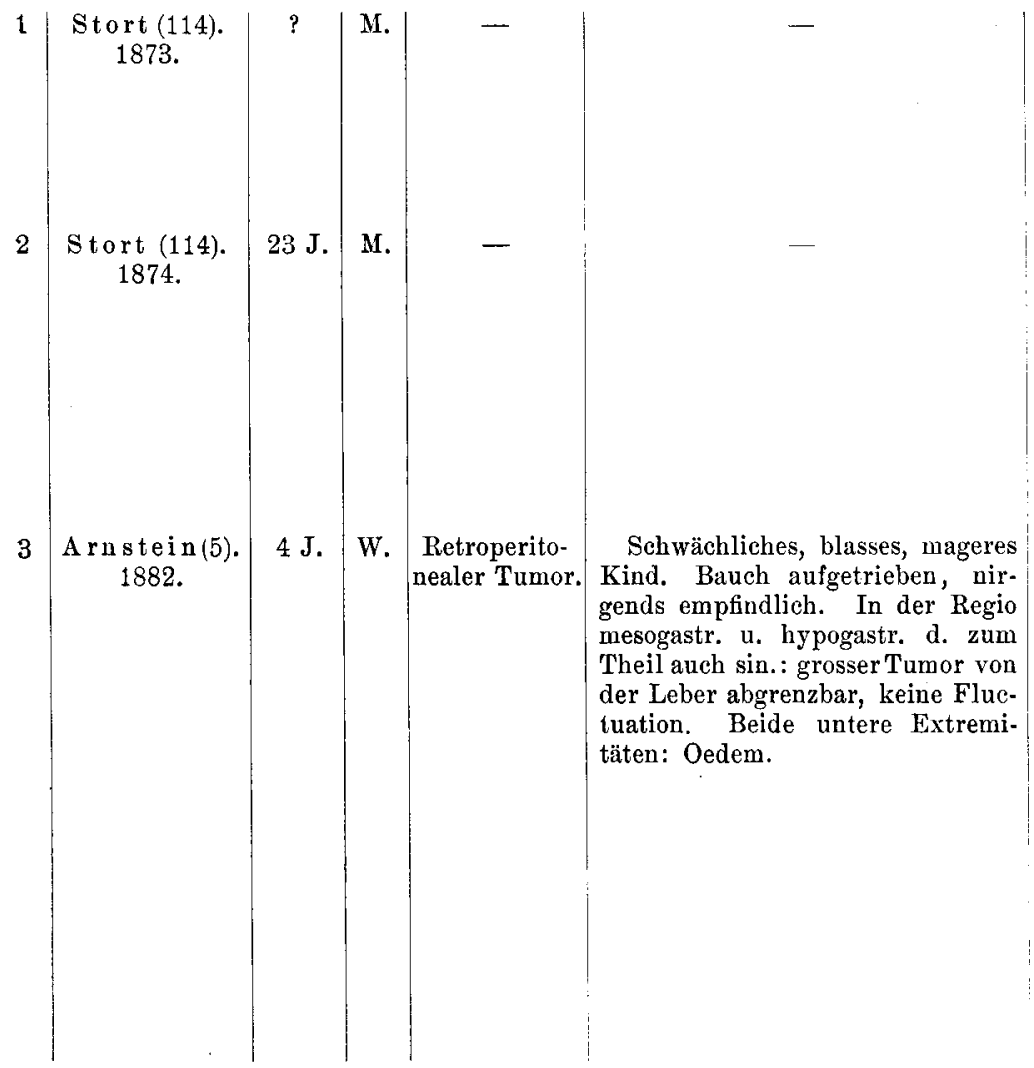




\begin{tabular}{|c|c|c|c|c|c|}
\hline $\begin{array}{l}\text { Seite, } \\
\text { Lage }\end{array}$ & Befund & $\begin{array}{l}\text { Mikroskop. } \\
\text { Befund }\end{array}$ & $\begin{array}{c}\text { Ausgangs- } \\
\text { punkt }\end{array}$ & Dauer & Resultat \\
\hline $\begin{array}{l}\text { iechts. } \\
\text { umbal- } \\
\text { liacal. }\end{array}$ & $\begin{array}{l}\text { Tumor reichte bis an die } \\
\text { 12. Rippe, mit der parietal. } \\
\text { Pleura verwachsen und mit } \\
\text { dem Darmbein, dessen Crista } \\
\text { rauh. Der N. cruralis im } \\
\text { Tumor. Sarkomatöse Lei- } \\
\text { stenlymphdrüse. }\end{array}$ & $\begin{array}{c}\text { Spindelzellen- } \\
\text { sarkom }\end{array}$ & $\begin{array}{l}\text { Periost des } \\
\text { Darmbeins. }\end{array}$ & $1^{1 / 2} \mathrm{Jahr}$. & $\begin{array}{c}\text { t nach einigen } \\
\text { Tagen. }\end{array}$ \\
\hline
\end{tabular}

\section{yxosarkome.}

3echts. Myxosarcoma retroperiumbal. toneale haemorrhagicum reg. lumb. d. fusicellulare. Tumor pulmonis d. durch das Zwerchfell durchgebrochen. Dislocatio et compressio hepatis.

Links. Myxosarcoma angiomatoumbal. sum teleangiectodes haemorrhagicum eysticum telae retroperiton. lateralis sin. Metastases pulmonum hepatis, renis sin., glandularum duodeni. Ureter erstreckt sich quer durch die Geschwulst, für die Sonde durchgängig.

Rechts. Grosser Tumor, hauptumbal. sächlich in der rechten Hälfte des Bauches. Auf dem Tumor stark ausgedehntes Colon transversum und Coecum. Alle anderen Darmtheile links u, collabirt. Netz stellenweise adhärent. Retroperitonealer Tumor mit der rechten Niere verwachsen, kugelig glatt, mit flachen Prominenzen, geringerer Zahl Cysten. An der vorderen Seite retroperiton. Drüsen bohnenbis mandelgross nicht ergriffen. $8,5 \mathrm{~kg}$ Gewicht. In den Wandungen theils frische, theils ältere Hämorrhagieen. Inhalt der Cysten gelb, dünnflüssig.

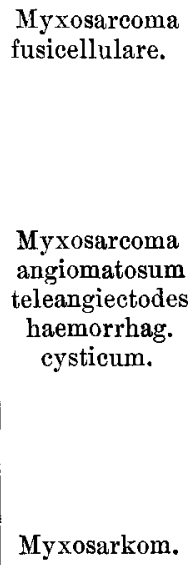

Myxosarcoma fusicellulare.

Myxosarcoma angiomatosum teleangiectodes haemorrhag. eysticum.

Myxosarkom.

Retroperitoneales Gewebe.

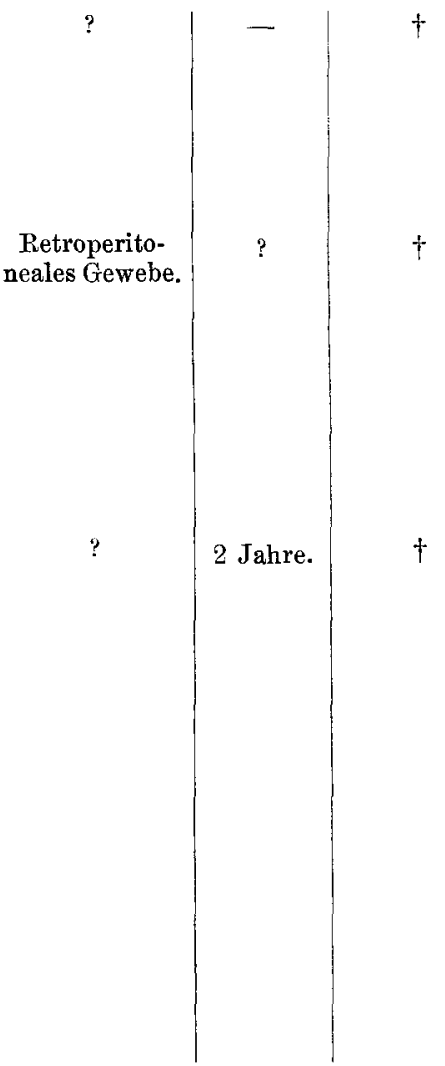




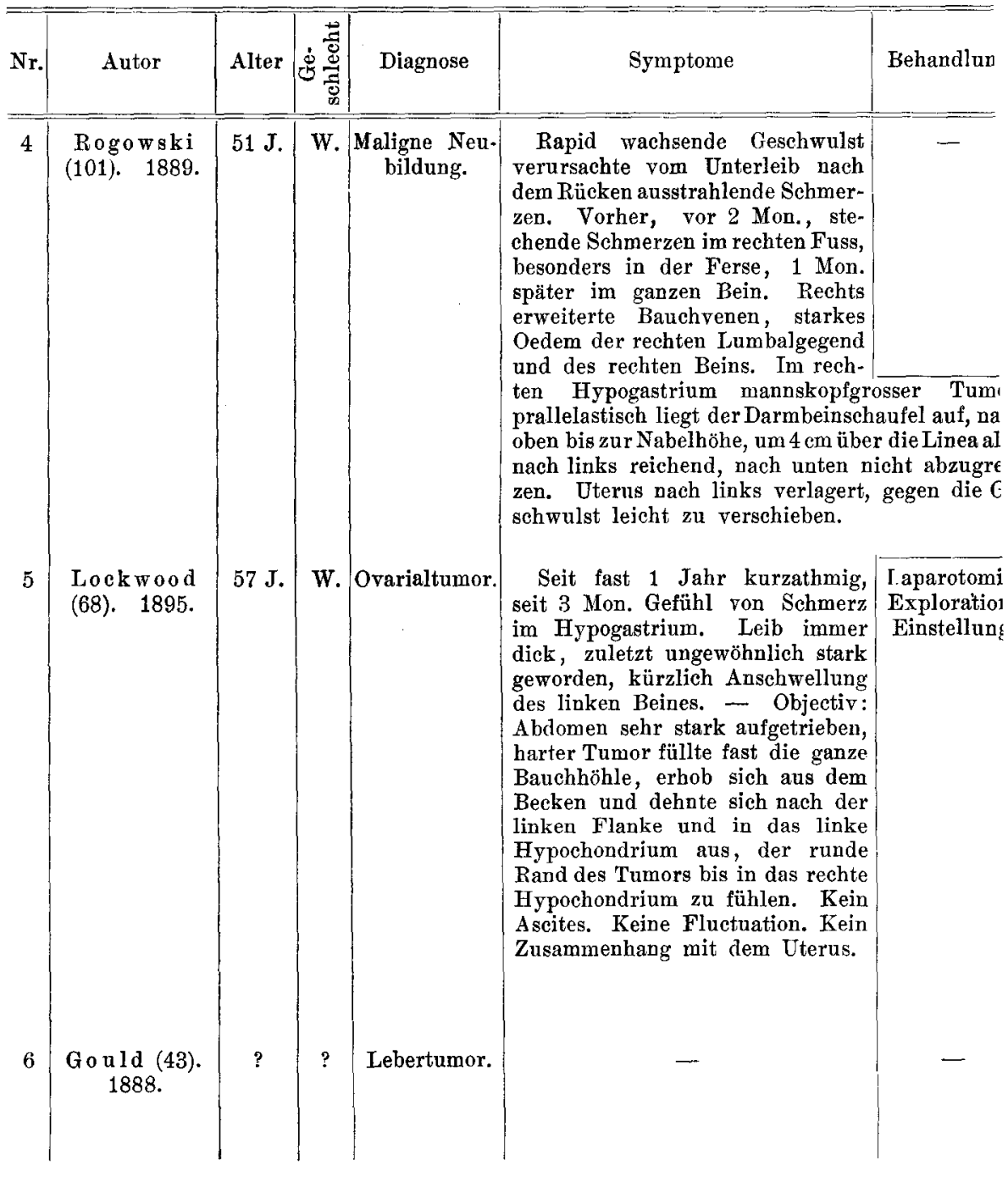

Tabeile XIT

1 Lossen (70). 1879.
$37 \mathrm{~J} . \mid$ W. Ovarialtumor.
Im Verlauf eines Jahres ent- Laparotomie wickelte, rechtsseitig gelegene, Nephrectokindskopfgrosse Geschwulst bei im mie.

3. Monat schwangerer Frau, rundlich, glatte Oberfläche, mässig feste Consistenz, keine Fluctuation. Geschwulst ausserordentlich verschieblich. Därme vor d. Tumor glitten zur Seite, wenn der Tumor nach vorn gedrängt wurde. Stiel nach dem Becken zu. Uterus gravidus, 2-3. Monat. 


\begin{tabular}{|c|c|c|c|c|}
\hline $\begin{array}{l}\text { Seite, } \\
\text { Lage }\end{array}$ & $\begin{array}{c}\text { Mikroskop. } \\
\text { Befund }\end{array}$ & $\begin{array}{l}\text { Ausgangs- } \\
\text { punkt }\end{array}$ & Dauer & Resultat \\
\hline $\begin{array}{l}\text { Rechts. } \\
\text { Iliacal. }\end{array}$ & \begin{tabular}{l|l} 
In der vordern rechten & Ziemlich grosse, \\
Hälfte des Abdomen, seit- & runde, z. Th. \\
lich vom und unter dem & auch etw. eckige \\
Coecum eine fast masus- & Zellen, grosser \\
kopfgrosse Geschwulst. & Kern und \\
Uterus der linken Darm- & blasser, leicht \\
beinschaufel anliegend. & granulirter Pro- \\
Oberhalb der Lendenwirbel & toplasmasaum, \\
ein Packet fester, knolliger & reichlich rothe \\
Massen u. retroperitonealer & Blutkörper- \\
Lymphdrüsen. Geschwulst & chen. Zwischen \\
weiche, breiige Masse. Vena & den Zellen \\
cruralis thrombosirt. Me- & Schleimgewebe. \\
tastasen in den Muskeln. & Grosse mit Blut \\
Nieren und Nebennieren & gefüllte Gefässe. \\
mit dem Tumor in keiner & von Blut mitten in \\
Verbindung. & sarcoma globocell
\end{tabular} & $\begin{array}{l}\text { Ansammlung } \\
\text { Tumor. Myxo- } \\
\text { lare cavernos. }\end{array}$ & 3 Mon. & $\dagger$ \\
\hline $\begin{array}{l}\text { Links. } \\
\text { Iliacal- } \\
\text { lumbal. }\end{array}$ & $\begin{array}{l}\text { Tumor wie eine dick- } \\
\text { wandige Cyste. Punction, } \\
\text { nichts entleert. Incision. } \\
\text { Festweicher Inhalt. Colon } \\
\text { links vorn. Mesenterium und Mesocolon v. } \\
\text { oberen Theil des Tumors eingenommen. } \\
\text { Beckenorgane frei. Nach den Seiten zu } \\
\text { nicht hinter den Tumor zu gelangen. } \\
\text { section; Retroperitoneales Gewebe von } \\
\text { einer enormen Neubildung eingenommen, } \\
\text { von dem linken Becken bis zum Diaphragma, } \\
\text { in d. Wurzel das Mesenterium, das Meso- } \\
\text { colon transvers. bis zum Hilus der Milz. } \\
\text { Sie umhüllte das Pankreas, die Nieren und } \\
\text { Nebennieren, ohne sie zu durchwuchern. } \\
\text { Sarkom röthlich-grau, fast weich bis gela- } \\
\text { tinös, gefässreich nur nahe den grossen Ge- } \\
\text { fässen, ohne Kapsel hatte die Gewebe vor } \\
\text { sich hergetrieben. Keine Metastasen. }\end{array}$ & $?$ & 1 Jahr. & $\begin{array}{l}+4 \text { Tage } \\
\text { nach d. Probe- } \\
\text { laparotomie. }\end{array}$ \\
\hline - & $\begin{array}{l}\text { Section: Perirenales } \\
\text { Myxosarkom mit intacter } \\
\text { Niere. }\end{array}$ & Perirenal. & $?$ & $\dagger$ \\
\hline
\end{tabular}

\section{Verschiedene Sarkome.}

Rechts. Angiosarkom der r. Nieren-| Angiosarkom. Lumbal. kapsel. Tumor vom Perito- Auf Durchneum bedeckt, glatte, bläu- schnitt markig lich weisse mit dicken Ve- weiss, vorquelnen durchzog. Oberfläche d. lend zahlreiche Geschwulst. Niere hinten Blutextravaam T'umor. Niere gesund. sate, marmorirt. Derbe fibröse Kapsel umgab den Tumor und ging auf

die fibröse Nierenkapsel an der Implantationsstelle ïber. Geschwulst seharf von der Niere abgegrenzt.

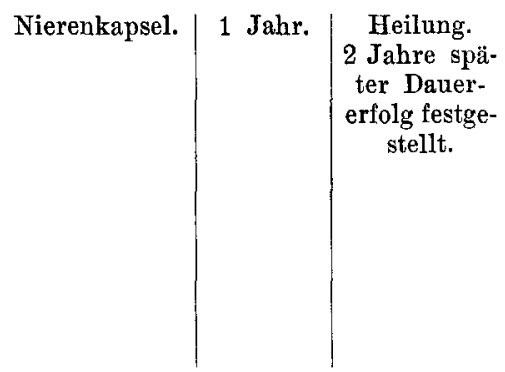




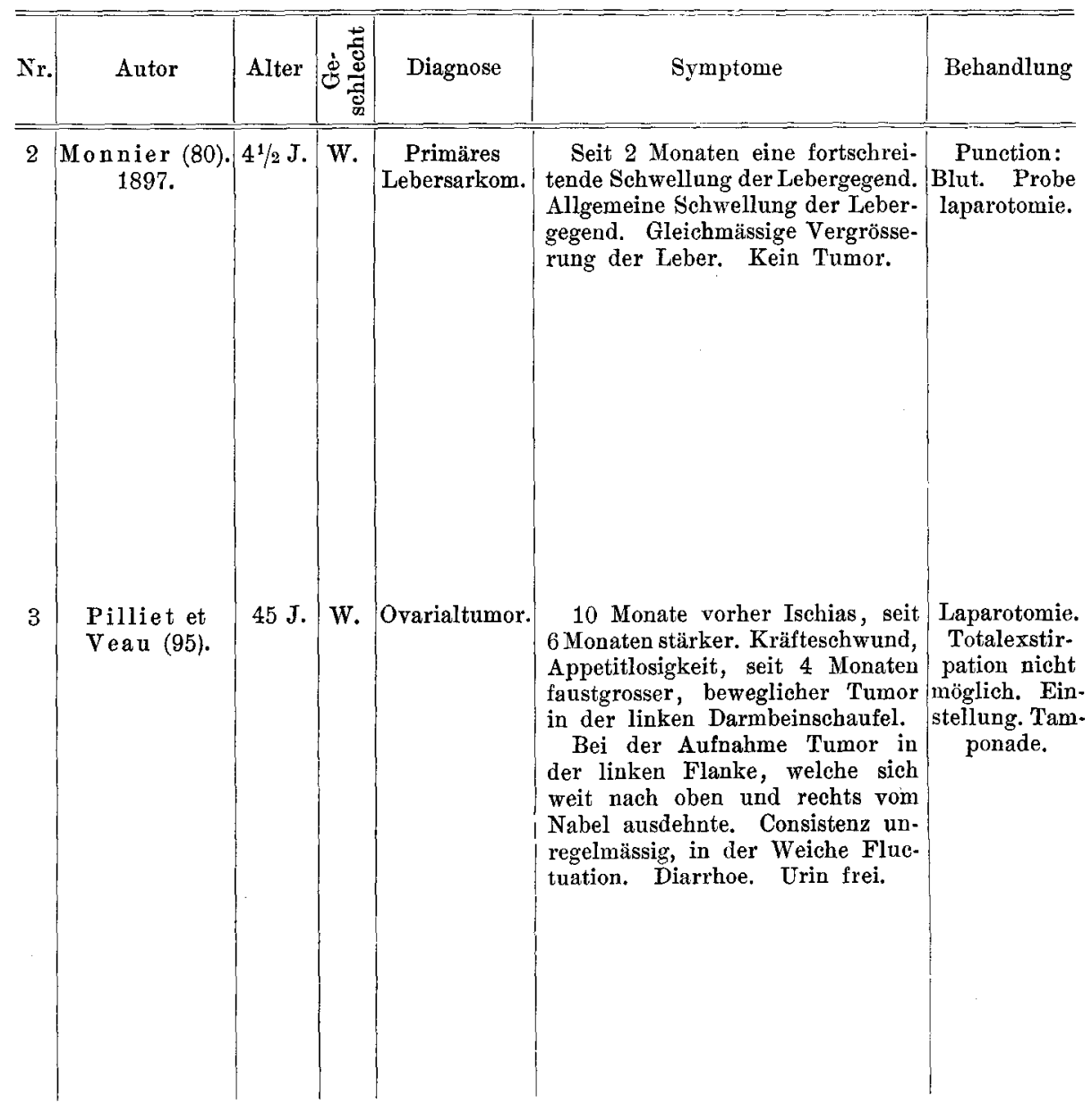

Tabelle XV. Tumoren der

\begin{tabular}{|c|c|c|c|c|c|c|}
\hline Nr. & Autor & Alter & 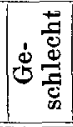 & Diagnose & Symptome & Operation \\
\hline 1 & $\begin{array}{c}\text { Chiari }(21) \\
1884 .\end{array}$ & $44 \mathrm{~J}$. & M. & $\begin{array}{c}\text { Retroperi- } \\
\text { tonealer Tu- } \\
\text { mor }\end{array}$ & $\begin{array}{l}\text { a) Mannskopfgrosser Tumor im } \\
\text { rechten Unterbauchraum. } \\
\text { b) Recidiv. Drucksymptome auf } \\
\text { den Plexus cruralis und die Schen- } \\
\text { kelgefässe. Recidiv. Mannskopf- } \\
\text { gross. }\end{array}$ & $\begin{array}{l}\text { 1. Operation. } \\
\text { Laparotomie. } \\
\text { Transperito- } \\
\text { neale Exstir- } \\
\text { pation. } \\
\\
\text { 2. Laparoto- } \\
\text { mie. Keine } \\
\text { scharfe } \\
\text { Grenze. }\end{array}$ \\
\hline
\end{tabular}




\begin{tabular}{l|l}
$\begin{array}{l}\text { Seite, } \\
\text { Lage }\end{array}$ & Befund \\
\hline
\end{tabular}

Rechts. $\quad$ Bei der Operation: Leber.

Lumbal. tumor, welcher bis zum Os pubis reicht.

Bei der Section: Leber intact, unterhalb enormer Tumor, retroperitoneal, im Mesocolon des Col. ascend. und eines gr. Theils des Mesocolon Col. transversum. Tumor haftet fest an dem oberen Drittel der rechten. Niere und besonders an der Nebenniere, welche mit ihm gewissermaassen e. Körper bildet. Vena cava comprimirt. Grau-weiss, festweich. Nirgends lipomartig.

Links, Retroperitonealer Tumor. Sarkom trotz Lumbal- Colon vor ihm, Dünndarm enormer Anzahl Von der Nebeniliacal. nach rechts verschoben. von Fettzellen. niere nichts erGraue Particen ähnlich dem Daneben RiesenCerebralgewebe, leicht zerdrückbar. Rechte Niexe einer Cyste im unteren Pol. Ovarien gesund. Totale Exstirpation nicht möglich.

Bei der Section: Iinke Niere bildet die hintere Wand des Tumors, welcher in der Fossa iliaca sin. $u$. Lendengegend gelegen, am Os sacrum und den letzten Lendenwirbeln festhaftet. Psoas ist infiltrirt. Der Ureter comprimirt. Der Sacral- und Lumbalplexus im Tumor. Auf dem Durchschnitt gelbliche Farbe, fettig. zellen. Sehr viele Gefässe mit hyaliner Degeneration. wähnt!

\section{ursäehlichen \\ Zusammenhang}

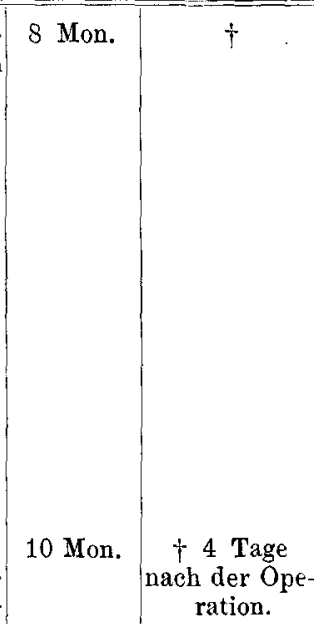

ration.

accessorischen Xebennieren.

\begin{tabular}{|c|c|c|c|c|c|}
\hline $\begin{array}{l}\text { Seite, } \\
\text { Lage }\end{array}$ & Befund & $\begin{array}{l}\text { Mikroskop. } \\
\text { Befund }\end{array}$ & $\begin{array}{c}\text { Ausgangs- } \\
\text { punkt }\end{array}$ & Dauer & Resultat \\
\hline $\begin{array}{l}\text { Rechts. } \\
\text { Iumbal- } \\
\text { iliacal. }\end{array}$ & $\begin{array}{l}\text { Bei der 1. Oper.: Manns- } \\
\text { kopfgrosse Geschwulst zwi- } \\
\text { schen Niere u. dem kleinen } \\
\text { Becken vor d. unteren Ab- } \\
\text { schnitt des M. quadratus } \\
\text { lumborum und dem M.ilia- } \\
\text { cus internus, hinter dem } \\
\text { Coecum u. dem Peritoneum } \\
\text { parietale der Fossa iliaca } \\
\text { nach aussen vom M. psoas, vo } \\
\text { Kapsel umgeben. Im Centrum } \\
\text { maşsegelblich-weiss, medullä } \\
\text { war der Tumor in der Gefä }\end{array}$ & $\begin{array}{l}\text { Ziemlich grosse } \\
\text { epithelioide Zel- } \\
\text { len mit grossen } \\
\text { Kernen, in eine } \\
\text { sehr zarte, thei } \\
\text { substanz eingela } \\
\text { len Stellen drüsi } \\
\text { liches Pigment } \\
\text { on einer mit der } \\
\text { ä Hohle mit frisch } \\
\text { är, zieml. brüchig, }\end{array}$ & $\begin{array}{l}\text { Accessorische } \\
\text { Nebenniere. } \\
\text { s schleimige, th } \\
\text { gert. Zellleiber } \\
\text { ger Charakter, Z } \\
\text { enthaltend. Ne }\end{array}$ & $\begin{array}{l}\text { Is feinfas } \\
\text { leist pol } \\
\text { en Fett } \\
\text { nnierent }\end{array}$ & $\begin{array}{l}\text { Heilung. } \\
\text { Später Reci- } \\
\text { div. } \uparrow \text {. } \\
\text { rige Zwischen. } \\
\text { gonal. An vie- } \\
\text { pfen u. bräun- } \\
\text { mor. } \\
\text { menhängenden } \\
\text { at, Geschwulst- }\end{array}$ \\
\hline
\end{tabular}




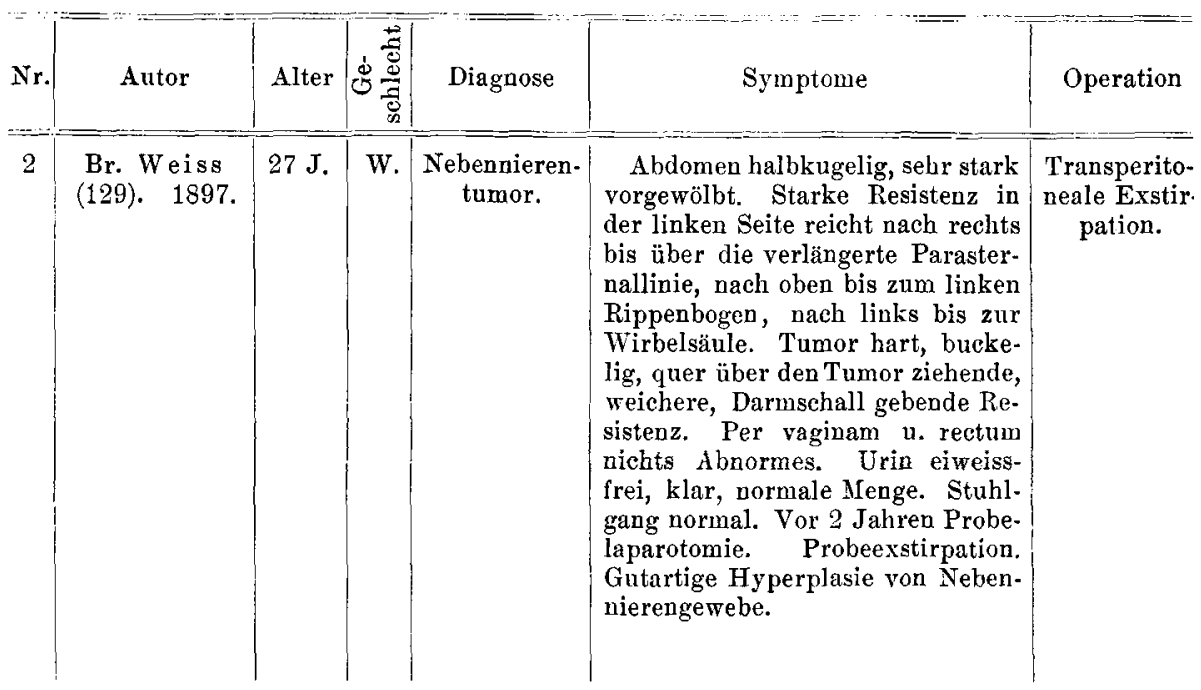

Tabelue XVI

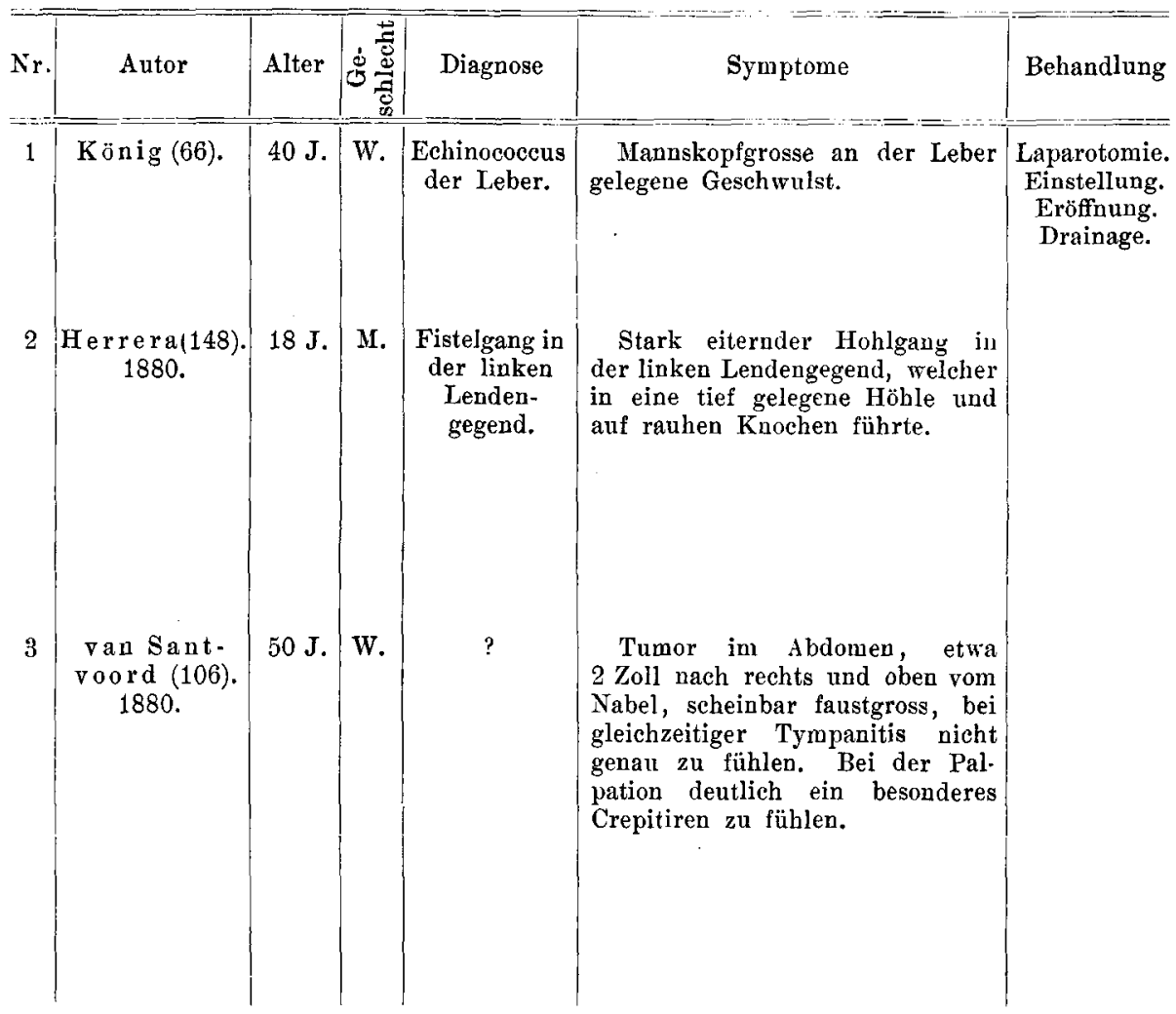




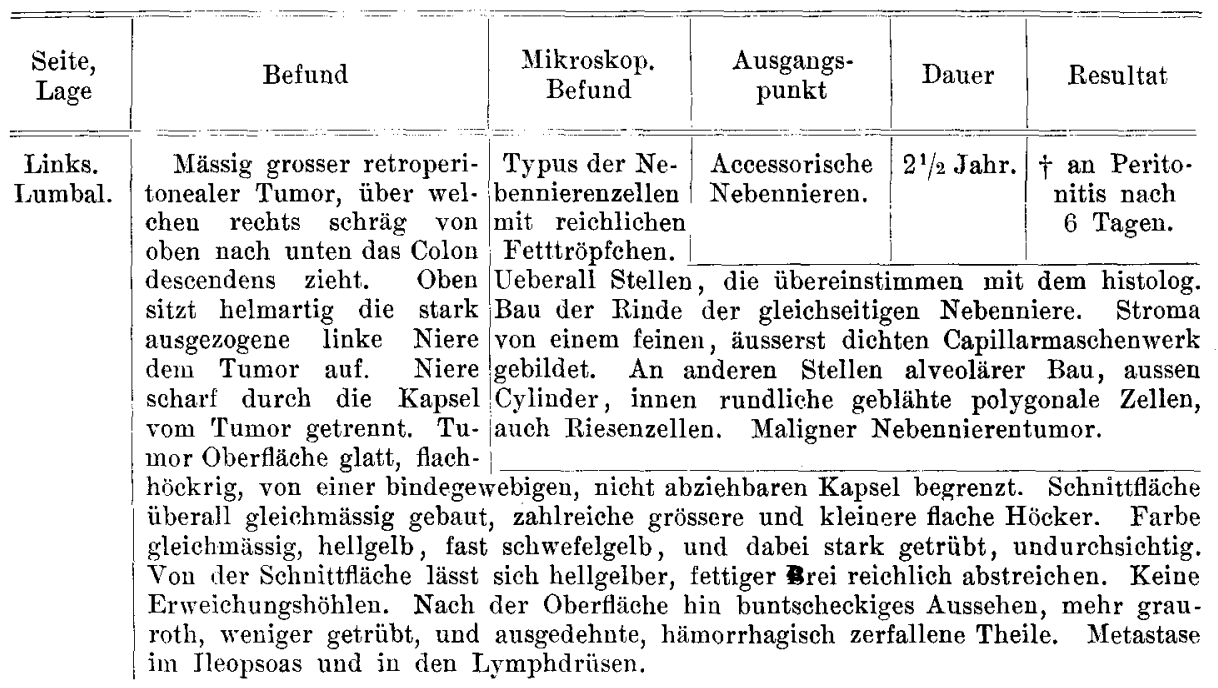

Dermoidcysten.

\begin{tabular}{|c|c|c|c|c|c|}
\hline $\begin{array}{l}\text { Seite, } \\
\text { Iage }\end{array}$ & Befund & $\begin{array}{l}\text { Mikroskop. } \\
\text { Befund }\end{array}$ & $\begin{array}{l}\text { Ausgangs. } \\
\text { punkt }\end{array}$ & Dauer & Pesultat \\
\hline $\begin{array}{l}\text { Rechts. } \\
\text { Lumbal. }\end{array}$ & $\begin{array}{l}\text { Cystische Geschwulst von } \\
\text { sehr fettreichem parietalen } \\
\text { Bauchfellblatt überzogen, } \\
\text { enthielt grosse Menge grïtz- } \\
\text { breiartiger Massen, darunter } \\
\text { Büschel fuchsrother Haare. }\end{array}$ & - & - & - & $\begin{array}{l}\text { Mit wenig } \\
\text { secernirender } \\
\text { Fistel ent- } \\
\text { lassen. }\end{array}$ \\
\hline $\begin{array}{l}\text { Links. } \\
\text { Lumbal. }\end{array}$ & $\begin{array}{l}\text { Ueber mannskopfgrosse } \\
\text { Dermoideyste mit talgigem } \\
\text { Inhalt, in ihrem grössten } \\
\text { Durchmesser von oben nach } \\
\text { unten gelagert, mit dem } \\
\text { Zwerchell, den Muskelu } \\
\text { und den Eingeweiden ver- } \\
\text { wachsen. Lendenwirbel } \\
5-7 \text {. cariös. Niere u. Milz } \\
\text { nach unten innen gedrängt. }\end{array}$ & - & $?$ & $?$ & $\dagger$ \\
\hline $\begin{array}{l}\text { Rechts. } \\
\text { Lumbal. }\end{array}$ & $\begin{array}{l}\text { Im Abdomen Tumor mit } \\
\text { glatter Oberfläche. Das aus- } \\
\text { gedehnte Colon bedeckte } \\
\text { den Tumor zun Theil rechts } \\
\text { oben, links unten lag Dünn- }\end{array}$ & - & $\begin{array}{l}\mathrm{R} \text {. undescen- } \\
\text { ded ovary. }\end{array}$ & $?$ & $\dagger$ \\
\hline & $\begin{array}{l}\text { darm. Ovaler } 61 / 2 \text { Zoll lang } \\
\text { rechte Tube zog senkrecht } \\
\text { das Fimbrienende verwachs } \\
\text { Tumor lag hinter dem Pe } \\
\text { ganen. In beträchtlicher A } \\
\text { dominalwand durch lockere } \\
\text { Gelbe, fettige, zu Butter ge } \\
\text { büschel an der Cystenwand }\end{array}$ & $\begin{array}{l}\text { Tumor } \mathrm{zw} \\
\text { f wärts zu d } \\
\text { war. Ute } \\
\text { woneum. Ke } \\
\text { dehnung } \mathrm{m} \\
\text { Gewebe bef } \\
\text { anende Flüs } \\
\text { aftend. Inn }\end{array}$ & $\begin{array}{l}\text { en Wirbelsäu } \\
\text { unteren Ende } \\
\text { linkes Oval } \\
\text { e Adhäsionen } \\
\text { einer Hinterf } \\
\text { gt. - Wand } \\
\text { eeit, mehrere } \\
\text { wand vollstän }\end{array}$ & $\begin{array}{l}\text { und rec } \\
\text { s Tumo } \\
\text { m, link } \\
\text { it den } \\
\text { ne an } \\
g \text { ausg } \\
\text { age, blo } \\
\text { entwic }\end{array}$ & $\begin{array}{l}\text { Niere. Die } \\
\text { mit welchem } \\
\text { Tube normal. } \\
\text { gebenden Or- } \\
\text { hinteren Ab- } \\
\text { hnt verkalkt. } \\
\text { e, feine Haar- } \\
\text { te Haut. }\end{array}$ \\
\hline
\end{tabular}




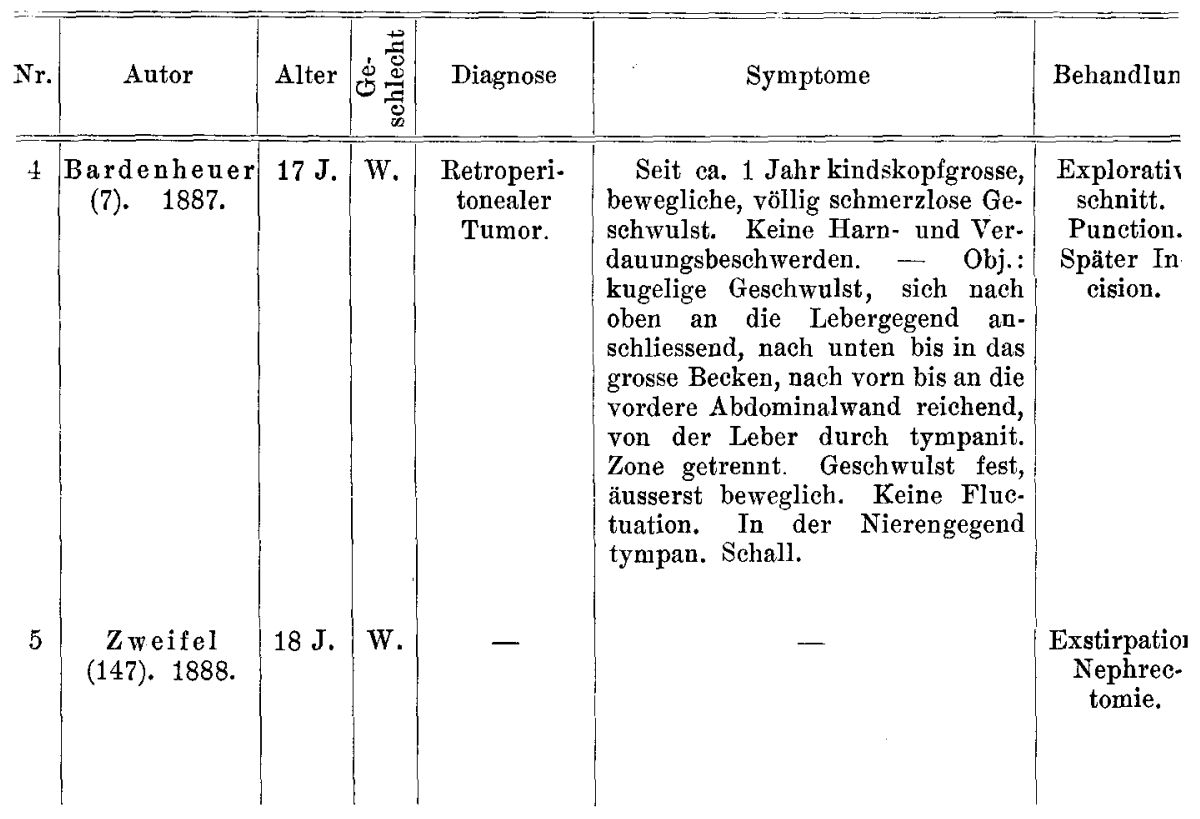

1 Howship | 2 J. | W. ? $\quad$ Stetig wachsender Tumor nahm die linke Ileolumbalgegend vom Rippenbogen bis zur Darmbeinschaufel ein. Die Geschwulst überschritt die Mittellinie des Bauches, hier von Därmen überlagert. Nach hinten konnte man sie bis zu der Lumbalmuskeln palpiren. 


\begin{tabular}{|c|c|c|c|c|c|}
\hline $\begin{array}{l}\text { Seite, } \\
\text { Lage }\end{array}$ & Befund & $\begin{array}{l}\text { Mikroskop. } \\
\text { Befund }\end{array}$ & $\begin{array}{c}\text { Ausgangs- } \\
\text { punkt }\end{array}$ & Dauer & Resultat \\
\hline $\begin{array}{l}\text { Rechts. } \\
\text { Lumbal. }\end{array}$ & $\begin{array}{l}\text { R. Niere schnitt mit dem } \\
\text { unteren Rand der Rippen } \\
\text { ab, Leber nicht vergrössert. } \\
\text { Geschwulst hart. Col. as- } \\
\text { cendens hinten aussen. Col. } \\
\text { transversum zog quer über } \\
\text { die Geschwulst hinweg. } \\
\text { Punction: breiige eitrige } \\
\text { Massen. Bei der Incision } \\
\text { Grütze, Haare, Zähne, rip- } \\
\text { penförmiger Knochen. Re- } \\
\text { troperitoneale Dermoidcyste } \\
\text { kranzförmigvorn Duodenum } \\
\text { umgeben mit dem Kopf des } \\
\text { Pankreas verwachsen. }\end{array}$ & $?$ & - & 1 Jahr & $\dagger$ \\
\hline $\begin{array}{l}\text { Links. } \\
\text { Lumbal. }\end{array}$ & $\begin{array}{l}\text { Grosser mit behaarter } \\
\text { Haut ausgekleideter Tumor } \\
\text { links vom Zwerchfell bis } \\
\text { zum Becken reichend, die } \\
\text { Niere unten mit dem Tu. } \\
\text { mor verwachsen. }\end{array}$ & - & $\begin{array}{c}\text { Oberhalb der } \\
\text { Niere. }\end{array}$ & - & Heilung. \\
\hline
\end{tabular}

\section{Teratome.}

Links. Linke Bauchhälfte von Inhalt:Schlein, Lumbal- dera Tumor ausgefüllt, Fettkrystalle iliacal. Dünndarmschlingen gröss- u. -Tröpfehen. tentheils nach rechts und Cholestearin. unten verdrängt, oben Zu- Zahlreiche Episammenhang mit dem Meso- thelien, rund, colon transversum. Colon oval oder transversum vor dem oberen cylindrisch. Rande der Geschwulst. FlimmerBlätter des Mesenterium epithelien. stark auseinander gedrängt. Auf dem Durchschnitt schwammiger Bau und Knoohen. Kleine Cysten, altes und junges Bindegewebe, Fettgewebe, Krorpe! Kuochen. In den Cysten Schleim.

Rechts. Därme links. Ganze rechte Bauchhälfte von Lumbal. einern Tumor eingenommen, der von der Leber bis zum Beckeneingang reicht. Hintere Fläche ruhte auf der rechten Niere. Alle Bauchorgane gesund. 2 engl. Pf. gelappt, kindskopfgross. An der Oberfläche Cysten, einzelne mit hautähnlicher Auskleidung und Epidermisbrei, andere mit Schleim und Flimmer- oder Cylinderepithel. \& Zoll langes Darmstïck. Der solide Theil enthielt im Fettgewebe: Knochen mit Markräumen, hyalinen Knorpel, Gbröse Züge, gestreifte Muskelfasern und Nervengewebe.

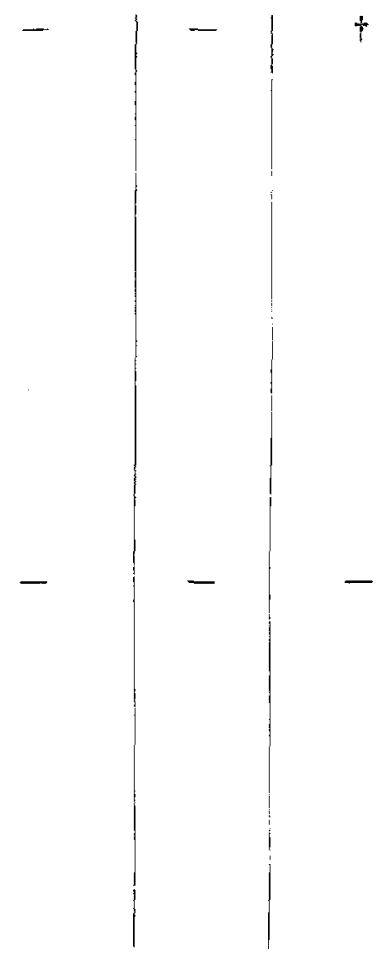




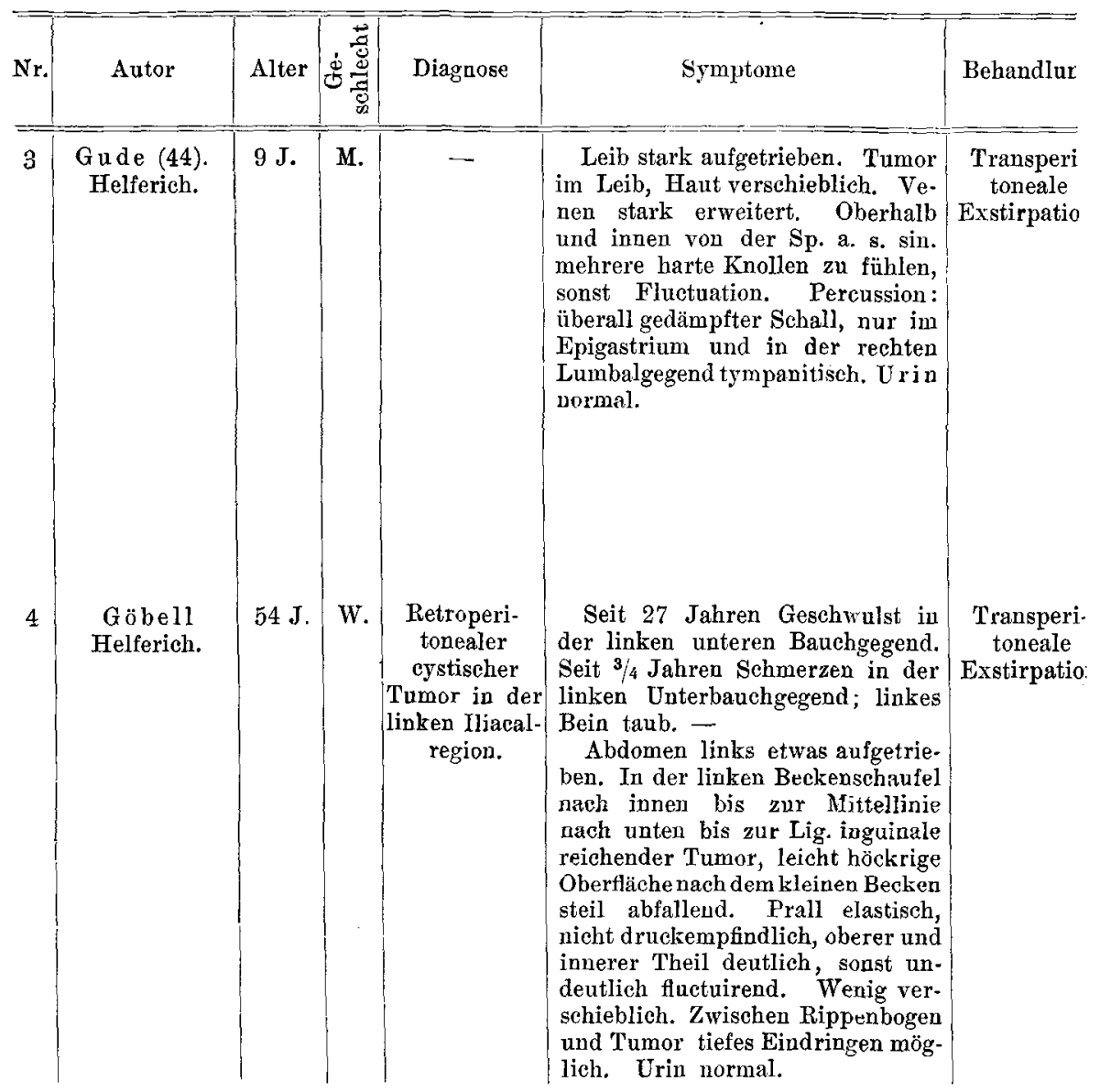

TABElle XVII

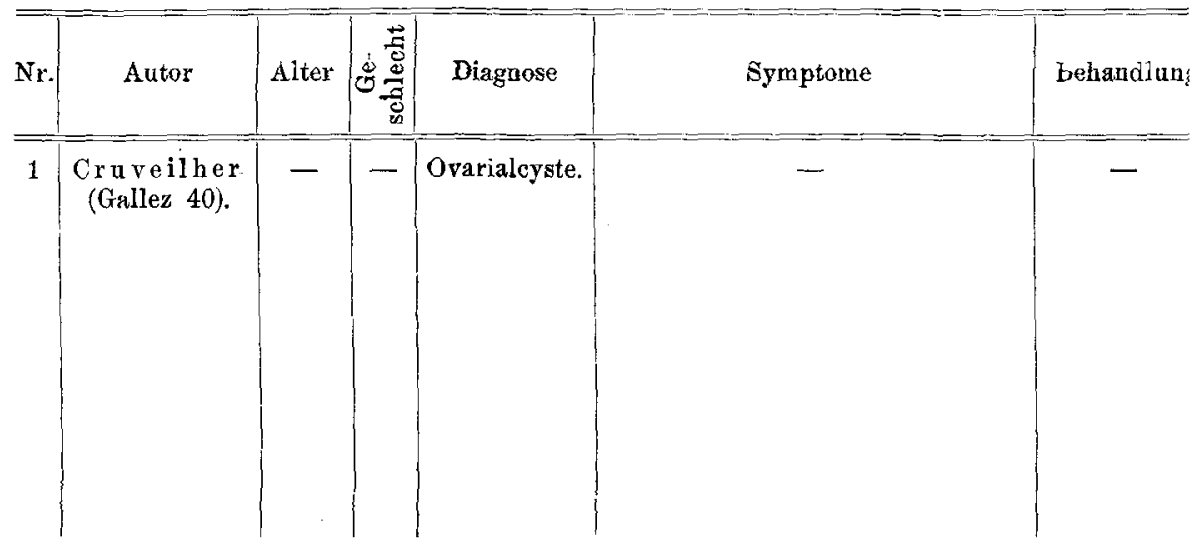




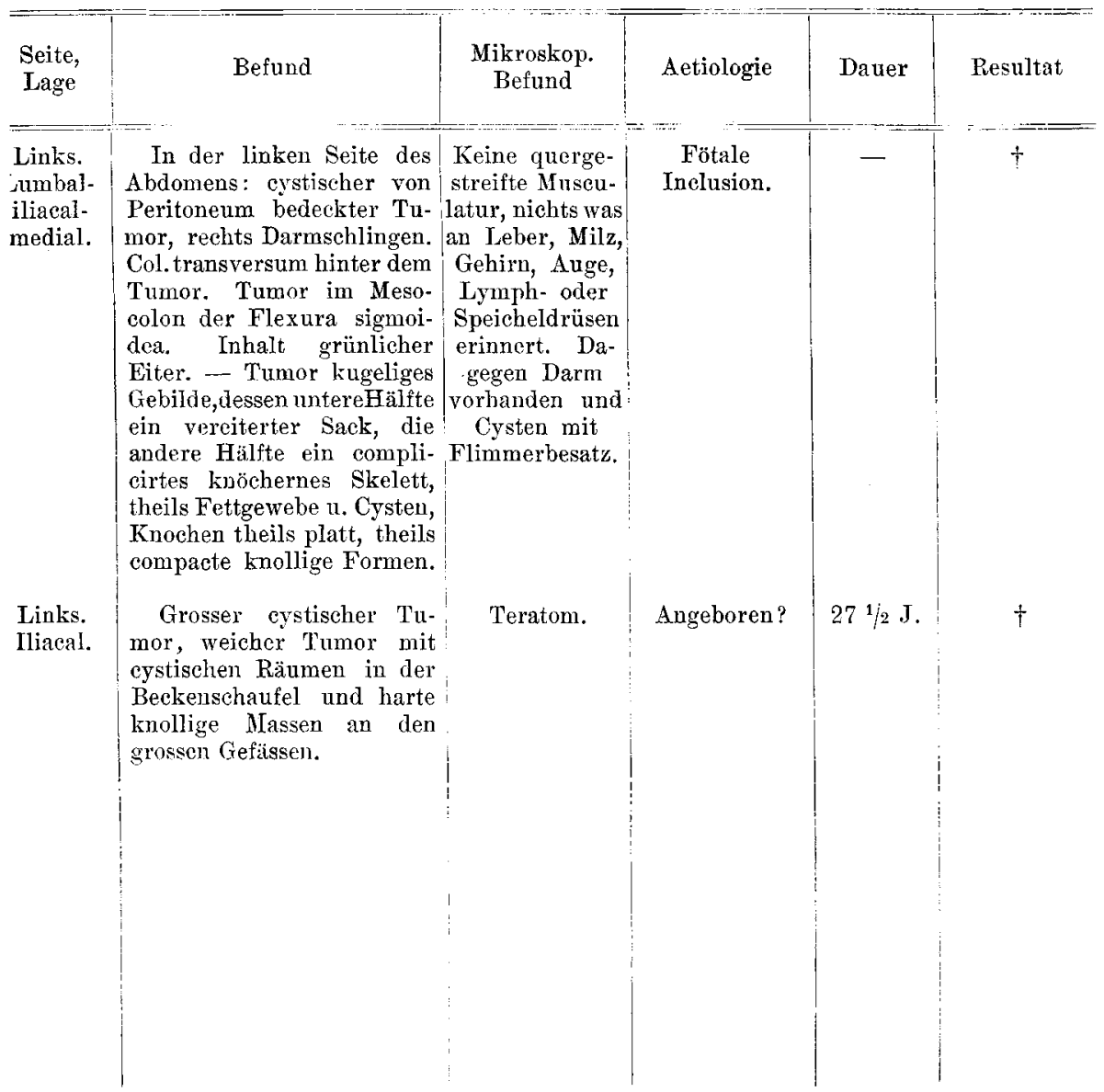

Seröse Cysten.

\begin{tabular}{|c|c|c|c|c|c|}
\hline $\begin{array}{l}\text { Seite, } \\
\text { Lage }\end{array}$ & Befund & $\begin{array}{l}\text { Mikroskop. } \\
\text { Befund }\end{array}$ & $\begin{array}{c}\text { Ausgangs- } \\
\text { punkt }\end{array}$ & Dauer & Resultat \\
\hline $\begin{array}{l}\text { Links. } \\
\text { Lumbal- } \\
\text { iliacal. }\end{array}$ & $\begin{array}{l}\text { In der linken Lumbal- } \\
\text { und Iliacalgegend eine grosse } \\
\text { Cyste, deren Axe von oben } \\
\text { links nach rechts unten } \\
\text { verlief, ohne Zusammen- } \\
\text { hang mit den Genitalien, } \\
\text { mit dem Col. desc. u. Flex. } \\
\text { sigmoid. verbunden, unter } \\
\text { dem Mesocolon. Cystenwand } \\
\text { fibro-serös. } \\
\text { Inhalt: klare seröse Flüs. } \\
\text { sigkeit. }\end{array}$ & - & $?$ & - & - \\
\hline
\end{tabular}




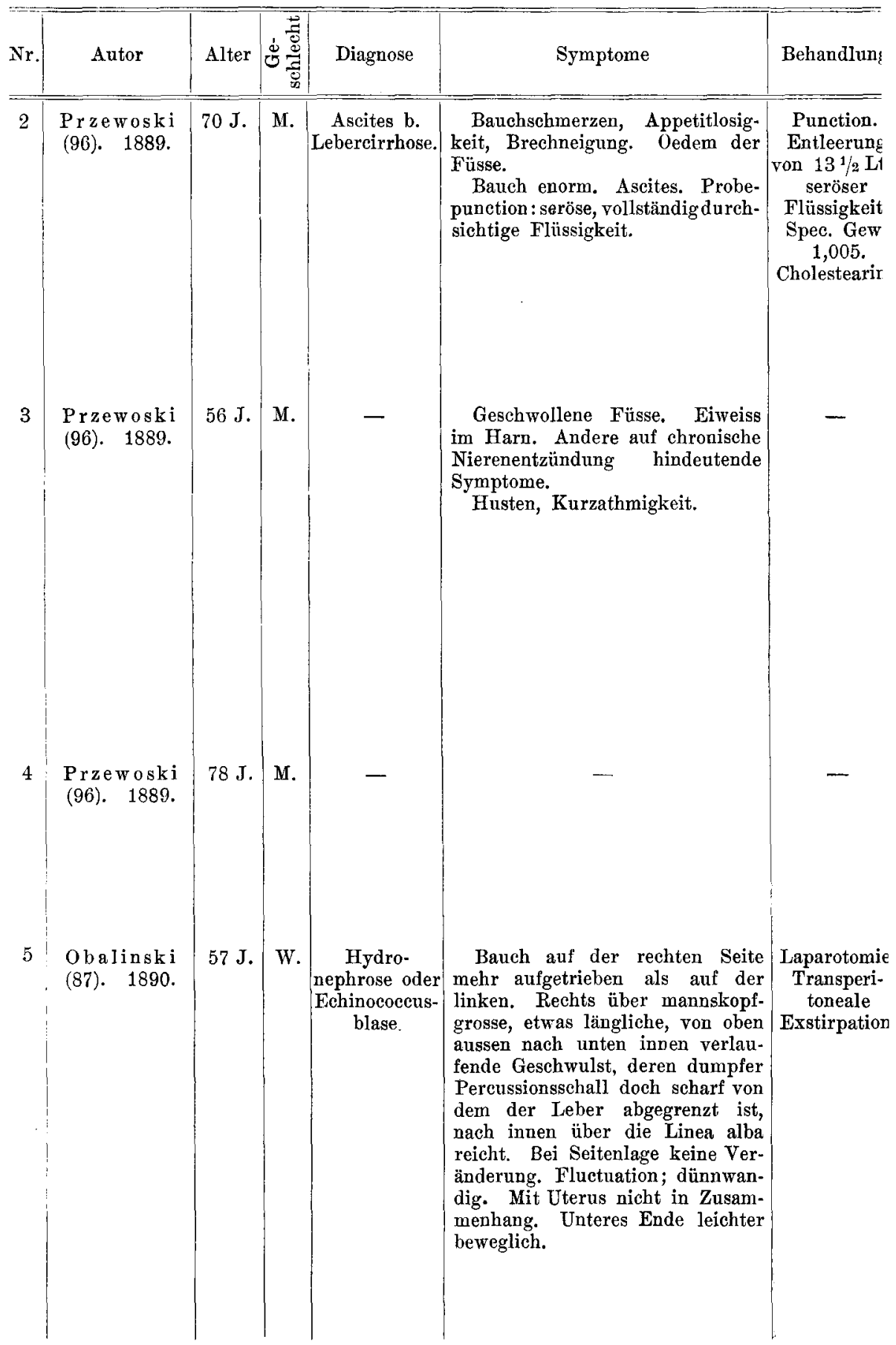




\begin{tabular}{|c|c|c|c|c|}
\hline $\begin{array}{l}\text { Seite, } \\
\text { Lage }\end{array}$ & $\begin{array}{l}\text { Mikroskop. } \\
\text { Befund }\end{array}$ & $\begin{array}{c}\text { Ausgangs- } \\
\text { punkt }\end{array}$ & Dauer & Resultat \\
\hline $\begin{array}{l}\text { Rechts. } \\
\text { sumbal. }\end{array}$ & 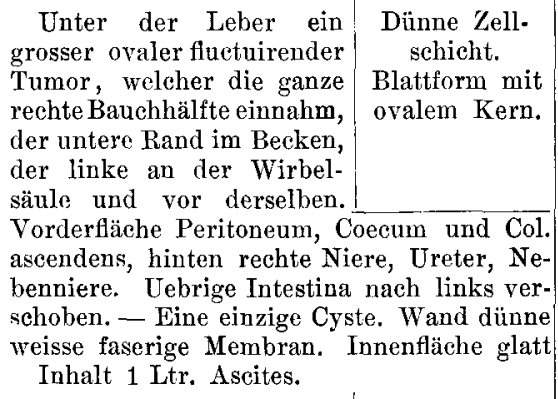 & $?$ & $3 \mathrm{~J}$ & + \\
\hline $\begin{array}{l}\text { Links. } \\
\text { umbal. }\end{array}$ & $\begin{array}{l}\text { Vor der unteren Hälfte } \\
\text { der linken Niere eine } \\
\text { kugelige deutlich fluctui- } \\
\text { rendeGeschwulstkindskopf- } \\
\text { gross, mit ihrem vorderen } \\
\text { Theil bis zwischen die } \\
\text { Blätter des Mesocolon des- } \\
\text { cendens reichend. Col. des- } \\
\text { cendens vorn von oben nach unten verlau- } \\
\text { fend. Mit der übrigen Nachbarschaft durch } \\
\text { lockeres Bindegewebe verbunden. Einkam- } \\
\text { merige Cyste, 0,5 mm dicke feste weissliche } \\
\text { faserige Membran mit glatter glänzender In- } \\
\text { nentläche. } \\
\text { Inhalt: seröse Flüssigkeit spec. Gew. 1,001, } \\
\text { kein Cholesteariu. }\end{array}$ & $?$ & $?$ & $\dagger$ \\
\hline $\begin{array}{l}\text { Links. } \\
\text { Lumbal. }\end{array}$ & $\begin{array}{l}\text { Unter dem Endstück des } \\
\text { Col. descendens und vor } \\
\text { der linken Niereein hühner- } \\
\text { eigrosser allseitig scharf } \\
\text { begrenzter und mit der Um- } \\
\text { gebung dureh Bindegewebe } \\
\text { verbundener Tumor, voll- } \\
\text { kommen analog dem obigen. }\end{array}$ & $\ldots$ & - & + \\
\hline $\begin{array}{l}\text { Rechts. } \\
\text { Lumbal. }\end{array}$ & \begin{tabular}{l|c} 
Mannskopfgrosser läng- & Wand gewöhnl. \\
licher Tumor mit dünner & Bindegewebe \\
durchscheinender und stark & und elastische \\
Gewebe. \\
ausgespannter Wand vom \\
hinteren Peritoneum be- \\
deckt, Peritoneum geht vom \\
Tumor nach innen auf das \\
Mesenterium und den Darm, \\
nach aussen auf die seitliche \\
Banchwand über. \\
Inhalt 3 Ltr. völlig durch- \\
sichtige wasserklare Flüssig- \\
keit. Keine Nierengefässe, - \\
kein Ureter gefunden. R. Niere nieht gefühlt. \\
Inhait: 0,12 $\%$ Albumen. Spuren Erd- \\
phosphate, ziemlich viele Chloride. Harn- \\
stoff und Harnsäure nicht unmittelbar nach- \\
zuweisen.
\end{tabular} & $?$ & $?$ & Heilung. \\
\hline
\end{tabular}




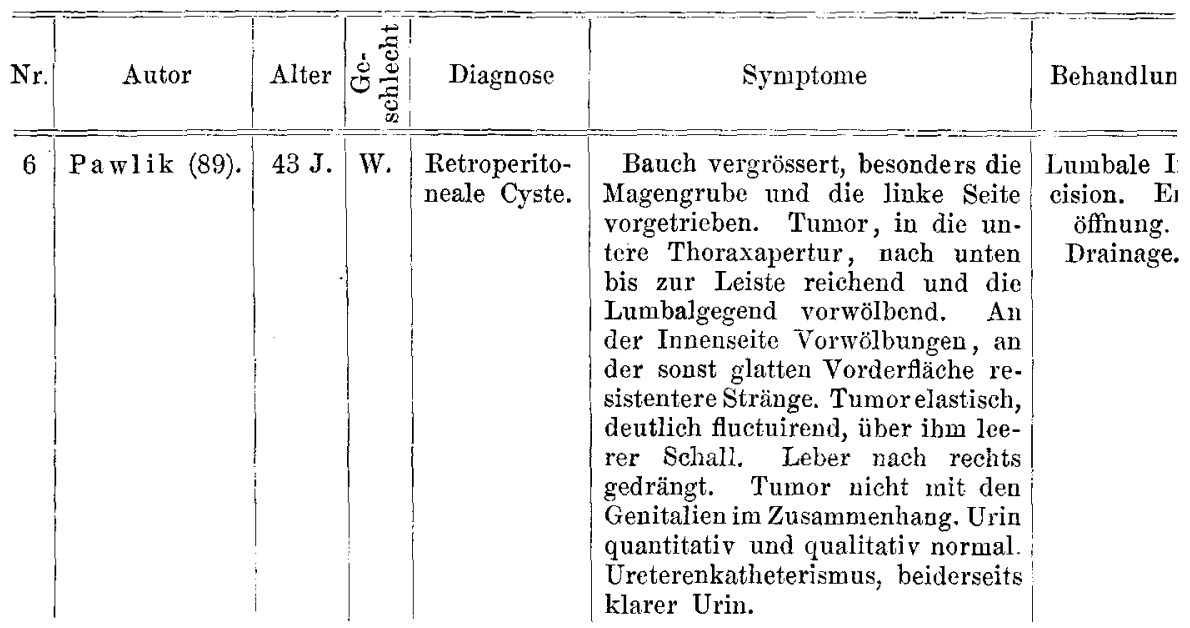

TABELLE XI2

1 Frank (37). $\mid$ 31 J. $\mid$ W. Rechtsseitiges $\mid$ Unterleib rechts unten rorge1895.

Narath (83). 1895 .
Ovarialkystom. tastbar. Mannskopfgrösse, nach innen bis neale Exsti an die Mittellinie, nach aussen bis an die $\mathrm{r}$. Achsellinie, obere $\mathrm{K}$ uppe bis 3 Querfinger breit unterhalb des Rippenbogens, untere Kuppe bis über den Beckeneingang reichend. Tumor kugelig, weich elastisch, fluctuirend, an der vorderen Fläche Stränge und Schneeballreiben, wenig beweglich, druckempfindlich. Nach rechts hinten tympanitischer Schall. Uterus nach allen Richtungen frei beweglich, rechte Adnexe nicht, linke Adnexe

Uebermannskopfgrosse Gesehwulst in der linken Bauchhälfte, elastisch fluctuirend, unverschieblich der hinteren Bauchwand aufsitzend. Schall über dem Tumor leer. Colon descendens $u$. transversum nach vorn $u$. unten verlagert. Urin, Eiweiss u. Zucker. pation.

Nierenschrä schnitt.

Einstellung. 


\begin{tabular}{|c|c|c|c|c|c|}
\hline $\begin{array}{l}\text { Seite, } \\
\text { Lage }\end{array}$ & Befund & $\begin{array}{c}\text { Mikroskop. } \\
\text { Befund }\end{array}$ & $\begin{array}{c}\text { Ausgangs- } \\
\text { punkt }\end{array}$ & Dauer & Resultat \\
\hline $\begin{array}{l}\text { Links. } \\
\text { Lumbal- } \\
\text { iliacal. }\end{array}$ & $\begin{array}{l}\text { Bläulich durchschim- } \\
\text { mernder Sack, } 4400 \text { ccm } \\
\text { klarer, nicht sedimentiren- } \\
\text { der Flüssigkeit mit leicht } \\
\text { gelbem Stich. Innen und } \\
\text { vorn normale linke Niere. } \\
\text { Keine Communication mit } \\
\text { der Niere. Wand sehr } \\
\text { dünn. Innenfläche glatt, } \\
\text { weiss. Keine Häkchen und } \\
\text { Scolices. }\end{array}$ & - & $?$ & 2 Jahre. & Heilung. \\
\hline
\end{tabular}

\section{Thyluscysten.}

Rechts. Tumor von adhärentem Wand bestand Lymphsystem. 8 Tage. Iliacal. Netz bedeckt. Kein Stiel. aus zieml, kernAdnexe normal, frei be-reichem, mässig weglich. Tumor reichte $v$. stark vasculariPeritoneum bedeckt bis an sirten faseridie Radix mesenterii, nach gen Bindegerechts z. Th. bis unter das webe. Nirgends Coecum u. Colon ascendens. Epithel. InTumor auslösbar.

Inhalt: viscide Flüssigkeit. Rechte Niere normal gelagert und normal gross. Wand der Cyste $2-3 \mathrm{~mm}$ dick. Innenfläche glatt. Chyluscyste.

\section{Links. Einkammerige Cyste}

Lumbal. unterhalb der Nierengefässe zwischen Ureter und Vena spermatica entstanden. An der Innenfläche der $1 \mathrm{~mm}$ dicken fibrösen Wand, einzelue leistenartige Vorsprünge und walzenartige Rauhigkeiten. Inhalt: Chylusartige Flüssigkeit, enthielt viel Eiweiss, Fett in Emulsion, Fibrin u. Lymphzellen. 4 Liter Flüssigkeit. Sack reicht vor der Wirbelsïule nach rechts, nach abwärts bis zur Darmbeinschaufel. Niere hoch oben am Zwerchfell mit schräger Längsachse. Innenfläche glatt. halt: Cholestea-

rincrystalle.

Fetttröpfchen und spärliche

Leukocyten.

Heilung.

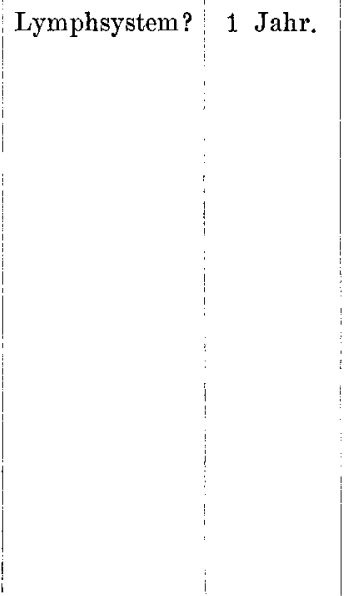

$t$

Sepsis. 


\begin{tabular}{|c|c|c|c|c|c|c|}
\hline Nr. & Autor & Alter & 焉 & Diagnose & Symptome & Behandlun \\
\hline 3 & $\begin{array}{c}\text { G. Killian } \\
(157) . \quad 1886 .\end{array}$ & $61 \mathrm{~J}$. & W. & Chyluscyste. & $\begin{array}{l}\text { Seit } 4 \text { Wochen Schwellung des } \\
\text { Leibes, Magenschmerzen, Erbre- } \\
\text { chen, Durchfall, Rückenweh. } \\
\text { Bauch: rechts von der Mittel- } \\
\text { linie und nach der Hüftgegend } \\
\text { zu stark vorgewölbt, Kuppe in } \\
\text { Nabelhöhle etwas nach rechts. } \\
\text { Glatter, runder, weich elastischer, } \\
\text { fluctuirender Tumor in der rechten } \\
\text { Oberbauchgegend, überragt die } \\
\text { Linea alba nach links um } 3-4 \mathrm{~cm} \text {, } \\
\text { hier wurstförnige quere } 10 \mathrm{~cm} \\
\text { lange, glatte, harte Masse, welche } \\
\text { auf den Tumor übergeht, mit } \\
\text { demselben versehieblich. Magen } \\
\text { links oben. Von rechts unten nach } \\
\text { links oben Darm. Leberdämpfung } \\
\text { geht auf die des Tumors über. } \\
\text { Kein Zusammenhang mit den Ge- } \\
\text { nitalorganen. }\end{array}$ & $\begin{array}{l}\text { Punction. } \\
2500 \mathrm{~cm} \text { Fli } \\
\text { sigkeit, wei } \\
\text { graue Milc } \\
\text { alkalisch, } \\
\text { stark eiwei } \\
\text { u. fetthalti } \\
\text { Keine Zell } \\
\text { Nach } 1 \text { Mor } \\
2 \text {. Punctio } \\
2200 \text { ccm cl } \\
\text { coladefarbi } \\
\text { ger, sonst } \\
\text { gleicher Fli } \\
\text { sigkeit. Na } \\
1 \text { Mionat Ol } \\
\text { ration, Lal } \\
\text { rotomie. Ei } \\
\text { stellung. I } \\
\text { offnung. At } \\
\text { spülung m } \\
\text { 3proc. Carb } \\
\text { lösung. Dr } \\
\text { nage. }\end{array}$ \\
\hline
\end{tabular}

Tabelale $\mathrm{X}$.

1

Schönwerth (110). 1895.

2

Petit u. Pophillat (91). 1898. Lockwood
$(68) . \quad 1898$.
$30 \mathrm{~J} . \mid \mathrm{W}$.

Retroperito-

nealer Tumor.

$20 \mathrm{~J}$.
(1)

M.

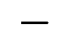

Nicht sicher, Art Nierentumor.
Kindskopfgrosse Geschwulst in Probelapar der linken Bauchgegend, fest, ab- tomie, spät grenzbar, sehr wenig beweglich. lumbale E Darm(Colon) vor dem Tumor. stirpation

Urämischer Patient.

Strausseneigrosse, schmerzlose, Laparotomi freibewegliche, fluctuirende $\mathrm{Ge}-$ schwulst, aussen ron Colon begrenzt. 
Zur Kenntniss der lateral-retroperitonealen Tumoren.

\begin{tabular}{|c|c|c|c|c|c|}
\hline $\begin{array}{l}\text { Seite, } \\
\text { Lage }\end{array}$ & Befund & $\begin{array}{c}\text { Mikroskop. } \\
\text { Befund }\end{array}$ & $\begin{array}{c}\text { Ausgangs- } \\
\text { punkt }\end{array}$ & Dauer & Resultat \\
\hline $\begin{array}{l}\text { Rechts. } \\
\text { Lumbal. }\end{array}$ & $\begin{array}{l}\text { Cyste retroperitoneal. } \\
\text { Wand } 1 \mathrm{~mm} \text { dick; glatte, } \\
\text { glänzende, rein seröse Innen- } \\
\text { fläche. Ijinks Wirbelsäule, } \\
\text { Psoas, Aorta, unten Darm- } \\
\text { beingrube, oben Leber, vorn } \\
\text { normale Niere, also retro- } \\
\text { renal. }\end{array}$ & $?$ & $\begin{array}{c}\text { Wahrscheinl. } \\
\text { Ductus thora- } \\
\text { cicus? }\end{array}$ & 4 Wochen. & Heilung. \\
\hline
\end{tabular}

\section{Blutcysten.}

Links. Grosse Höhle innerhalb Iliacal. des Ileopsoas. Trübe, gelbe, dickliche Flüssigkeit.

Cystische Geschwulst hinter dem Coecum faustgross von Adhärenzen umgeben. Wand aus Bindegewebe bestehend, Fibrin und Blut enthaltend.

Links. Iliacal.
Cyste aussen rom Colon descendens, oben vom Colon transversum, innen vom Jejunum begrenzt, mit 1/s Zoll dicker aus Bindegewebe $u$. Blutgefässen bestehender Wand, hinter dem Peritoneum frei beweglich gelegen. Kein Zusammenhang mit der Niere, Pankreas oder Dünndarm, Inhalt: Blutcoagula.
Massenhafte Fettzellen und Cholestearintafeln.

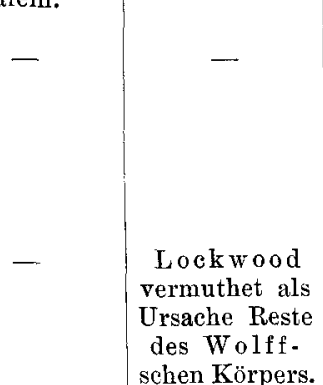

Hämatom.
$11 / 2$ J. Heilung.

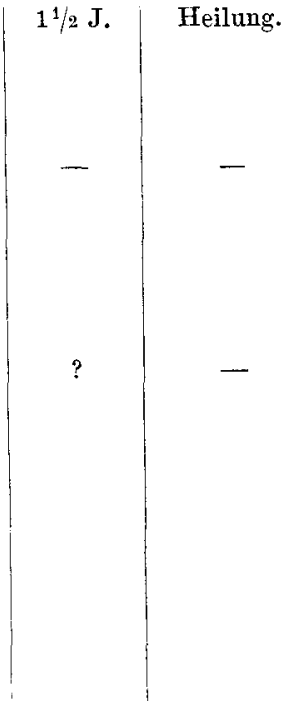




\section{Litteraturverzeichniss.}

1) J. Albarran, Néoplasmes primitifs du bassinet et de l'urétère. Ann. des malad. des org. gén. urin. 1900. No. 7. 9. 11.

2) A. Alsberg, Exstirpation eines grossen retroperitonealen Lipoms und Resection eines $18 \mathrm{~cm}$ langen Stückes des Dickdarms. Darmnaht. Heilung. Deutsche med. Wochenschrift. 1887. S. 994.

3) Derselbe, Zur Dystopie der Nieren. Festschr. zur Feier des 80 jährigen Stiftungsfestes des ärztlichen Vereins zu Hamburg. Leipzig 1896.

4) William Anders on, The Surgery of the subperitoneal Tissue. The Lancet. 1896. August 15.

5) J. Arnstein, Ueber einen Fall von primärem retroperitonealen Sarkom. Diss. Berlin 1883.

6) v. Bardeleben, Bericht über die chirurgische Klinik des Prof. Dr. Bardeleben pro 1881. Charité-Annalen. VIII. S. 462.

7) B. Bardenheuer, Der extraperitoneale Explorativschnitt. Stuttgart 1887.

8) Beaud oux, Perichondrome volumineux développé sur l'os iliacque etc. Presse méd. XXXVI. 27.1884.

9) C. A. Bergh, Kasuistik aus dem Lazareth in Gefle. Hygieia 1897. p. 550.

10) E. v. Bergmann, Exstirpation eines Becken-Enchondroms mit Unterbindung der Art. und V. iliaca communis. Heilung. Deutsche med. Wochenschr. 1885. Nr. 42.

11) Beveridge, R., Case of large fibrous tumour of the abdomen. Med. Times and Gaz. 1870. June 4.

12) Billroth, Chirurgische Klinik. Wien 1871-1876.

13) Brentano, Leber Mesenterialcysten. Berliner klin. Wochenschr. 1895. Nr. 18.

14) Brock, G., Eine Geschwulst der Nierengegend mit quergestreiften Muskelfasern. Virch. Arch. Bd. CXL. S. 493.

15) von Brunn, Ueber drüsenähnliche Bildungen in der Schleimhaut des Nierenbeckens, des Ureters und der Harnblase beim Menschen. Archiv f. Mikroskop. Anatomie XLI. 2. p. 294. 1893.

16) Brunzel, R., Exstirpation der linken Niere wegen eines kolossalen $37^{1 / 4} \mathrm{Pf}$. schweren Fibroms der Nierenkapsel. Berliner klin. Wochenschr. 1882. S. 745 .

17) Baron Buschmann, Exstirpation eines sehr grossen retroperitonealen Fibroms. und der damit verwachsenen im Becken gelegenen linken Niere. Wiener med. Wochensehr. 1880. Nr. 28.

18) Campbell, Succesful removal of a cystic abdominal tumour from a child aged seven months. British medical journal 1897. May 15.

19) Casarini, Ectasia sacciforme dell' uretera simulante una idronefrosi. Ref. Centralblatt f. innere Medicin. 1895. No. 18.

20) Chadwick, J. R., Exstirpation of a retrorenal sarcoma by abdominal section. Boston medical and surgery Journal. 1884. Oct. 13.

21) Chiari, H., Zur Kenntnis der accessorischen Nebennieren des Menschen. Zeitschr. f. Heilkunde, Bd. V. S. 449.

22) Chvostek, Ein Fall von medullärem retroperitonealen Carcinom. Oesterr. Zeitschr. f. prakt. Heilk. XII. 41, 42. Oct. 1866.

23) Choussat, Tumeurs solides du tissu conectif rétropéritonéal. Thèse de Montpellier 1898.

24) Harrison Cripps and H. Williamson, The British Medical Journal. 1899. Vol. II. S. 10.

25) Czerny, Zur Exstirpation retroperitonealer Geschwülste. Archiv f. klin. Chirurgie. Bd. XXV. S. 865.

26) Dagonet, J., Beiträge zur pathol. Anatomie der Nebenniere des Menschen. Zeitschr. f. Heilkunde. Bd. VI. S. 1.

27) Dalziel, A large retroperitoneal lipoma from a child. Edinbourgh Journal. 1898. Oct.

28) Dandridge, N. P., Report on a case, in which a myxolipoma weighing eighty pounds. was removed from the abdominal wall. The medical Record. 1883 . XXXIII.

29) Descazals et Milhiet, Tumenr liquide rétropéritonéale. Bull. de la soc. anatom. de Paris 1898. No. 14. 
30) Dom ke, Leber einen Fall von Exstirpation cines inneren Beckenenchondroms mit particller: Resection rles Darmbeins. I.angenbeck's Archiv. Bd. L. S. 177 .

31) Dorn, H., Leber einen Fall von Fibrosarcoma ossis ilei mit Resection des Iarmbeins. Inang.-Diss. Würzburg 1894.

32) I uplay, Rétropéritoneal carcinom. Archiv général. XXIV. 1874.

33) Ebstein, W., Osteom des linken Hüftheins und des M. psoas. Archiv f. pathol. Anat. und Physiol. Bd. L.I. Heft 3.

34) Elliot, F., Sareomatous Growth in the Abdomen involving the right Kidney. The Lancet. 1879. II. p. $42 \%$.

35) Ellis, E., On a case of carcinoma in the collular tissue surrounding the left Kindney in a child seven years of age. The Lancet. 1866. Jan. 20.

36) J. Cooper Forster, Fibrolipom des Abdomen. Transactions of the Pathological socicty. London. Vol. XIX, p. 246.

37) Frank, Eduard, Beitrag zur Kenntriss der retroperitonealen cystisehen 'Tumoren. Wiener klin. Wochenschr. 1894. S. 649.

38) Freyer, Otto, Zur Kenntniss der von versprengten Keimen der Nebenniere ausgehenden Abdominalgeschwïlste. Inaug.-Diss. 1900. Kiel.

39) Gaillard, Thomas, Medical News. 1882. Jan. 7.

4i1) Gallez, Jiagnostic des tumeurs du ventre. 1890. p. 339.

41) Gatti, Ueber die von abgesprengten Nebennierenkeimen ausgehenden Nierengeschwülste. Virch. Arch. Bd. CXLIV. Fleft 3.

42) Gerster, Retroperitoneal fibrolipoma. Annals of surgery. May 1895.

48) Gould, Case of Yerirenal myxoma. Retroperitoneal abdominal Nephrectomy. Recovery. Remarks. The Lancet. 1888. II. p. 518.

44) W. G u d e, Ueber ein retroperitoneales 'Teratom. Inaug.-Diss. Greifswald 1898.

45) W. Heineke, Entzïndungen, Anschwellumgen und Geschwülste des Unterleibs. Handbuch der allgem. und spec. Chirurgie. Bd. III. Abth. II. 1582.

46) C. Helbing, Veber seltene extraperitoneal gelegene eystische Bauchtumoren. Dentsche med. Wochenseltr. 1901. Ni.15.

4i) Henoch, Beitrïge zur Kinderhcilkunde. 1868.

45) C. Hey der, Beiträge zur Chirurgie der weiblichen IIarnorgane. I. Geschwülste der Nierenkapsel. Arch. f. Gynäkol. 1890. Bd. XXXVIII. S. 301.

49) Heymann und Fiedler, Ein Fall von Netzhautgliom mit zahlreichen Netastasen. Archiv f. Ophthalmologic Bd. XIl. Abth. II. S. 173.

5i) Homans, A case of succesful removal of a retroperitoneal fatty tumour. Americ. Journal 1891. Avili.

51) Derselbe, 'Two cases of removal of immense fatty tumours by abdominal section. Buston med. Jonrnal 1883.

52) Hulke, A series of renal cases with Remarks. The Lancet. 1887. II. S. 1065.

53) Hertwig, O., Lehrbuch der Entwicklungsgeschichte des Menschen und der Wirbelthiere. Jena 1888.

54) Jenner,W., Case of abdominal Enchondroma. Brit. med. Joumal. 1870. Jan. 1.

55) Joubert, H., Fibrous tumours of the Pelvis simulating ovarian tamours. Brit. gynace. Joumal. 1890. November.

56) Kapusei 1 k i, B., Retroperitoneal-Sarkome. Inaug.-Diss. Berlin 1873.

5) Kaufmann, Ė̀., Beitrag zu den retroperitonealen Gesehwülsten im Becken. C.-Bl. f. Gunäkol. 1898. ㅍ. 8.

58) Kelseli und"Wannebroce, Le progrès médical. 1881.

$59)$ Keresztzegl y, Ueber retroperitonealc Sarkome. Beiträge zur pathol. Anat. und Pathol. Bd. XII.

b0) Kidd, A., Removal of a large tumour, Med. press. and circular. 1877. July 4.

(61) Kölıler, Bericht ïber die chir. Klinik des Geheimrath Bardeleben pro 1655 und 1587. Charité-Amnalen. XII. und XIV. Jahrgang.

62) Krukeuberg, Archiv f. Gynäkol. XXX.

63) Kümmell, Demonstration einel grossen l'ettgeschwulst. Deutsche merl. Wochenschr. 1856. S. 903 .

(64) Kun ll rat, citirt b. Salzer.

65) Latte, Ceber ein primär im retroperitonealon Ramme entstandenes Adenomyoma myxosarcomatodes. Inaug.-Diss. Erlangen 1897. 
66) Lexer, E., Ueber teratoide Geschwülste in der Bauchhöhle und deren Operation. Archiv f. klin. Chir. Bd. LXI. S. 648.

67) Lobstein, Lehrbuch der pathologischen Anatomie. Bd. I, II, Stuttgart 183 j.

68) Lockwood, C. B., The diagnosis of retroperitoneal Sarcoma, with cases. The Lancet. 1895 . p. 1300.

69) Derselbe, Retroperitoneal Cyst. Pathological Society of London. The Lancet. 1898. March 5.

70) Lossen, Exstirpation der sarkomatösen rechten Niere (Angiosarkom) bei einer Gravida im 3. Monate. Heilung. Deutsche Zeitschr. f. Chirurgie. Bd. XIII. S. 199.

71) Lubarsch, Ueber Cysten der ableitenden Harnwege. Arch. f. mikroskop. Anatomie. XLI, 2 S. 303. 1893.

72) Derselb e, Beiträge zur Histologie der von Nebennierenkeimen ausgehenden Nierengeschwülste. Virch. Arch. Bd. CXXXV. Heft 2.

73) Madelung, Exstirpation eines vom Mesenterium ausgehenden Lipoma oedematosum myxomatodes mit partieller Resection des Dünndarms. Berliner klin. Wochenschr. 1881. Nr. 6.

74) Maininger, Fin Fall von retroperitonealem Fibromyom. Allgem. Wiener med. Zeitung. 1898. Nr. 34 .

75) Marchand, Ueber accessorische Nebennieren im Lig. lat. Virch.'s Archiv. Bd. XCII. S. 11.

76) Mars. Ungemein umfangreiches Fibroma retroperitoneale. Przeglad lekarski. 1876. 25.

7i) Möricke, Casuistische Mittheilungen. Zeitschr. f. Geb. und Gyn. Bd. VII.

78) Jos. Mayer, Dermoidcyste des Mesenterium. Wiener klin. Wochenschr. Bd. XI. 1898. Nr. 47.

79) Ivan Michael, Zum Vorkommen der accessorisehen Nebennieren. Arch. f. klin. Med. Bd. XLIII. S. 120.

80) Monnier,L., Sarcome rétropéritoneal inopérable du mésocolon simulant une tumeur du foie. - Mort - Autopsie. Bulletin de la Soc. anatomique de Paris. 1897.

81) Monti, Jahrb. f. Kinderheilkunde. 1863.

82 ) H. H. Mudd, (Weekly Medical Review. St. Loms). 1859. July 6.

83) Narath, Ueber retroperitoneale Lympheysten. Arch. f. klin. Chir. Bd. I. S. 763.

84) Nicolaysen, Mesenterialsarkom. Centralbl. f. Gynäkologie. Bd. VIII.

85) Neumann, Ein Fall von Retroperitonealabscess mit amyloider Degeneration der Unterleibsorgane und secundärer Sarkombildung in den Abscesswänden und dem Peritoneum. Arch. f. Heilkunde. Bd. X. S. 221.

86) W. v. Noorden, Zur Operation der grossen Chondrome des Rumpfes. Deutsche med. Wochenschr. 1896. Nr. 15, 16.

87) Obalinsky, Ueber seröse retroperitoneale Cysten. Wiener klin. Wochenschr. 1891. IV. 39.

88) Ogston, The Lancet. 1896. August.

89) $\mathrm{Pa}$ a lik, K., Casuistischer Beitrag zur Diagnose und Therapie der Geschwälste der Nierengegend. Langenbeck's Archiv. Bd. LIII. S. 571 .

90) Pellegrini, L., Un caso die carcinoma delle glandule retro-peritoneali. Riforma medica. 1893. Marzo 1.

91) Petit und Pophillat, Kyste rétrocoecal. Bulletins de la Société anatomique de Paris. 1898. No. 8.

92) Pf annenstiel, Ueber Myome des Dickdarms. Centralbl. f. Gyn. 1897.

93) Derselbe, Ueber die Histogenese der Dermoidcysten und Teratome des Eierstocks. Centralbl. f. Gyn. 1897.

94) Philipson, Primary Sarcoma of the Retroperitoneal Glands. The Lancet. 1885. May.

95) Pilliet et Veau, Sarcome rétropéritonéal. Bulletins de la Socićté anatomique de Paris. 1896. 5. Serie. Bd. X. p. 719.

96) Przewoski, Gazeta lekarska 1889. Bd. IX. No. 41. p. 820.

97) De Quervain, Zur Differentialdiagnose der Bauchgeschwiilste. D. Z. f. Chirurgie. Bd. XLIX. S. 67.1898.

98) Rans oh off, J., Retroperitoneal cystosarcoma. The Medical News. Bd. XLIII. p. 575 . 
99) Edes Robert, Morbid. Growth of the semilunar ganglia of the sympathic. Amer. Journ. of med. sciences. 1871. Jan.

100) Mayo Robson, Three cases of removal of the suprarenal capsula. 67. Congress der British medical association. 1900. August.

101) Rogowski, Ueber primäre retroperitoneale Sarkome. Inaug.-Diss. Freiburg. 1899.

102) Rolleston and Mark, Primary malignant disease of the suprarrnal bodies. Amer. Journ. of med. Sciences. 189S. Oct.

103) Rosmanit, siehe b. Salzer.

104) $\mathrm{R}$ uge, E., Inaug.-Diss. Greifswald. 1892.

105) Salzer, F., Myxoma lipomatodes capsulac adiposae renis. Wiener klin. Wochenschr. 1888. p. 199.

106) Van Santroord, Case of Dermoid eyst of an undescended ovary. Medical Progress. 1882. Jan. 21.

107) Sarwey, Fin Fall von retroperitoncaler Chyluscyste b. e. 11 jälırigen Mädchen. Exstirpation. Heilung Centralbl. f. Gyn. 1898. Nr 16.

108) Saurenhaus, Centralbl. f. Geburtshülfe und Gynäkologie. Bd. XIX. S. 300.

109) Schmorl, Zur Kenntniss der access. Nebennieren. Ziegl. Beitr. IX. S. 522.

110) Sch ïnw erth, Ueber einen seltenen Fall von retroperitoncaler Cyste. Münch. med. Wochenschr. 1895. Nr. 2. S. 28.

111) Schulze, O., Grundriss der Entwicklungsgeschichte des Menschen und der Siingethiere. Leipzig 1897.

112) Seitz, L., Ueberzählige u, acess. Ovarien. Volkmann's klin. Vortr. N. F. 286.

113) Stobbe, F., Ein Myosarkom der Mesenterialdrüson. Archiv f. Heilkunde. Bd. XVII. S. 466.

114) Stort, Br., Ueber das Sarkom und seine Metastasen. Inaug.-Diss. Berlin. 1877.

115) Strang, W. D., Myxo-lipomatöser' Tumor. The Lancet. 1883. II. 35.

116) Tauffer, E., Ueber die primär carcinomatöse Degeneration von Dermoidcysten. Virchow's Archiv. Bd. CXLII. Heft 3. 1895.

117) Terrier et Guillemain, Note sur les lipomes rétropéritonéaux. Revue de chir. 1892. No. 9.

118) Tillmann, G., Exstirpation einer von der linken Nierenkapsel ausgehenden $10 \mathrm{~kg}$. wiegenden Geschwulst. Hygieia. S. $277-285$.

119) Alexis 'Thoms on, On Neuroma and Neurofibromatosis. Edinburg 1900.

120) Thiriar, Sur un cas de fibrolipome de la capsule cellulo-adipeuse du roin, qui a nécessité de la laparotomie et la néphrectomie. Revue de chir. 1889. No.11.

121) Thornton, Abdominal Nephrectony for large Sarcoma of the Capsule of the Ieft Kidney. Recovery. Brit. med. Journ. 1890. Bd. I. p. 665.

122) Ulrich, A., Anatomische Untersuchungen über ganz und partiell verlagerte und accessorische Nebennieren, über die sog. echten Lipome der Nieren uni über die Frage der von den Nebennieren abgeleiteten Nierengeschwülste. Ziegler's Beiträge. Bd. XVIII. S. 589.

123) Van del Veer, Retro-peritoneal 'Tumours. 'Their anatomical Relations, Pathology, Diagnosis and 'Treatment. Transactions of the American Surgical $\Lambda$ ssociation. Bd. IX. 1891. S. 375.

124) Vilch ow, Die krankhaften Geschwülste. Bd. II. S. 271.

125) Derselbe, Gesammolte $\Lambda$ bhandlungen. S. 566 .

126) Waldeyer, Das Becken. 1900.

127) Walser, F., Lipona myxomatodes subperitoneale. Allgemeine Wiener med. Zeitung. 1891. Nr. 6. S. 63.

128) C. A. Weber, Chirurgische Erfahrungen und Untersuchungen. 1859. S. 364.

129) Weiss, Bruno, Zur Kenntniss der von versprengten Nebennierenkeimen ausgehenden Geschwülste. Ziegler's Beiträge. Bd. 24. S. 34.

130) Spencer Wells, Successfull Removal of two solid circumrenal Tumours. The British med. Journal. 1884. April 19.

131) Wiesl, Accessorische Nebennieren im Bereiche des Nebenhodens. Wiener klin. Wochenschr. 1895. No. 18.

132) Wiglesworth, J., On a case of an enormous myxolipomatodes Tumour within the abdomen. The Lancet. 1883. June 30.

133) Willutzki, E., Ueber ein primäres Sarkom des Ureters. Inaug.-Dissert. Königsberg i. Pr. 1891. 
134) Wilms, Max, Ueber die Dermoidcysten und Teratome mit besonderer Berïcksichtigung der Dermoide der Ovarien. Deutsches Archiv f. klin. Med. Bd. LV. 1893. S. 289.

135) Der'selbe, Ueber die soliden Teratome des Ovariums. Ziegler's Beitr. Bd.XIX.

136) Derselbe, Die teratoiden Geschwälste des Hodens. Ziegler's Beiträge Bi. XIX. S. 233.

137) A. Winckel, Exstirpation eines über $10 \mathrm{~kg}$ schweren retroperitonealen Fibroms mit centralem Sarkom. Berichte und Studien aus dem köngl. sächs. Entbindungsinstitute in Dresden. II. Bd. Leipzig 1576.

138) Witzel, 0,, Beiträge zur Chirurgie der Bauchorgane. Dentsche Zeitschr. f. Chirurgie. Bd. XXIV. S. 326.

139) Woods, Enormous Lymphatic. Growth in the abrlomen. Death. Necropsy. The Lancet. 1885. Bd. II. S. 804 .

140) Yamagiwa, K., Zwei Fälle von Dermoidcyste des Ovarium mit carcinomatöser Degeneration und Metastasenbildung. Virch,'s Archiv Bd. CXLVII.

141) Zander, Beziehungen der Nebennieren zu anderen Organen. Ziegler's Beiträge. Bd. VII. S. 441.

\section{N a ch trag.}

142) Rossa, E., Ueber accessorisches Nebennierengewebe im Lig. latum und seine Beziehungen zu den Cysten und Tumoren des Ligaments. Archiv f. Gynäkologie LVI. Bd. (Ausführliche Bibliographie!) 1898.

143) Bonnet, R., Zur Aetiologie der Embryome. Monatsschr. f. Geburtshülfe und Gynäkologie. Bd. XIIII. Heft. 2.

144) Förster, Handb. der pathol. Anat. Leipzig 1854. Bd. II. 5, 6, 47.

145) K ü ster, Die chirurg. Kranklieiten der Nieren. 1. Hälfte. Deutsche Chirurgie.

146) Kön ig, Lehrb. der speciellen Chirurgie.

147) Zw eifel, Centralblatt f. Gynäkologie. 1888. S. 439.

148) Herrera, Nach Virchow-Hirsch. 1850. II. S. 297.

149) Hartz, Neuere Arbeiten über die mesonephrischen Geschwïlste. Monatsschr. f. Geburtshülfe und Gynäkologic. Bd. XIII. Heft 1 u. 2.

150) Funke, Hegar's Beitr. zur Gynäkologie und Geburtshülfe. Bd. III. 1. Heft.

151) Mantel, Dermoidcysten des Ovarium. Inang.-Dissert. Heidelberg 1892.

152) A jutolo, G., Intorno ad un caso di capsula suprarenale accessoria nel corpo pampiniforme di un feto. Archivo par le scienze med. Vol. VIII. No. 14.

1อ3) Friedland, F., Ueber einen Fall von accessorischen Nebennieren in den beiden Samensträngen bei gleichzeitigem Conflux des Ureters und des Vas deferens der rechten Seite. Prag. med. Wochenschr. Jahrg. XX. Nr. 14.

154) Steele, Dutton, Eine kritische Zusammenstellung dor Litteratur iiber Retroperitoneales Sarkom. American. Journal of the Iled. sciences 1900. CXIX. Bd. S. 311.

155) Generisch, Multiple Neuromata. Virchow's Archiv. Bd. XLIX.

156) Busse, 0., Ein grosses Neuroma gangliocellulare des Nervus sympathicus. Virchow's Archiv. Bd. CLI. Suppl.

157) Killian, Eine grosse retroperitoneale Cyste mit chylusartigem Inhalt. Berliner klin. Wochenschr. 1586. Nr. 25. 